This article may be downloaded for personal use only. Any other use requires prior permission of the author and AIP Publishing. This article appeared in Thol, M, Richter, M, May, EF, Lemmon, EW \& Span, R 2019, 'EOS-LNG: A fundamental equation of state for the calculation of thermodynamic properties of liquefied natural gases' Journal of Physical and Chemical Reference Data, vol. 48, no. 3, 033102; and may be found at https://doi.org/10.1063/1.5093800

\title{
EOS-LNG: A Fundamental Equation of State for the Calculation of Thermodynamic Properties of Liquefied Natural Gases
}

\author{
Monika Thol $^{\mathrm{a} \S}$, Markus Richter ${ }^{\mathrm{a}, \mathrm{b}, \dagger}$, Eric F. May ${ }^{\mathrm{b}}$, Eric W. Lemmon ${ }^{\mathrm{c}}$, Roland Span $^{\mathrm{a}}$
}

${ }^{a}$ Ruhr-Universität Bochum, Faculty of Mechanical Engineering, Thermodynamics, Universitätsstraße 150, 44801 Bochum, Germany

${ }^{\mathrm{b}}$ The University of Western Australia, Fluid Science and Resources Division, Crawley, Western Australia, Australia

${ }^{\mathrm{c}}$ National Institute of Standards and Technology, Applied Chemicals and Materials Division, Boulder, CO, USA

†Present address: Chemnitz University of Technology, Department of Mechanical Engineering, Applied Thermodynamics, Germany

\begin{abstract}
A new mixture model (EOS-LNG) for the accurate representation of thermodynamic property data of multicomponent natural gas mixtures in the liquid state is presented. The mathematical approach of the GERG-2008 equation of state of Kunz and Wagner is adopted and new binary-specific functions for methane $+n$-butane, methane + isobutane, methane $+n$ pentane, and methane + isopentane are developed. The representation of all experimental data available in the literature for the corresponding binary systems is carefully analyzed so that these functions can also be applied at fluid states beyond the liquefied natural gas region. The EOS-LNG represents all available binary and multicomponent data in the liquefied natural gas region within their specified experimental uncertainty, which is significantly more accurate than the GERG-2008 model. The main focus was given to the representation of new density data measured between $100 \mathrm{~K}$ and $180 \mathrm{~K}$ with a maximum pressure of $10 \mathrm{MPa}$. Deviations from the EOS-LNG presented here do not exceed $0.02 \%$ for binary data and $0.05 \%$ for multicomponent systems. Deviations of calculated values from experimental data in other fluid regions are similar to or better than those calculated with the GERG-2008 model.
\end{abstract}

Keywords: density, equation of state, Helmholtz energy, liquefied natural gas, mixture, thermodynamic properties

§Corresponding author, m.thol@thermo.ruhr-uni-bochum.de 


\section{CONTENTS}

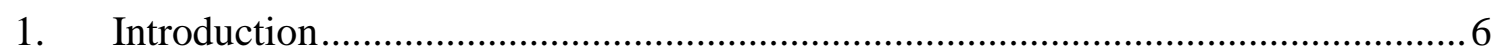

2. The Helmholtz Energy Equation of State for Mixtures ....................................... 9

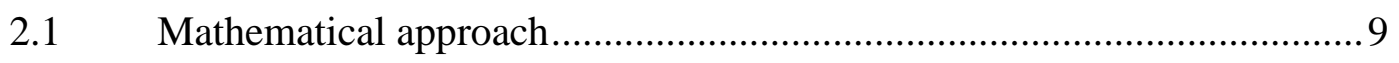

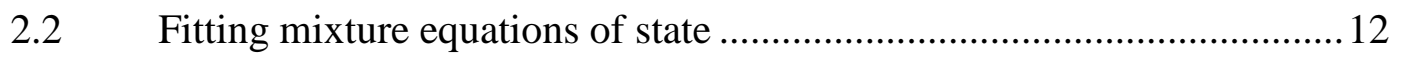

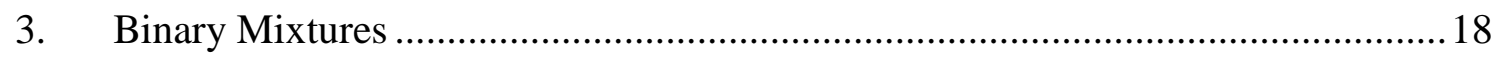

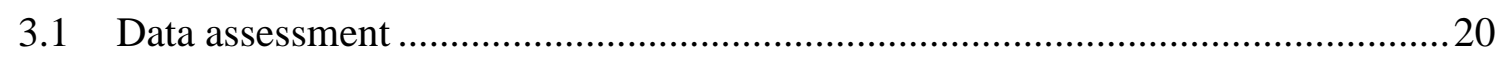

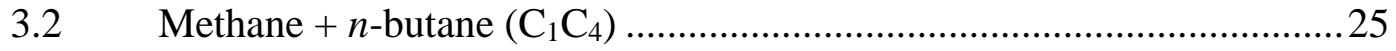

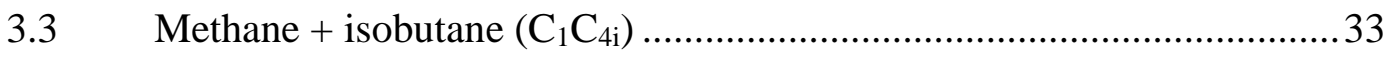

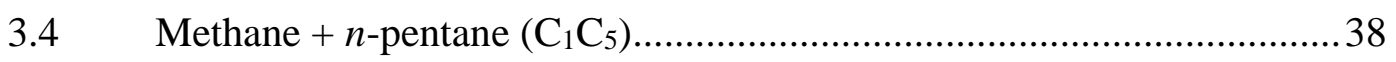

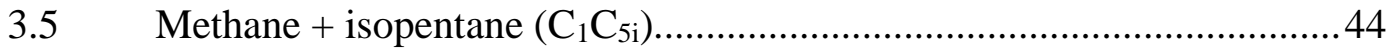

4. Representation of Multicomponent Mixtures .....................................................4 47

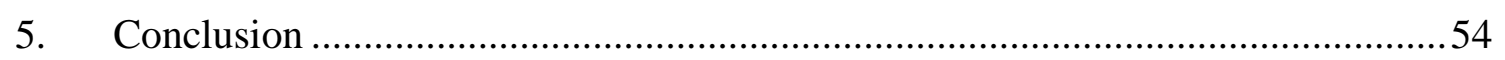

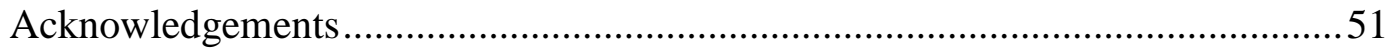

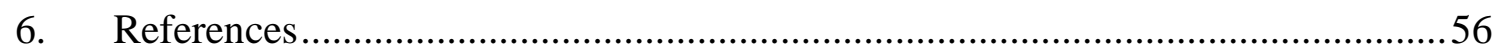




\section{List of Tables}

1. Binary parameters of the reducing functions for density and temperature

2. Parameters of the departure functions for the systems $\mathrm{C}_{1} \mathrm{C}_{4}, \mathrm{C}_{1} \mathrm{C}_{4 \mathrm{i}}, \mathrm{C}_{1} \mathrm{C}_{5}$, and $\mathrm{C}_{1} \mathrm{C}_{5 \mathrm{i}}$

3. Average absolute relative deviations calculated with the new equation of state for the binary system $\mathrm{C}_{1} \mathrm{C}_{4}$

4. Average absolute relative deviations of vapor-liquid equilibrium pressures for the binary system $\mathrm{C}_{1} \mathrm{C}_{4}$

5. Average absolute relative deviations of density data from values calculated with the new equation of state for the binary system $\mathrm{C}_{1} \mathrm{C}_{4}$

6. Average absolute relative deviations of vapor-liquid equilibrium pressures for the binary system $\mathrm{C}_{1} \mathrm{C}_{4}$

7. Average absolute relative deviations for density and excess enthalpy data from values calculated with the new equation of state for the binary system $\mathrm{C}_{1} \mathrm{C}_{5}$

8. Average absolute relative deviations of vapor-liquid equilibrium pressures for the binary system $\mathrm{C}_{1} \mathrm{C}_{5}$

9. Average absolute relative deviations calculated with the new equation of state for the binary system $\mathrm{C}_{1} \mathrm{C}_{5 \mathrm{i}}$

10. Average absolute relative deviations of vapor-liquid equilibrium pressures for the binary system $\mathrm{C}_{1} \mathrm{C}_{5}$

11. Molar compositions of the three multicomponent mixtures labeled as Libya, Norway, and Oman

12. Molar compositions of the three multicomponent mixtures LNG 2, LNG 5, and LNG 7 


\section{List of Figures}

1. $\quad p, T$-diagrams for methane + ethane, carbon dioxide + nitrogen, and methane + chlorine calculated based on the linear and the Lorentz-Berthelot combining rules.

2. Results obtained from applying typical constraints during the fitting procedure. Top: Residual isochoric heat capacity as a function of temperature along selected Bottom: Residual Grüneisen parameter as a function of temperature along selected isobars

3. Percentage deviations of experimental data measured over the temperature range (293 to 395) $\mathrm{K}$ for the systems $\mathrm{C}_{1} \mathrm{C}_{2}$ of Sage and Lacey ${ }^{57}$ and $\mathrm{C}_{1} \mathrm{C}_{3}$ of Sage et al. ${ }^{69}$ from the GERG-2008 model ${ }^{11}$

4. Percentage deviations of experimental data for the binary system $\mathrm{C}_{1} \mathrm{C}_{2}$ of Sage and Lacey ${ }^{57}$ and other accurate data from the GERG-2008 model ${ }^{11}$

5. Percentage deviations of experimental data of Lentner et al. ${ }^{20,72}$ for the binary systems $\mathrm{C}_{1} \mathrm{C}_{4 \mathrm{i}}$ and $\mathrm{C}_{1} \mathrm{C}_{5}$ from the GERG-2008 model $^{11}$

6. Percentage deviations of homogeneous density data for the binary system $\mathrm{C}_{1} \mathrm{C}_{4}$ from the EOS-LNG and the GERG-2008 ${ }^{11}$ in selected temperature ranges below $400 \mathrm{~K}$.

7. Percentage deviations of homogeneous density data for the binary system $\mathrm{C}_{1} \mathrm{C}_{4}$ from the EOS-LNG and the GERG-2008 ${ }^{11}$ in selected temperature ranges above $400 \mathrm{~K}$

8. Percentage deviations of bubble-point pressure data for the binary system $\mathrm{C}_{1} \mathrm{C}_{4}$ from the EOS-LNG, the GERG-2008, ${ }^{11}$ and the modification of Rowland et al. ${ }^{73}$

9. $p, x$-diagrams representing the vapor-liquid equilibrium data for the binary system $\mathrm{C}_{1} \mathrm{C}_{4}$.

10. Percentage deviations of isobaric heat capacity data of Syed et al. ${ }^{71}$ for the binary system $\mathrm{C}_{1} \mathrm{C}_{4}$ from EOS-LNG, GERG-2008, ${ }^{11}$ and the modification of Rowland et al. . $^{73}$

11. Percentage deviations of homogeneous density data in the low and medium temperature region from the EOS-LNG for the binary system $\mathrm{C}_{1} \mathrm{C}_{4 \mathrm{i}}$

12. Percentage deviations of homogeneous density data of Olds et al. ${ }^{52}$ in the high-temperature region from the EOS-LNG for the binary system $\mathrm{C}_{1} \mathrm{C}_{4 \mathrm{i}}$

13. Percentage deviations of bubble-point pressure data for the binary system $\mathrm{C}_{1} \mathrm{C}_{4 \mathrm{i}}$ from the EOS-LNG and the GERG-2008 ${ }^{11}$

14. Percentage deviations of homogeneous density data from the EOS-LNG for the binary system $\mathrm{C}_{1} \mathrm{C}_{5}$ 
15. Percentage deviations of vapor-liquid equilibrium pressure data for the binary system $\mathrm{C}_{1} \mathrm{C}_{5}$ from the EOS-LNG and the GERG-2008 ${ }^{11}$ as a function of the composition $x_{\mathrm{C} 1}$

16. $p, x$-diagrams representing the vapor-liquid equilibrium data of Sage et al. ${ }^{54}$ for the binary system $\mathrm{C}_{1} \mathrm{C}_{5}$

17. $p, T$-diagrams for the binary system $\mathrm{C}_{1} \mathrm{C}_{5}$ including the critical and cricondenbar lines calculated with EOS-LNG and GERG-2008 ${ }^{11}$

18. Percentage deviations of homogeneous density data of Amick et al. ${ }^{107}$ from EOS-LNG for the binary system $\mathrm{C}_{1} \mathrm{C}_{5 \mathrm{i}}$.

19. $p, x$-diagrams representing the vapor-liquid equilibrium data for the binary system $\mathrm{C}_{1} \mathrm{C}_{5}$

20. $T, x$-diagram at $p=0.1 \mathrm{MPa}$ for the binary system $\mathrm{C}_{1} \mathrm{C}_{5 \mathrm{i}}$ with the liquid-liquid equilibrium phase boundary calculated with EOS-LNG and GERG-2008 ${ }^{11}$ .46

21. Percentage deviations of the density data of three multicomponent LNG mixtures from the EOS-LNG and GERG-2008 ${ }^{11}$

22. Percentage deviations of the density data of three multicomponent LNG mixtures from the EOS-LNG and the GERG-2008 ${ }^{11}$

23. Percentage deviations of the experimental density data of two multicomponent LNG mixtures from the GERG-2008 ${ }^{11}$ and the GERG-2008 model with the Lorentz-Berthelot combining rule for the binary system methane + nitrogen

24. Percentage deviations of the experimental vapor-liquid equilibrium data of Hughes et al. ${ }^{112}$ from the EOS-LNG, the GERG-2008, ${ }^{11}$ and the modification of Rowland et $a l .{ }^{73}$

25. Percentage deviations of the experimental isobaric heat capacity data of Syed et al. from the EOS-LNG, the GERG-2008, ${ }^{11}$ and the modification of Rowland et al..$^{73}$ 


\section{Introduction}

In this work, an accurate model is presented to calculate thermodynamic properties of natural gas mixtures at liquid states (liquefied natural gas, LNG). Accurate knowledge of these properties is important for safe and efficient designs of any process in the production, storage, distribution, and re-gasification of liquefied natural gas. Accurate thermodynamic property models are required for most custody transfer applications. In particular, the energy equivalent factor $E$ is the central quantity upon which the economic value of the natural gas is determined:

$$
E \approx V \rho \Delta h_{\mathrm{CV}} \text { or } \dot{E} \approx \dot{V} \rho \Delta h_{\mathrm{CV}}
$$

To determine the energy content $E$ with sufficient accuracy for large-scale financial transactions, accurate knowledge of the density $\rho$ is an essential element in addition to the directly measurable volume $V$ or volume flow rate $\dot{V}$, and the calculated calorific value $\Delta h_{\mathrm{CV}}$ based only on the composition. The density depends on temperature, pressure, and composition of the natural gas mixture. Since no robust and sufficiently accurate apparatus for in situ density measurement is available for LNG custody transfer operations, equations of state are currently used to supply this information from measurements of pressure, temperature, and composition.

A variety of equations of state is available in the literature. For example, in most process simulation tools, it is common to apply cubic equations, such as Peng-Robinson ${ }^{1,2}$ or SoaveRedlich-Kwong. ${ }^{3,4}$ These have the advantage that they are rather simple, computationally fast, and easy to extend to new components because only a few substance-specific parameters are needed. Alternatively, the Lee-Kesler-Plöcker ${ }^{5,6}$ equation, which is based on a correspondingstates principle, may be used particularly for single-phase property calculations. However, due to their relative simplicity, none of these equations is very accurate in predicting properties other than saturation pressure for vapor-liquid equilibria. They are certainly not able to reproduce accurate experimental density data within their experimental uncertainty. Several authors, including Klimeck et al., ${ }^{7}$ Dauber and Span, ${ }^{8}$ and George, ${ }^{9}$ have shown that the uncertainties of thermodynamic property data calculated with these simple models are unacceptably high given the accuracy demands of the natural gas industry. Therefore, more accurate equations of state such as the DETAIL characterization method of AGA8 (Part 1) ${ }^{10}$ and the GERG-2008 ${ }^{11}$ equation of state have been developed. Due to its moderately simple form (a virial expansion), Part 1 of $\mathrm{AGA} 8^{10}$ is still widely used for the calculation of gaseous properties in the natural gas industry. However, GERG-2008 ${ }^{11}$ is more accurate and covers not only the gaseous region but liquid and supercritical states as well, with uncertainties based on the availability of experimental measurements. It additionally allows for the calculation of bubble-point and dew-point pressures, which is not possible with the DETAIL model ${ }^{10}$ Part 2 of AGA8, ${ }^{12}$ which is based on the GERG-2008 model, ${ }^{11}$ was recently adopted as a U.S. standard. This follows the adoption by ISO of the GERG-2008 model ${ }^{11}$ in 2015 , but contains significantly more information due to research conducted between the time when ISO and AGA 
released their standards. In particular, see Lemmon ${ }^{13}$ for information on the revised limits of the DETAIL equation of state. AGA also released computer code in Fortran, C++, and Visual Basic that is highly optimized for both models along with a spreadsheet for quick calculations of properties. This is available at Ref. ${ }^{14}$

The GERG-2008 ${ }^{11}$ model is a modern equation of state for multicomponent mixtures expressed in terms of the Helmholtz energy, which includes 21 components taking into account the most common natural gas components such as the normal alkanes (and some isomers), nitrogen, carbon dioxide, and water as well as relevant impurities, e.g., argon, helium, and hydrogen sulfide.

Over the last several years, LNG has become an important commodity. In contrast to compressed natural gas transported in pipelines, LNG can be shipped between continents. This transportation route increases the potential customers for natural gas producers. With increasing trade volume and growing demands on accurate custody transfer, as well as the optimization of the energy-intensive LNG production, accurate calculation of liquid phase properties is a new challenge for the industry. Since most models used for accurate description of natural-gas properties focus mainly on pipeline conditions, other empirical models had to be developed that enable accurate calculation of thermodynamic properties in the subcooled liquid state region: namely at temperatures between approximately $90 \mathrm{~K}$ and $180 \mathrm{~K}$ with pressures up to $10 \mathrm{MPa}$. Since the highest demand on accuracy is for density, special equations have been developed for calculating saturated and homogeneous liquid-phase densities over this temperature and pressure range. In the United States, the Costald correlation ${ }^{15}$ is often used, whereas Europe follows the guidance of the LNG custody transfer handbook, ${ }^{16}$ which recommends the revised Klosek-McKinley equation ${ }^{17}$ for densities at saturated liquid states. In the most recent edition, ${ }^{16}$ this model was replaced by the enhanced revised Klosek-McKinley equation by Tietz et al., ${ }^{18}$ which describes not only saturated states but also homogeneous liquid and supercritical dense states. However, these equations cannot reproduce the most accurate available measurements of LNG densities within their experimental uncertainties. ${ }^{18-20}$ Furthermore, these models cannot be used to calculate thermodynamic properties other than densities.

The GERG-2008 mode ${ }^{11}$ is currently used to accurately calculate properties of LNG, even though it was mainly developed with a focus on calculations at pipeline conditions. As a fundamental equation of state, the GERG-2008 model ${ }^{11}$ yields consistent results for all thermodynamic properties. However, while the recent density measurements by Lentner et al. ${ }^{20}$ are reproduced within the uncertainty specified for the GERG-2008 model, ${ }^{11}$ they are not reproduced within their experimental uncertainty. In this work, new correlations are presented for a number of binary mixtures essential for accurately calculating LNG properties. In combination with the correlations given for other binary mixtures by GERG-2008, ${ }^{11}$ these new models reproduce even the most accurate experimental data within their specified uncertainties. 
Furthermore, thermodynamic properties in other regions such as those at pipeline conditions, can be calculated with the same quality as achieved with the GERG-2008 model. ${ }^{11}$ 


\section{The Helmholtz Energy Equation of State for Mixtures}

This section explains the mathematical background of mixture models expressed in terms of the Helmholtz energy. The mixture model in this work can be traced back to the DETAIL model in the 1992 version of AGA8 and also given in the same form in the in the 2016 version. ${ }^{10}$ Although it was originally expressed as an equation of state explicit in pressure, its origin was based on the Helmholtz energy and most of the equations below are valid for this model. The work of Lemmon ${ }^{21}$ followed shortly after the second edition of AGA8 was released in 1994 and presented the original version of the equations given in this work. A revised model was later published in the work of Klimeck et al. ${ }^{22}$ and even later by Kunz et al. ${ }^{23}$ as GERG-2004. The latter was again revised and published by Kunz and Wagner, ${ }^{11}$ and labeled as the GERG2008 equation of state with three additional fluids (21 fluids in total).

\subsection{Mathematical approach}

The present mixture model is expressed in terms of the molar Helmholtz energy $a$ as a function of temperature $T$, density $\rho$, and the composition vector $x$. For practical reasons, it is made dimensionless by reducing by the molar gas constant $R$ and the temperature:

$$
\alpha(T, \rho, \boldsymbol{x})=\frac{a(T, \rho, \boldsymbol{x})}{R T} .
$$

The reduced Helmholtz energy $\alpha$ is commonly separated into an ideal gas contribution $\alpha^{\mathrm{o}}$ and a residual part $\alpha^{\text {r: }}$

$$
\alpha(\tau, \delta, \boldsymbol{x})=\alpha^{\mathrm{o}}(T, \rho, \boldsymbol{x})+\alpha^{\mathrm{r}}(\tau, \delta, \boldsymbol{x}) .
$$

The ideal part consists of a linear combination of contributions of the ideal-gas fluids in a mixture with $N$ components and an additional composition-dependent term that accounts for the entropy of mixing:

$$
\alpha^{\mathrm{o}}(T, \rho, \boldsymbol{x})=\sum_{i=1}^{N} x_{i}\left[\alpha_{\mathrm{o}, i}^{\mathrm{o}}\left(\tau_{\mathrm{o}, i}, \delta_{\mathrm{o}, i}\right)+\ln x_{i}\right]
$$

Following the convention used for modern Helmholtz equations of state for pure fluids, the inverse temperature and density are reduced by the critical parameters of the corresponding pure fluids to evaluate the ideal gas contribution

$$
\tau_{\mathrm{o}, i}=T_{\mathrm{c}, i} / T \text { and } \delta_{\mathrm{o}, i}=\rho / \rho_{\mathrm{c}, i} .
$$

In this work, values of $T_{\mathrm{c}, i}$ and $\rho_{\mathrm{c}, i}$ from the pure fluid models of GERG-2008 ${ }^{11}$ were adopted.

The residual part is further split into a linear combination of the reduced residual Helmholtz energy of the pure fluids at their corresponding states and a departure term $\Delta \alpha^{\mathrm{r}}$

$$
\alpha^{\mathrm{r}}(\tau, \delta, \boldsymbol{x})=\sum_{i=1}^{N}\left[x_{i} \alpha_{\mathrm{o}, i}^{\mathrm{r}}(\tau, \delta)\right]+\Delta \alpha^{\mathrm{r}}(\tau, \delta, \boldsymbol{x}) .
$$


The reduced inverse temperature and reduced density of the mixture are used to evaluate $\alpha^{\mathrm{r}}$ both for the pure-fluid contributions and for the departure term:

$$
\tau=T_{\mathrm{r}} / T \text { and } \delta=\rho / \rho_{\mathrm{r}} .
$$

The reducing temperature and density are in turn functions of the critical parameters of the pure fluids, the composition $\boldsymbol{x}$, and four adjustable parameters $\beta_{T, i j}, \gamma_{T, i j}, \beta_{v, i j}$, and $\gamma_{v, i j}$ for each binary pair:

$$
T_{\mathrm{r}}(\boldsymbol{x})=\sum_{i=1}^{N} x_{i}^{2} T_{\mathrm{c}, i}+\sum_{i=1}^{N-1} \sum_{j=i+1}^{N} 2 x_{i} x_{j} \beta_{T, i j} \gamma_{T, i j} \frac{x_{i}+x_{j}}{\beta_{T, i j}^{2} x_{i}+x_{j}} \sqrt{T_{\mathrm{c}, i} T_{\mathrm{c}, j}}
$$

and

$$
\frac{1}{\rho_{\mathrm{r}}(\boldsymbol{x})}=\sum_{i=1}^{N} x_{i}^{2} \frac{1}{\rho_{\mathrm{c}, i}}+\sum_{i=1}^{N-1} \sum_{j=i+1}^{N} 2 x_{i} x_{j} \beta_{v, i j} \gamma_{v, i j} \frac{x_{i}+x_{j}}{\beta_{v, i j}^{2} x_{i}+x_{j}} \frac{1}{8}\left(\frac{1}{\rho_{\mathrm{c}, i}^{1 / 3}}+\frac{1}{\rho_{\mathrm{c}, j}^{1 / 3}}\right)^{3} \text {. }
$$

To ensure that the results do not depend on the order of numbering the components, the following relations have to be maintained:

$$
\beta_{T, i j}=\frac{1}{\beta_{T, j i}}, \beta_{v, i j}=\frac{1}{\beta_{v, j i}}, \gamma_{T, i j}=\gamma_{T, j i}, \text { and } \gamma_{v, i j}=\gamma_{v, j i} .
$$

This structure of the reducing functions was introduced by Klimeck ${ }^{22}$ and differs from other approaches already available in the literature due to several considerations made for highly accurate mixture models that represent not only data for binary mixtures but also multicomponent data. For example, in the limit of pure fluids $\left(x_{i} \rightarrow 0\right.$ or 1$)$, the reducing functions have to exhibit a smooth transition to the corresponding pure fluid parameters $T_{\mathrm{c}}$ and $\rho_{\mathrm{c}}$. Furthermore, the functional form has to be suitable for the description of both symmetric and asymmetric shapes with respect to equimolar compositions. Finally, the adjustable parameters $\beta_{T, i j}, \gamma_{T, i j}, \beta_{v, i j}$, and $\gamma_{v, i j}$ are binary-specific interaction parameters that can either be adjusted to obtain agreement with available thermodynamic property data for binary mixtures or be defined by a predictive combining rule, $c f$. Bell and Lemmon ${ }^{24}$ or Lemmon and McLinden. ${ }^{25}$ Without the departure term in Eq. (6), Eqs. (3) to (10) can be considered as an extended corresponding-states approach - the known features and theoretical limitations of this kind of approach explain both the advantages of the model and its limitations, which occur, for example, for mixtures of components with very different critical temperatures. ${ }^{26,27}$

The departure term was first introduced by Lemmon and Jacobsen ${ }^{28}$ and can be considered as a correction to the corresponding-states approach, allowing for higher accuracy in calculated properties that cannot be achieved with the use of the corresponding-states method alone. It consists of a weighing factor $F_{i j}$ and either a binary-specific or a generalized departure function $\alpha_{i j}^{\mathrm{r}}:$ 


$$
\Delta \alpha^{\mathrm{r}}(\tau, \delta, \boldsymbol{x})=\sum_{i=1}^{N-1} \sum_{j=i+1}^{N} x_{i} x_{j} F_{i j} \alpha_{i j}^{\mathrm{r}}(\tau, \delta) .
$$

In the literature, the departure function is generally constructed from polynomial, exponential, and special exponential terms:

$$
\begin{aligned}
\alpha_{i j}^{\mathrm{r}}(\tau, \delta) & =\sum_{k=1}^{K_{\mathrm{pol}, i j}} n_{i j, k} \delta^{d_{i j, k}} \tau^{t_{i j, k}}+\sum_{k=K_{\mathrm{po}, i, j}+1}^{K_{\mathrm{pol}, i, j}+K_{\mathrm{exp}, i j}} n_{i j, k} \delta^{d_{i j, k}} \tau^{t_{i j, k}} \exp \left(-\beta_{i j, k} \delta^{l_{i j, k}}\right) \\
& +\sum_{k=K_{\mathrm{po}, i j}+K_{\mathrm{ex}, i, j}+1}^{K_{\mathrm{po}, i, j}+K_{\mathrm{exp}, i j}+K_{\mathrm{spc}, i j}} n_{i j, k} \delta^{d_{i j, k}} \tau^{t_{i j, k}} \exp \left[-\eta_{i j, k}\left(\delta-\varepsilon_{i j, k}\right)^{2}-\beta_{i j, k}\left(\delta-\gamma_{i j, k}\right)\right]
\end{aligned}
$$

The number of terms in each of these summations varies depending on the quality and quantity of the available experimental data. Typically, not more than ten terms are used. The last summation in Eq. (12) was introduced by Kunz and Wagner, ${ }^{11}$ however, two of the parameters are unnecessary, and the special terms in the summation can be reduced to

$$
n_{i j} \delta^{d_{i j}} \tau^{t_{i j}} \exp [-\eta_{i j} \delta^{2}+\delta \underbrace{\left(2 \eta_{i j} \varepsilon_{i j}-\beta_{i j}\right)}_{v_{i j}} \underbrace{+\beta_{i j} \gamma_{i j}-\eta_{i j} \varepsilon_{\varepsilon_{i j}}^{2}}_{\omega_{i j}}],
$$

where the parameters $v_{i j}$ and $\omega_{i j}$ are used for convenience to represent the constants

$$
v_{i j}=2 \eta_{i j} \varepsilon_{i j}-\beta_{i j}
$$

and

$$
\omega_{i j}=\beta_{i j} \gamma_{i j}-\eta_{i j} \varepsilon_{i j}^{2}
$$

resulting in the following expression:

$$
n_{i j} \exp \left(\omega_{i j}\right) \delta^{d_{i j}} \tau^{t_{i j}} \exp \left[-\eta_{i j} \delta^{2}+v_{i j} \delta\right] .
$$

With the addition of the nomenclature

$$
\xi_{i j}=\frac{v_{i j}}{2 \eta_{i j}}
$$

and the modified coefficient

$$
n_{i j}^{*}=n_{i j} \exp \left(\omega_{i j}+\eta_{i j} \xi_{i j}^{2}\right),
$$

Eq. (16) results in

$$
n_{i j}^{*} \delta^{d_{i j}} \tau^{t_{i j}} \exp \left[-\eta_{i j}\left(\delta-\xi_{i j}\right)^{2}\right]
$$

Eq. (19) is similar to the density-dependent part of the well-established Gaussian bell-shaped terms for pure fluids. ${ }^{29,30}$ It was further extended to include the temperature-dependent contribution by Bell et al., ${ }^{31}$ and already successfully applied for several binary mixture 
models. ${ }^{32,33}$ However, in order to be consistent with the GERG-2008 model, ${ }^{11}$ the original notation given in Eq. (12) is applied in this work.

Due to the fraction in Eq. (17), an exception is required for the situation when $\eta_{i j}=0$ to avoid division by zero ( $c f$. the binary function of methane + ethane in the GERG-2008 model ${ }^{11}$ ). In this case, the special exponential term becomes a simple exponential term, $c f$. Eq. (12):

$$
n_{i j} \delta^{d_{i j}} \tau^{t_{i j}} \exp \left[-\eta_{i j}\left(\delta-\varepsilon_{i j}\right)^{2}-\beta_{i j}\left(\delta-\gamma_{i j}\right)\right]
$$

with $\eta_{i j}=0$ :

$$
\begin{aligned}
& =n_{i j} \delta^{d_{i j}} \tau^{t_{i j}} \exp \left[-\beta_{i j} \delta+\beta_{i j} \gamma_{i j}\right] \\
& =n_{i j} \exp \left(\beta_{i j} \gamma_{i j}\right) \delta^{d_{i j}} \tau^{t_{i j}} \exp \left[-\beta_{i j} \delta\right] .
\end{aligned}
$$

\subsection{Fitting mixture equations of state}

The development of equations of state either for pure fluids or mixtures is highly dependent on the underlying experimental database. For pure fluids, only about 15 have been sufficiently well investigated so that a reference equation of state could be developed. These can be used to reproduce all highly-accurate experimental data within their experimental uncertainty. Approximately 135 additional fluids are characterized by equations of state, also formulated in terms of the Helmholtz energy, but are based on less comprehensive and less accurate experimental data.

The properties of other fluids for which Helmholtz equations are not available are often calculated with generalized equations of state such as cubic equations (e.g., Peng-Robinson ${ }^{1,2}$ or Soave-Redlich-Kwong ${ }^{3}$ ) or other various extensions, e.g., the CPA equation, ${ }^{34}$ equations based on statistical associating fluid theory, ${ }^{35-38}$ or corresponding states approaches such as the Lee-Kesler ${ }^{5}$ equation. Since mixture equations require composition as a set of additional independent variables, the experimental databases are even less comprehensive than for pure fluids. Furthermore, the experimental uncertainty of the measured properties for mixtures is generally higher than for pure fluids due to the additional uncertainty in the measurement of the composition. Finally, the determination of phase boundaries is a complex challenge in comparison to the rather simple vapor-liquid equilibrium calculation for pure fluids.

The methods of adjusting binary parameters in Helmholtz models to improve the description of mixtures can generally be separated into four classes depending on the amount and quality of the available experimental data, as discussed in the following subsections. 


\subsubsection{No experimental data available}

If experimental data are not available, it is (obviously) not possible to adjust binary-specific parameters based on measurements. Only predictive combining rules can be applied to determine the parameters for the reducing functions for temperature and density [Eqs. (8) and (9)]. Although there are many different combining rules available in the literature, Kunz and Wagner ${ }^{11}$ evaluated the Lorentz-Berthelot and linear combining rules and found them to be suitable for natural gases applications:

- Lorentz-Berthelot combining rule:

$$
\beta_{T, i j}=\beta_{v, i j}=\gamma_{T, i j}=\gamma_{v, i j}=1
$$

- Linear combining rule:

$$
\begin{gathered}
\gamma_{T, i j}=\frac{1}{2} \frac{\left(T_{\mathrm{c}, i}+T_{\mathrm{c}, j}\right)}{\left(T_{\mathrm{c}, i} \cdot T_{\mathrm{c}, j}\right)^{0.5}} \text { and } \gamma_{v, i j}=4 \frac{\left(\frac{1}{\rho_{\mathrm{c}, i}}+\frac{1}{\rho_{\mathrm{c}, j}}\right)}{\left(\frac{1}{\rho_{\mathrm{c}, i}^{1 / 3}}+\frac{1}{\rho_{\mathrm{c}, j}^{1 / 3}}\right)^{3}}, \\
\beta_{T, i j}=\beta_{v, i j}=1 .
\end{gathered}
$$

However, to date it is still unknown which of these combining rules [Eq. (22) or Eqs. (23) and (24)] should be applied for a given mixture. For asymmetric mixtures (mixtures of pure fluids with significantly different critical parameters) or components with different physical properties (e.g., polar vs. non-polar fluids), different combining rules often yield quantitatively and even qualitatively varying results, particularly for phase-equilibrium calculations. Figure 1 shows that the linear and the Lorentz-Berthelot combining rules yield comparable results for the mixture methane + ethane, which are both hydrocarbons with simple repulsive and attractive intermolecular forces. However, for other mixtures, e.g., carbon dioxide + nitrogen, additional electrostatic interactions occur. For pressures $p>10 \mathrm{MPa}$, the quantitative characterization of the two combining rules differs remarkably. In the case of methane + chlorine, even the qualitative descriptions of the mixture predicted by the two approaches are not similar. 


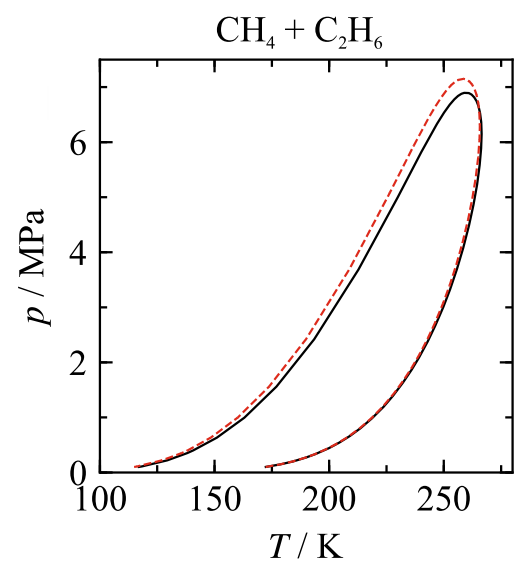

----Lorentz-Berthelot combination rule

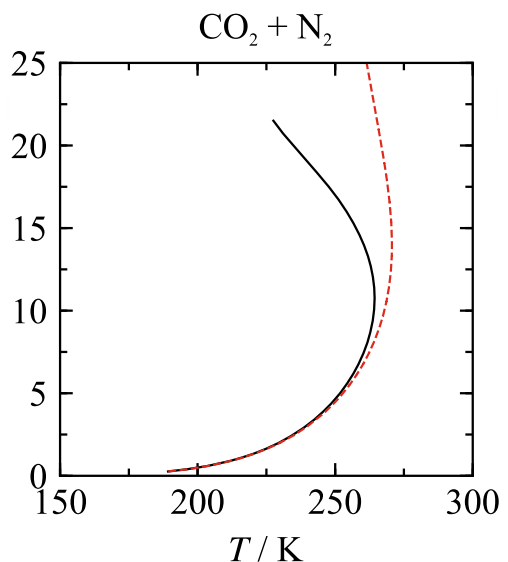

- Linear combination rule

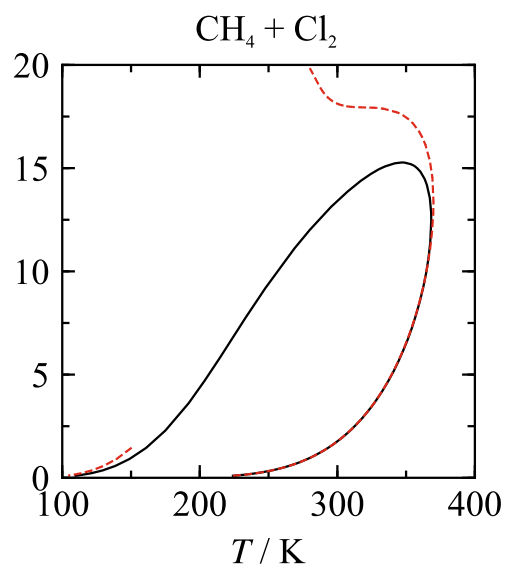

Fig. 1. $p, T$-diagrams for methane + ethane (left), carbon dioxide + nitrogen (center), and methane + chlorine (right) calculated based on the linear (solid line) and the Lorentz-Berthelot (dashed line) combining rules.

Unfortunately, well-established methods for selecting the correct combining rule based on macroscopic properties (e.g., vapor pressure, virial coefficients, critical properties, etc.) or microscopic properties (e.g., dispersive/repulsive forces, electrostatic charges and multipoles, hydrogen bonds, etc.) are not yet available. Therefore, the choice of the combining rule for these mixtures should always be critically evaluated before use. For this purpose, more predictive mixture models (e.g., equations based on statistical associating fluid theory) should be analyzed. Other methods for improving the predictive capabilities of multi-fluid mixture models have recently been published by Jäger et al. (9,40 $^{39}$

\subsubsection{Few experimental data or only a single type of thermodynamic property available}

If some experimental data are available, preferably for vapor-liquid equilibrium pressures and compositions (VLE data), the binary interaction parameters $\beta_{T, i j}, \gamma_{T, i j}, \beta_{v, i j}$, and $\gamma_{v, i j}$ can be adjusted. The number of fitted parameters depends on the quality, quantity, and range of data available. The mixture model may then be able to represent at least the correct vapor-liquid equilibrium behavior. In theory, these parameters are not subject to any restrictions. However, based on experience, they mostly vary between 0.8 and 1.2 ( $c f$. Kunz and Wagner ${ }^{11}$ or Gernert and $\operatorname{Span}^{41}$ ). There are a few exceptions, such as mixtures with hydrogen or water, that exhibit more non-ideal binary-specific parameters that significantly differ from those of the LorentzBerthelot or linear combining rules. During the fitting procedure, it can be beneficial to vary the parameters successively instead of simultaneously. Depending on the quality, quantity, and range of the data, it might also be helpful to adjust only certain parameters and set the remaining ones to unity, as is done, e.g., for nitrogen + several hydrocarbons (pentane to octane) or argon $+n$-butane. ${ }^{11}$ 


\subsubsection{Experimental data of adequate quality and quantity available for similar binary mixtures}

This category allows for the use of a departure term through a weighting factor $F_{i j}$ or the full development of a new generalized departure function $\alpha_{i j}^{\mathrm{r}}(\tau, \delta)$. If a departure function is available for physically and chemically similar binary mixtures, the weighing factor $F_{i j}$ can be adjusted in addition to the binary interaction parameters. For the second option, setting up a generalized departure function requires that at least one binary mixture out of a group of "similar" binary mixtures has a comprehensive database with accurate data for different thermodynamic properties, e.g., density, speed of sound, and vapor-liquid equilibrium data. This database serves as the basis for the optimization of the generalized departure function. If available, reliable datasets from similar binary mixtures can be considered concurrently during a simultaneous optimization process. ${ }^{42}$ This approach enables a more accurate reproduction of the experimental measurements while ensuring better representation of mixture properties for all similar binary mixtures that only have a restricted database. The functional form of the generalized function is not restricted to certain term types or numbers of terms. Lemmon and Jacobsen ${ }^{28}$ first used this method for mixtures of methane through butane. It was later improved in the GERG-2008 model, ${ }^{11}$ where this approach was applied for mixtures of, e.g., (methane or ethane $)+(n$-butane or isobutane $)$.

\subsubsection{Comprehensive database available that includes many state points for different thermodynamic properties and with known experimental uncertainties}

If a comprehensive and accurate database is available, it is possible to develop a binaryspecific departure function. This function may consist of polynomial terms and exponential functions [see Eq. (12)], each with an arbitrary number of terms, which leads to a very flexible functional form. The adjustment of its parameters requires substantial knowledge of their impact to ensure that the physical behavior of the mixture equation is not compromised in regions where data are not available. Therefore, only selected binary systems have dedicated departure functions in the literature (e.g., 7 out of 221 binary mixtures in the GERG-2008 mode $\left.{ }^{11}\right)$. However, fitting algorithms and computing power have significantly improved over the last decade, so that both experimental measurements and constraints on the thermodynamic properties can be utilized in the optimization process. Several of the key binary systems, which are investigated here, still have not been comprehensively measured; and, thus, the development of departure functions for these binaries may not be considered advisable. However, since the aim of this work is to represent new accurate density measurements in the subcooled liquid state within their experimental uncertainty, departure functions were necessary. Based on extensive studies of pure fluids, ${ }^{43-47}$ several constraints, which are also valid for binary mixtures, were devised and applied to the fitting procedure. Two examples are illustrated in Fig. 2. 

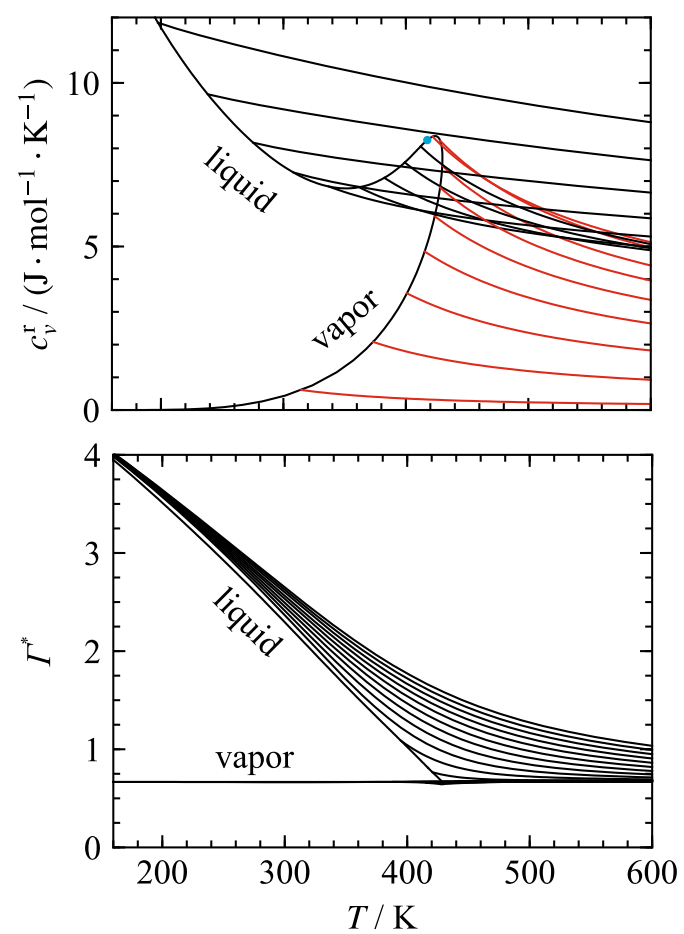

Fig. 2. Results obtained from applying typical constraints during the fitting procedure. Top: Residual isochoric heat capacity as a function of temperature along selected isochores (illustrated density range: $0.1 \mathrm{~mol} \cdot \mathrm{dm}^{-3}-$ $2.5 \mathrm{~mol} \cdot \mathrm{dm}^{-3}$ ). Isochores in the gaseous state are colored red. The location of the critical point is indicted with a blue circle. Bottom: Residual Grüneisen parameter as a function of temperature along selected isobars (illustrated pressure range: $0.1 \mathrm{MPa}-30 \mathrm{MPa}$ ). The new equation of state for methane $+n$-pentane developed in this work was used at equimolar composition for the calculations shown in the two diagrams.

In the top panel, the residual isochoric heat capacity as a function of temperature along selected isochores is shown. Characteristic features of this property include values on the saturated vapor line, where both the slope and curvature should be positive up to the vicinity of the critical point. The corresponding isochores in the vapor phase should have a negative slope and positive curvature. To transition correctly to the ideal gas limit, the residual isochoric heat capacity has to diminish at high temperatures. In contrast, the saturated liquid $c_{v}^{\mathrm{r}}$ has to retain positive curvature to the critical point. The slope has to be negative at low temperatures and must change sign after passing through the minimum.

In the bottom panel of Fig. 2, the residual Grüneisen parameter ${ }^{48}$ [with $\Gamma$ $\left.=(\partial p / \partial T)_{\rho} /\left(\rho c_{v}\right)\right]$ along selected isobars is depicted as a function of temperature. The saturated vapor line exhibits negative slope and curvature up to the vicinity of the critical point. The saturated liquid line and the corresponding isobars have negative slopes and positive curvatures throughout.

Any departure function for the systems investigated in this work must satisfy each of the constraints shown in Fig. 2. There might be exceptions, e.g., for water or hydrogen mixtures, but these are not part of the present study. By applying these constraints with the fitting procedure, the new models developed exhibited physically reasonable behavior despite the limited data available in some cases. The flexibility of the functional form of the departure 
function then allows for the development of a correlation that achieves the required accuracy while ensuring the correct reproduction of the mixture thermodynamic behavior. 


\section{Binary Mixtures}

The new equations of state for four binary mixtures are presented in this section, which are designated collectively as EOS-LNG. Special focus was given to the accurate representation of the liquefied natural gas (LNG) region. The reproduction of all other available data was simultaneously monitored so that the uncertainty of EOS-LNG is smaller than or at least similar to the uncertainty of the GERG-2008 mode ${ }^{11}$ over the whole temperature and pressure range for which the models are valid. To accurately calculate mixture LNG properties with the models in this work, the models must be used simultaneously with the models of GERG-2008 ${ }^{11}$ for the other binary subsystems. Otherwise, uncertainties can be larger than $0.1 \%$ in terms of density and $0.5 \%$ in terms of speed of sound.

Statistical analyses were generally carried out by evaluating relative deviations according to

$$
\Delta X=100 \frac{X_{\mathrm{DATA}}-X_{\mathrm{EOS}}}{X_{\mathrm{DATA}}}
$$

and the average absolute relative deviation

$$
\mathrm{AARD}=\frac{1}{N} \sum_{i=1}^{N}\left|\Delta X_{i}\right| .
$$

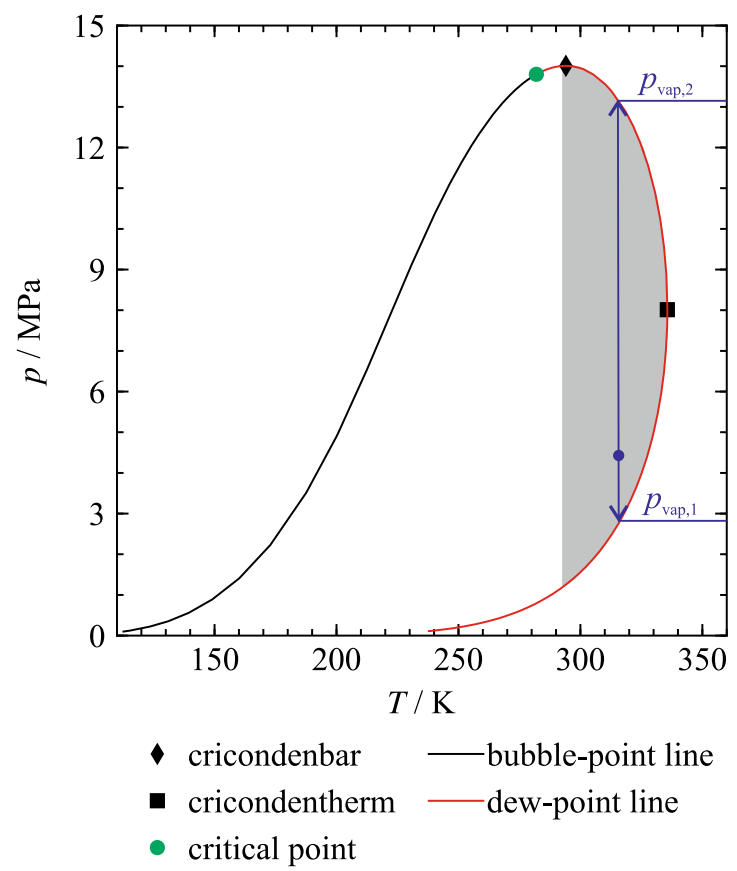

Fig. 3. Pressure as function of temperature for the binary system $\mathrm{C}_{1} \mathrm{C}_{4}$ at $x_{\mathrm{C} 1}=0.8$ calculated with the EOS-LNG. Two solutions ( $p_{\text {vap1 }}$ and $\left.p_{\text {vap } 2}\right)$ are present in the shaded area between the temperature at the cricondenbar and cricondentherm when calculating deviations in terms of dew-point pressures.

Dew-point data are treated differently because the steep slope of the dew-point line in the vicinity of the cricondenbar ( $c f$. Fig. 3) causes significant deviations in terms of dew-point pressures when only slightly changing the temperature. Furthermore, above the temperature at 
the cricondenbar, two solutions are present when calculating deviations between an experimental state point (blue solid circle in Fig. 3 ) and calculated values ( $p_{\text {vap }, 1}$ and $\left.p_{\text {vap }, 2}\right)$. In the vicinity of the cricondentherm, it is especially difficult to determine which solution is correct. Therefore, the dew-point line is statistically evaluated in terms of absolute deviations with respect to mole fraction of methane according to

$$
\Delta y_{\mathrm{C} 1}=100\left(y_{\mathrm{C} 1, \mathrm{DATA}}-y_{\mathrm{C} 1, \mathrm{EOS}}\right)
$$

and an average absolute deviation

$$
\mathrm{AAD}=\frac{1}{N} \sum_{i=1}^{N}\left|\Delta y_{\mathrm{C} 1, i}\right| .
$$

The evaluation of the experimental density data measured for six typical multicomponent natural gas mixtures ${ }^{19,49}$ with the GERG-2008 model $^{11}$ showed that four binary systems needed refinement to represent the multicomponent data within their experimental uncertainty: methane $+n$-butane $\left(\mathrm{C}_{1} \mathrm{C}_{4}\right)$, methane + isobutane $\left(\mathrm{C}_{1} \mathrm{C}_{4 \mathrm{i}}\right)$, methane $+n$-pentane $\left(\mathrm{C}_{1} \mathrm{C}_{5}\right)$, and methane + isopentane $\left(\mathrm{C}_{1} \mathrm{C}_{5 \mathrm{i}}\right)$. The new models were made consistent with the GERG-2008 ${ }^{11}$ through the use of the same pure fluid equations and the same mathematical structure as for the mixture models described in Sec. 2.1. Due to the data situation prevalent at the time of its formulation, no binary-specific departure functions were developed for these four mixtures in GERG-2008. ${ }^{11}$ A generalized departure function was fitted for the methane + butane mixtures $\left(\mathrm{C}_{1} \mathrm{C}_{4}\right.$ and $\left.\mathrm{C}_{1} \mathrm{C}_{4 \mathrm{i}}\right)$, whereas only the reducing functions were adjusted for the methane + pentane mixtures $\left(\mathrm{C}_{1} \mathrm{C}_{5}\right.$ and $\left.\mathrm{C}_{1} \mathrm{C}_{5 \mathrm{i}}\right)$. Modern fitting techniques and experimental data published over the last decade now allow for the development of binary-specific departure functions for these four binary mixtures. The corresponding parameters of each binary-specific function of the new EOS-LNG model are given in Tables 1 and 2. The departure functions only include polynomial and special exponential terms as per Eq. (12).

Table 1. Binary parameters of the reducing functions for density and temperature, $c f$. Eqs. (8) and (9). Component $i$ refers to methane $\left(\mathrm{C}_{1}\right)$.

\begin{tabular}{lcccc}
\hline \hline Component $j$ & $\beta_{T, i j}$ & $\gamma_{T, i j}$ & $\beta_{v, i j}$ & $\gamma_{v, i j}$ \\
\hline$n$-butane $\left(\mathrm{C}_{4}\right)$ & 0.9421 & 1.0307 & 1.035 & 1.118 \\
isobutane $\left(\mathrm{C}_{4 \mathrm{i}}\right)$ & 0.9405 & 0.9917 & 1.0434 & 1.143 \\
$n$-pentane $\left(\mathrm{C}_{5}\right)$ & 0.9082 & 1.03884 & 1.02874 & 1.13209 \\
isopentane $\left(\mathrm{C}_{5 \mathrm{i}}\right)$ & 0.886 & 0.993 & 1.023 & 1.076 \\
\hline
\end{tabular}


Table 2. Parameters of the departure functions for the systems $\mathrm{C}_{1} \mathrm{C}_{4}, \mathrm{C}_{1} \mathrm{C}_{4 \mathrm{i}}, \mathrm{C}_{1} \mathrm{C}_{5}$, and $\mathrm{C}_{1} \mathrm{C}_{5 \mathrm{i}}, c f$. Eq. (12).

\begin{tabular}{|c|c|c|c|c|c|c|c|}
\hline$k$ & $n_{i j, k}$ & $t_{i j, k}$ & $d_{i j, k}$ & $\eta_{i j, k}$ & $\varepsilon_{i j, k}$ & $\beta_{i j, k}$ & $\gamma_{i j, k}$ \\
\hline \multicolumn{8}{|c|}{$\mathrm{C}_{1} \mathrm{C}_{4}$} \\
\hline 1 & 0.7588 & 1.02 & 1 & & & & \\
\hline 2 & -0.4386 & 0.71 & 2 & & & & \\
\hline 3 & -0.02273 & 1.57 & 3 & & & & \\
\hline 4 & 45.05 & 3.41 & 1 & 1.34 & 0.59 & 1.07 & 0 \\
\hline 5 & -2.291 & 2.12 & 1 & 1.45 & 1.90 & 1.06 & 0 \\
\hline 6 & -62.51 & 3.28 & 1 & 0.96 & 0.87 & 1.11 & 0 \\
\hline 7 & 33.32 & 3.37 & 2 & 1.33 & 1.12 & 1.20 & 0 \\
\hline 8 & -12.14 & 3.40 & 1 & 1.90 & 1.43 & 1.23 & 0 \\
\hline \multicolumn{8}{|c|}{$\mathrm{C}_{1} \mathrm{C}_{4 \mathrm{i}}$} \\
\hline 1 & 0.9396 & 1.43 & 1 & & & & \\
\hline 2 & -0.1439 & 0.30 & 2 & & & & \\
\hline 3 & -0.1413 & 1.20 & 3 & & & & \\
\hline 4 & 35.32 & 3.10 & 1 & 1.87 & 1.73 & 1.67 & 0 \\
\hline 5 & -4.216 & 1.78 & 1 & 1.05 & 0.78 & 1.76 & 0 \\
\hline 6 & 59.17 & 3.36 & 1 & 1.78 & 1.75 & 1.02 & 0 \\
\hline 7 & -76.68 & 2.70 & 2 & 1.19 & 1.84 & 1.76 & 0 \\
\hline 8 & -41.39 & 3.70 & 1 & 2.0 & 1.71 & 1.06 & 0 \\
\hline \multicolumn{8}{|c|}{$\mathrm{C}_{1} \mathrm{C}_{5}$} \\
\hline 1 & 0.03711 & 1.54 & 2 & & & & \\
\hline 2 & -0.12154 & 0.95 & 3 & & & & \\
\hline 3 & 27.086 & 0.47 & 1 & 0.6 & 0.7 & 0.916 & 0.5 \\
\hline 4 & -13.614 & 0.9 & 1 & 0.43 & 0.61 & 0.87 & 0.5 \\
\hline 5 & -14.45 & 0.22 & 1 & 0.7 & 0.7 & 0.86 & 0.5 \\
\hline 6 & -0.46867 & 2.65 & 2 & 1.40 & 0.46 & 2.8 & 0.5 \\
\hline \multicolumn{8}{|c|}{$\mathrm{C}_{1} \mathrm{C}_{5 \mathrm{i}}$} \\
\hline 1 & 0.051 & 0.2 & 2 & & & & \\
\hline 2 & -0.1580 & 0.53 & 3 & & & & \\
\hline 3 & -67.49 & 1.79 & 1 & 0.64 & 0.5 & 1.56 & 0 \\
\hline 4 & -88.27 & 2.1 & 1 & 0.39 & 0.5 & 1.33 & 0 \\
\hline 5 & 154.9 & 2.0 & 1 & 0.48 & 0.5 & 1.46 & 0 \\
\hline 6 & 3.725 & 0.2 & 2 & 1.00 & 0.5 & 2.7 & 0 \\
\hline
\end{tabular}

\subsection{Data assessment}

The new mixture models are mainly based on homogeneous density and vapor-liquid equilibrium data. Thorough assessment of the quality of the datasets available for developing the mixture models was an essential step in the tuning process. For three systems $\left(\mathrm{C}_{1} \mathrm{C}_{4}, \mathrm{C}_{1} \mathrm{C}_{4 \mathrm{i}}\right.$, and $\mathrm{C}_{1} \mathrm{C}_{5}$ ), the largest number of datasets for both properties were provided by the same research group: over the course of several API (American Petroleum Institute) research projects 
between 1930 and 1960, more than 30 papers presenting measurements on natural gas mixtures were published by Sage, Lacey, Olds, Reamer, and other authors.

The apparatus used for these measurements was described in detail by Sage and Lacey, ${ }^{50}$ with refinements and mixture-specific modifications occurring as the experimental campaign proceeded. The apparatus was basically a U-tube with mercury used as a confining fluid, the pressure of which was varied to change the volume of a known mass of the sample. The effective volume of the chamber filled with the sample was obtained by measuring the elevation of the mercury, which was determined by a moveable electrical contact. The temperature was controlled by a temperature bath and the pressure was measured with a Bordon tube gauge connected to the part of the U-tube filled with air. The authors state that this apparatus could be used to measure pure fluids, simple mixtures, and complex mixtures at homogeneous (gaseous and liquid) conditions as well as at vapor-liquid equilibrium states over a broad temperature and pressure range (approximately $290 \mathrm{~K}$ to $590 \mathrm{~K}$ with pressures up to $70 \mathrm{MPa}$ ). They report an overall uncertainty of $0.2 \%$ in density for all measurements, although recent mixture modelling has demonstrated that this claim is too optimistic. Sage and Lacey were very thoughtful in setting up their apparatus as they were aiming at a low uncertainty in measurement; however, the estimate of $0.2 \%$ is questionable based on comparisons with other data. There are many subtle details reported about the construction of the experimental apparatus (e.g., even a home-made "pressure balance" was developed) as well as in conducting the measurements. When analyzing their paper, no obvious source of error becomes apparent; nevertheless, it is well-known that volumetric measurement techniques typically have issues with accurate volume and sample mass determination. It can thus be stated that the complexity of the apparatus makes it prone to errors. Since no reliable estimate of the actual experimental uncertainty is available, the data for methane + ethane $\left(\mathrm{C}_{1} \mathrm{C}_{2}\right)$ and methane + propane $\left(\mathrm{C}_{1} \mathrm{C}_{3}\right)$ measured with this apparatus were compared to the GERG-2008 ${ }^{11}$ as shown in Fig. 4. Deviations of up to $3 \%$ in the case of $\mathrm{C}_{1} \mathrm{C}_{2}$ and more than $5 \%$ for $\mathrm{C}_{1} \mathrm{C}_{3}$ are observed. Comparisons to other binaries such as $\mathrm{C}_{1} \mathrm{C}_{4}$ (Sage et al..$^{51}$ ), $\mathrm{C}_{1} \mathrm{C}_{4 \mathrm{i}}$ (Olds et al. ${ }^{52}$ ), $\mathrm{C}_{1} \mathrm{C}_{5}$ (Sage et al. $\left.{ }^{53,54}\right), \mathrm{C}_{2} \mathrm{C}_{5}$ (Reamer et al. ${ }^{55}$ ), and $\mathrm{C}_{3} \mathrm{C}_{5}$ (Sage and Lacey ${ }^{56}$ ) show similar results.

To eliminate the equation of state as the source of the deviations, the binary $\mathrm{C}_{1} \mathrm{C}_{2}$ was investigated in further detail. In addition to the data of Sage and Lacey ${ }^{57}$ (red symbols), Fig. 5 shows a comparison of the GERG-2008 ${ }^{11}$ to more recent experimental data with small, wellcharacterized uncertainties from several authors ${ }^{58-63}$ covering the same temperature, pressure, and composition ranges. These other data are consistent and are represented far more accurately than the data of Sage and Lacey. ${ }^{57}$ Similar results were demonstrated for the binary $\mathrm{C}_{1} \mathrm{C}_{3}$ by Karimi et al. ${ }^{64}$ who showed that the data of Reamer et al. ${ }^{65}$ (as well as those of Huang et al. ${ }^{66}$ and Arai and Kobayashi ${ }^{67}$ ) were significantly lower in quality than other more modern data available in the literature and should be given low weights when developing improved equations of state. All the data from the Sage and Lacey group were thus assumed to be less 
accurate than claimed in their publications. While no clear indication of errors in their measurement procedure could be found, it is known from literature ${ }^{68}$ and our own critical data analysis that variable-volume devices do not enable uncertainties in density significantly smaller than $1 \%$ for pure substances. Considering possible inconsistencies in temperature and pressure measurement, and particularly in the determination of the mixture composition, an experimental uncertainty of approximately $4 \%$ was assigned to these data in the model development, based on comparisons with the GERG-2008 model ${ }^{11}$ averaged across each of the binary systems.

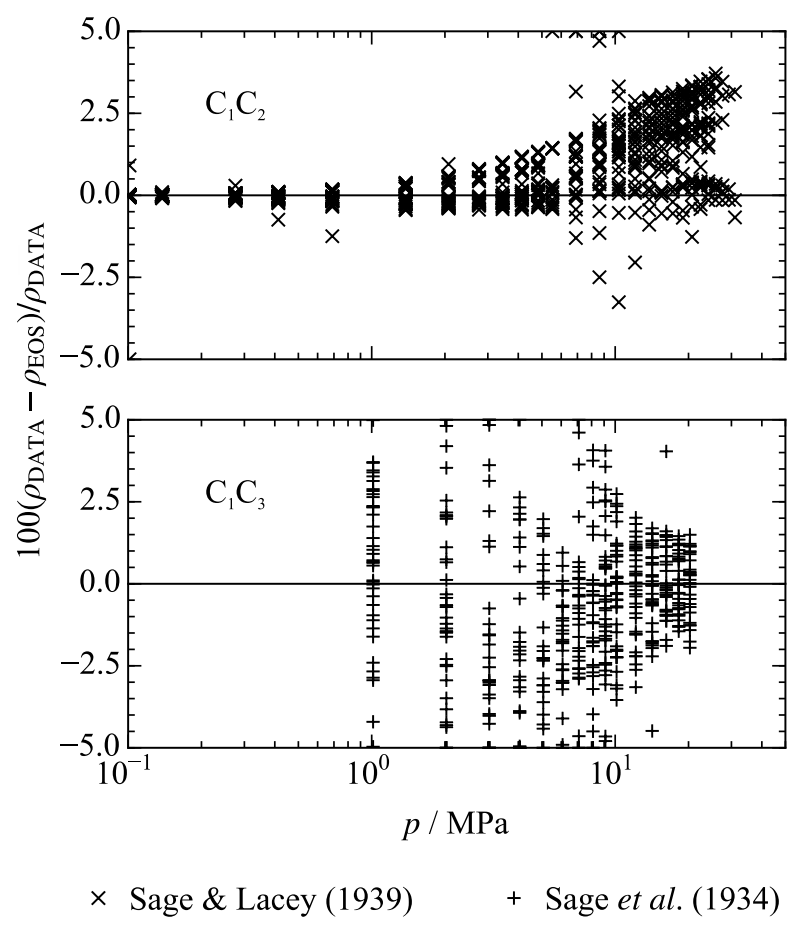

Fig. 4. Percentage deviations of experimental data measured over the temperature range (293 to 395 ) $\mathrm{K}$ for the systems $C_{1} C_{2}$ of Sage and Lacey ${ }^{57}$ and $C_{1} C_{3}$ of Sage et al. ${ }^{69}$ from the GERG-2008 model. ${ }^{11}$

In contrast, the development of the EOS-LNG was strongly influenced by recent, accurate measurements of key binaries published after the development of GERG-2008. ${ }^{11}$ These include the VLE data of May et al. ${ }^{70}$ for $\mathrm{C}_{1} \mathrm{C}_{4 \mathrm{i}}$ and $\mathrm{C}_{1} \mathrm{C}_{4}$, the heat capacity data of Syed et al. ${ }^{71}$ for $\mathrm{C}_{1} \mathrm{C}_{4}$, and the liquid mixture density datasets recently published by Lentner et al. ${ }^{20,72}$ To illustrate this point, we consider the case of Lentner et al. ${ }^{20,72}$ in further detail: during their measurements, special focus was given to the temperature, pressure, and composition ranges that are important for LNG transport, storage, and custody transfer. They measured one mixture composition of $\mathrm{C}_{1} \mathrm{C}_{4 \mathrm{i}}$ and one of $\mathrm{C}_{1} \mathrm{C}_{5}$. Comparisons to the GERG-2008 ${ }^{11}$ show negative deviations that increase with increasing temperatures and decreasing pressures for $\mathrm{C}_{1} \mathrm{C}_{4 \mathrm{i}}$ as shown in Fig. 6 . The maximum deviation is $-0.58 \%$. A systematic offset of approximately $0.5 \%$ can be observed for the system $\mathrm{C}_{1} \mathrm{C}_{5}$. The relative combined expanded uncertainty $(k=2)$ in experimental density was specified to be $0.02 \%$ by Lentner et al., ${ }^{20,72}$ which indicates the need to improve the equation of state for these binaries. 

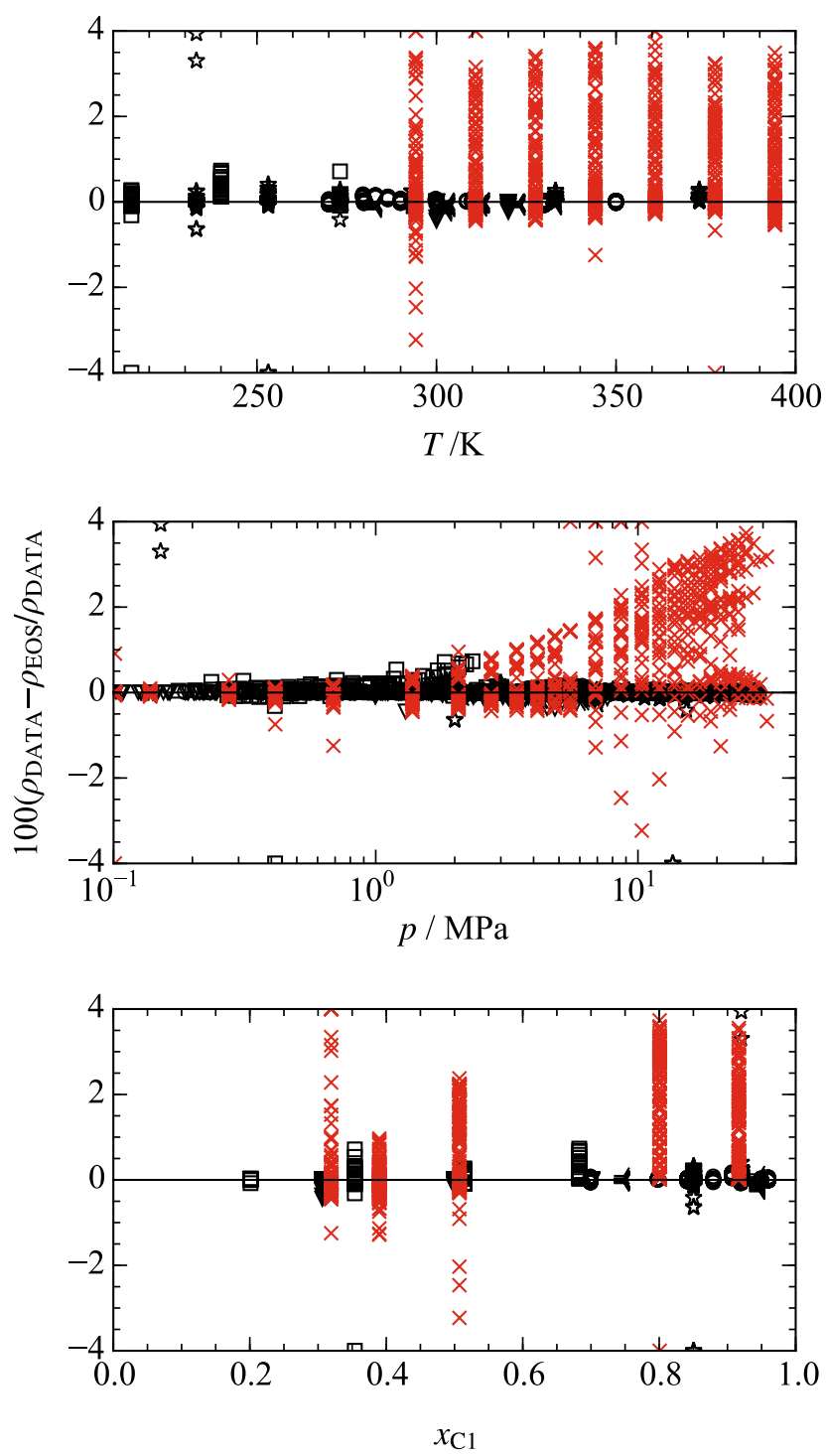

$\begin{array}{ll}\prec \text { Blanke \& Weiss (1995) } & \text { ○ Jaeschke et al. }(1991,1997) \\ \square \text { Hoover (1965) } & \times \text { Sage \& Lacey }(1939) \\ \nabla \text { Hou } \text { et al. }(1996) & \longleftarrow \text { Wöll \& El Hawary }(2003)\end{array}$

Fig. 5. Percentage deviations of experimental data for the binary system $C_{1} C_{2}$ of Sage and Lacey ${ }^{57}$ and other accurate data ${ }^{58-63}$ from the GERG-2008 model. ${ }^{11}$ 


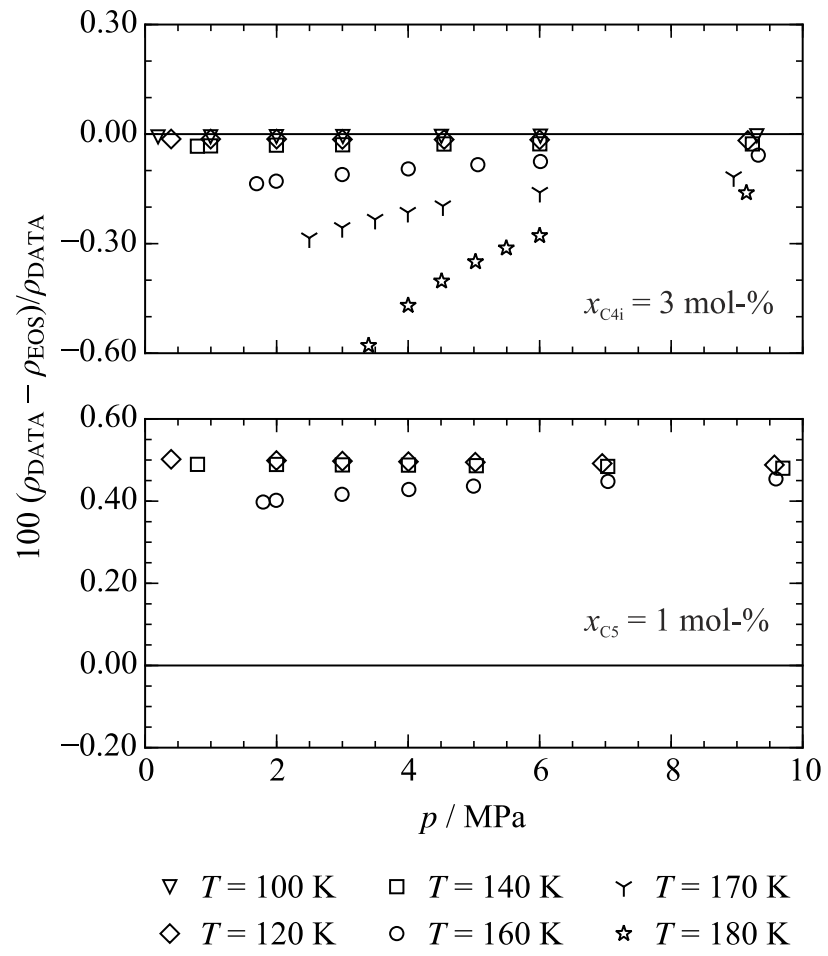

Fig. 6. Percentage deviations of experimental data of Lentner et al. ${ }^{20,72}$ for the binary systems $\mathrm{C}_{1} \mathrm{C}_{4 \mathrm{i}}$ (top) and $\mathrm{C}_{1} \mathrm{C}_{5}$ (bottom) from the GERG-2008 model. ${ }^{11}$ 


\subsection{Methane $+n$-butane $\left(\mathrm{C}_{1} \mathrm{C}_{4}\right)$}

The most comprehensively investigated binary system considered in this work is methane $+n$-butane. Summaries of the available data are given in Tables 3 and 4 . Rowland et al. ${ }^{73}$ published a modification of the GERG-2008 equation of state ${ }^{11}$ that improved the description of this binary. They carried out investigations on the generalized departure function used for this binary in GERG-2008 ${ }^{11}$ and found that the term with high temperature and density exponents often made the representation of caloric data worse, in particular the representation of isobaric heat capacities measured for butane-rich binaries by Syed et al. ${ }^{71}$ They also improved the representation of the VLE at lower temperatures. However, the overall representation of density data by GERG-2008 ${ }^{11}$ and by the modification of Rowland et al. ${ }^{73}$ does not differ significantly. Therefore, this modification is not shown for comparisons with the available homogeneous density data presented here.

Table 3. Average absolute relative deviations (AARD / \%) calculated with the new equation of state for the binary system $\mathrm{C}_{1} \mathrm{C}_{4}$. For a better overview, comprehensive datasets are separated into different composition ranges and the overall AARD is given. Comparisons with available VLE data for this binary are listed in Table 4.

\begin{tabular}{|c|c|c|c|c|c|c|}
\hline Author & $N$ & $\begin{array}{c}T_{\min }-T_{\max } \\
/ \mathrm{K}\end{array}$ & $\begin{array}{c}p_{\min }-p_{\max } \\
/ \mathrm{MPa}\end{array}$ & $x_{\mathrm{C} 1, \min }-x_{\mathrm{C} 1, \max }$ & $\begin{array}{c}\text { AARD } \\
\text { (EOS-LNG) }\end{array}$ & $\begin{array}{c}\text { AARD } \\
\text { (GERG-2008) }\end{array}$ \\
\hline & & Density $p \rho T$ & & & & \\
\hline \multirow[t]{3}{*}{ Beattie et al. $(1941)^{74}$} & 83 & $398-574$ & $3.0-33.7$ & 0.2507 & 1.4 & 0.75 \\
\hline & 94 & $373-574$ & $3.1-35.7$ & 0.5044 & 1.2 & 0.82 \\
\hline & 125 & $348-574$ & $3.2-35.7$ & 0.749 & 1.4 & 1.1 \\
\hline Overall & 302 & $348-574$ & $3.0-35.7$ & $0.250-0.749$ & 1.3 & 0.94 \\
\hline Ellington $(1986)^{75}$ & 27 & $278-300$ & $0.7-6.3$ & 0.9576 & 0.03 & 0.06 \\
\hline \multirow[t]{6}{*}{ Fenghour et al. (1999) ${ }^{76}$} & 15 & $366-478$ & $8.7-31.1$ & 0.3458 & 1.3 & 1.0 \\
\hline & 8 & $362-415$ & $8.8-19.5$ & 0.3522 & 1.2 & 0.34 \\
\hline & 11 & $381-479$ & $8.7-21.0$ & 0.3724 & 2.1 & 0.36 \\
\hline & 16 & $336-480$ & $10.0-48.2$ & 0.4396 & 0.70 & 0.39 \\
\hline & 9 & $316-405$ & $12.0-40.9$ & 0.5034 & 0.71 & 0.48 \\
\hline & 12 & $339-479$ & $11.5-38.7$ & 0.5333 & 0.83 & 0.23 \\
\hline Overall & 71 & $316-480$ & $8.7-48.2$ & $0.345-0.533$ & 1.1 & 0.47 \\
\hline Haynes $(1983)^{77}$ & 19 & $115-141$ & $p_{\text {liq }}$ & $0.777-0.928$ & 0.10 & 0.44 \\
\hline Hiza et al. $(1977)^{78}$ & 4 & $120-131$ & $p_{\text {liq }}$ & 0.5883 & 0.048 & 0.26 \\
\hline $\begin{array}{l}\text { Jaeschke \& Humphreys } \\
(1991)^{62} \text { and }\end{array}$ & 268 & $270-354$ & $0.3-28.2$ & 0.985 & 0.017 & 0.014 \\
\hline Jaeschke et al. $(1997)^{61}$ & 285 & $280-350$ & $0.4-27.9$ & 0.9492 & 0.029 & 0.030 \\
\hline Overall & 553 & $270-354$ & $0.3-28.2$ & $0.949-0.985$ & 0.023 & 0.023 \\
\hline Kestin \& Yata $(1968)^{79}$ & 34 & $293-304$ & $0.1-0.7$ & $0.355-0.844$ & 0.47 & 0.44 \\
\hline Pan et al. $(1975)^{80}$ & 2 & $108-116$ & $0.1-0.2$ & 0.9499 & 0.098 & 0.38 \\
\hline \multirow[t]{4}{*}{ Reamer et al. $(1947)^{81}$} & 120 & $310-511$ & $1.3-69.0$ & 0.1879 & 0.71 & 0.75 \\
\hline & 131 & $310-511$ & $1.3-69.0$ & 0.396 & 3.5 & 3.6 \\
\hline & 126 & $310-511$ & $1.3-69.0$ & 0.6002 & 0.57 & 0.53 \\
\hline & 135 & $310-511$ & $1.3-69.0$ & 0.7997 & 0.57 & 0.47 \\
\hline Overall & 512 & $310-511$ & $1.3-69.0$ & $0.187-0.800$ & 1.4 & 1.4 \\
\hline
\end{tabular}




\begin{tabular}{|c|c|c|c|c|c|c|}
\hline Author & $N$ & $\begin{array}{c}T_{\min }-T_{\max } \\
/ \mathrm{K}\end{array}$ & $\begin{array}{c}p_{\min }-p_{\max } \\
/ \mathrm{MPa} \\
\end{array}$ & $x_{\mathrm{C} 1, \min }-x_{\mathrm{C} 1, \max }$ & $\begin{array}{c}\text { AARD } \\
\text { (EOS-LNG) }\end{array}$ & $\begin{array}{c}\text { AARD } \\
\text { (GERG-2008) }\end{array}$ \\
\hline Sage et al. $(1940)^{51}$ & 138 & $294-395$ & $0.2-10.4$ & $0.002-0.921$ & 3.8 & 2.6 \\
\hline Tomlinson $(1985)^{82}$ & 21 & $279-323$ & $2.6-24.3$ & 0.0242 & 10.0 & 10.0 \\
\hline \multicolumn{7}{|c|}{ Speed of sound $w$} \\
\hline \multirow[t]{3}{*}{ Plantier et al. $(2005)^{83}$} & 9 & 311 & $3.9-13.8$ & 0.158 & 1.5 & 1.0 \\
\hline & 11 & 311 & $13.1-17.3$ & 0.724 & 17.0 & 14.0 \\
\hline & 23 & 311 & $2.0-17.3$ & 0.894 & 1.6 & 1.1 \\
\hline Overall & 43 & 311 & $2.0-17.3$ & $0.158-0.894$ & 5.6 & 4.4 \\
\hline \multicolumn{7}{|c|}{ Isobaric heat capacity $c_{p}$} \\
\hline \multirow[t]{3}{*}{ Syed et al. $(2014)^{71}$} & 4 & $148-179$ & 5.05 & 0.95 & 2.3 & 2.0 \\
\hline & 6 & $118-169$ & 5.15 & 0.88 & 2.6 & 3.2 \\
\hline & 6 & $118-169$ & 5.15 & 0.6 & 0.62 & 20.0 \\
\hline Overall & 16 & $118-179$ & $5.0-5.2$ & $0.600-0.950$ & 1.8 & 9.1 \\
\hline \multicolumn{7}{|c|}{ Excess enthalpy $h^{\mathrm{E}}$} \\
\hline Hutchings et al. $(1978)^{84}$ & 97 & $277-395$ & 0.1 & $0.209-0.898$ & 20.0 & 10.9 \\
\hline
\end{tabular}

Reamer et al. ${ }^{81}$ published approximately 500 state points in the homogeneous state region at temperatures between $310 \mathrm{~K}$ and $511 \mathrm{~K}$ with pressures up to $69 \mathrm{MPa}$ over a wide composition range. This publication was part of the comprehensive API research project on natural gases discussed above. Deviations are mostly within $2 \%$ except for the mixture with $x_{\mathrm{C} 1}=0.396$. For this composition, the data scatter around the equation of state within $10 \%$, which causes the comparably high AARD of $3.5 \%$. For the remaining binary mixtures (AARD $=0.57 \%-0.71 \%$ ), the data are more consistent and more accurate as shown in Figures 7 and 8. In most regions, the data of Reamer et al. ${ }^{81}$ are reproduced more accurately by the EOS-LNG than with the GERG-2008. ${ }^{11}$ However, the deviations between the data of Reamer et al. ${ }^{81}$ and the EOS-LNG increase at higher temperatures more than they do for GERG-2008. ${ }^{11}$ This is caused by the different representation of the vapor-liquid equilibrium of the two models (see Fig. 9). The EOS-LNG was adjusted to the phase-equilibrium data of Sage et al., ${ }^{85}$ which caused a shift in the equilibrium curves predicted at higher temperatures, as shown in Fig. 10. This shift has a significant influence on the slope and curvature of the isotherms in a pressure-density plane. Therefore, the representation of homogeneous density data near the phase boundary, where the data of Reamer et al. ${ }^{81}$ are located, is different for both models; consequently, the comparison of the AARD statistics of the EOS-LNG and the GERG-2008 ${ }^{11}$ models in Table 3 does not give a complete representation of the model performance with a temperature-dependent analysis being preferable for this dataset. Older density measurements by Beattie et al. ${ }^{74}$ and Sage et $a l .{ }^{51}$ exhibit even larger deviations from both models and were, therefore, not considered in the fitting procedure.

Jaeschke and Humphreys ${ }^{62}$ and Jaeschke et al. ${ }^{61}$ published more than 550 accurate density data between $270 \mathrm{~K}$ and $354 \mathrm{~K}$ with a maximum pressure of $28 \mathrm{MPa}$. Because they focused on 
hydrocarbon mixtures with typical natural gas compositions, they only considered two binary mixtures with high methane contents. However, due to the very low reported uncertainties of less than $0.05 \%$, these data had a larger influence while developing both the GERG-2008 ${ }^{11}$ and the EOS-LNG model. The data are similarly reproduced by both models and are mostly represented within the experimental uncertainty.

EOS-LNG

GERG-2008

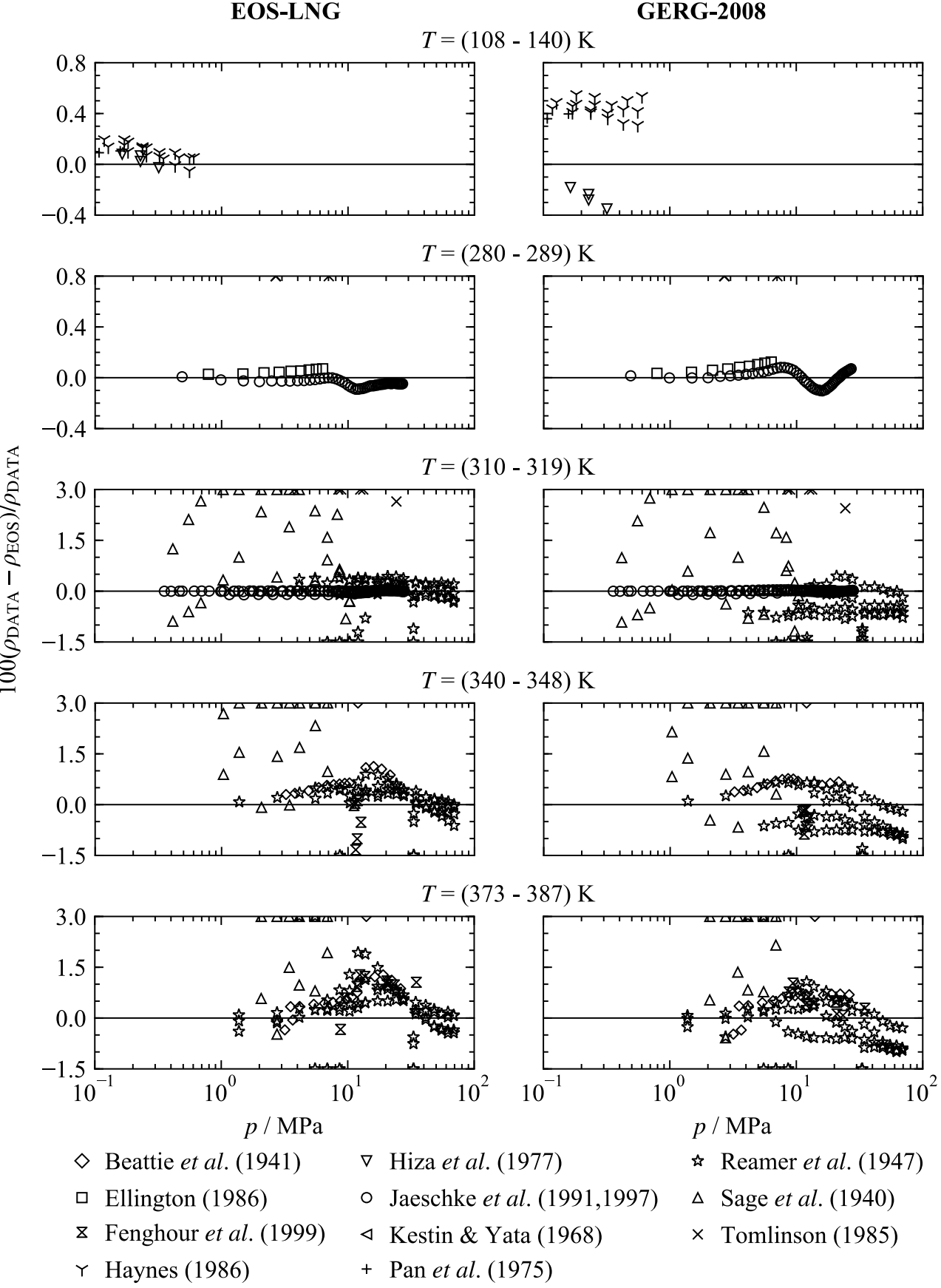

Fig. 7. Percentage deviations of homogeneous density data for the binary system $\mathrm{C}_{1} \mathrm{C}_{4}$ from the EOS-LNG (left) and the GERG-2008 (right) in selected temperature ranges below $400 \mathrm{~K}$.

Ellington ${ }^{75}$ made similar measurements, which were carried out in a restricted temperature range. They agree very well with the data of Jaeschke and Humphreys ${ }^{62}$ and Jaeschke et al., ${ }^{61}$ as well as with the equations of state. The most recent density dataset of Fenghour et al. ${ }^{76}$ 
comprises 71 data points between $316 \mathrm{~K}$ and $480 \mathrm{~K}$ with pressures up to $48 \mathrm{MPa}$ and methane concentration of approximately $x_{\mathrm{C} 1}=0.4$. Although a very detailed and careful description of the experiment is provided and the overall uncertainty in density is reported to be less than $0.05 \%$, the overall AARD from the EOS-LNG is $1.1 \%$ while for the GERG-2008 model $^{11}$ the AARD is $0.47 \%$. The difference in the performance of the two models in representing this dataset is most likely caused by the choice of data favored while fitting the two models. As explained earlier, the representation of the vapor-liquid equilibrium data of Sage et al. ${ }^{85}$ was significantly improved by EOS-LNG in comparison to the GERG-2008 model. ${ }^{11}$ Neither model can accurately represent both the VLE data and the density data measured at similar temperatures, and EOS-LNG prioritized the VLE data over the density data of Fenghour et al. ${ }^{76}$ For future work, accurate measurements overlapping with the Tpx ranges of Reamer et al. ${ }^{81}$ and more accurate vapor-liquid equilibrium data would be valuable to clarify this situation.

In the low-temperature region for which the fluid compositions are more similar to liquefied natural gases, only two state points of Pan et al. ${ }^{80}$ are available for the compressed liquid density. They are represented within $0.1 \%$ by the EOS-LNG. In addition, two datasets of Hiza et $a l .{ }^{78}$ and Haynes ${ }^{77}$ are available for the saturated liquid density. Both were measured with the same magnetic-suspension densimeter, which is known to be an accurate apparatus for this purpose. [Note: The "magnetic-suspension densimeter" of William (Mickey) Haynes and colleagues at NBS (today NIST) differs significantly from more modern magnetic-suspension densimeters, which is in particular a densimeter incorporating a magnetic-suspension coupling ${ }^{86,87}$ as, e.g., used by McLinden, ${ }^{88}$ Richter et al. ${ }^{49}$ and Lentner et al. ${ }^{19,20,72}$ for recent LNG density measurements.] For the measurements at NBS, the mixtures were prepared gravimetrically. According to a very detailed analysis of the experimental uncertainties, the authors state an overall uncertainty of $0.13 \%$ and $0.12 \%(k=2)$, respectively. Comparisons of their data for well-known binary mixtures such as $\mathrm{C}_{1} \mathrm{C}_{2}$ or $\mathrm{C}_{1} \mathrm{C}_{3}$ show that they do not deviate by more than $0.1 \%$ from values calculated with GERG-2008. ${ }^{11}$ In the case of $\mathrm{C}_{1} \mathrm{C}_{4 \mathrm{i}}$, Hiza et $a l .{ }^{78}$ suspected problems during the filling process or dew-point related errors in the mixture preparation so that the experimental uncertainty might be slightly higher. They assumed that similar problems occurred for the system $\mathrm{C}_{1} \mathrm{C}_{4}$. However, these data can be reproduced within $0.08 \%$ (AARD $=0.048 \%$ ), which is consistent with the representation of the data of Haynes ${ }^{77}$ $(\mathrm{AARD}=0.10 \%)$. Due to the high methane concentrations of these mixtures, the correct representation of these saturated liquid density data is crucial to the model's performance in describing liquefied natural gases. 
EOS-LNG

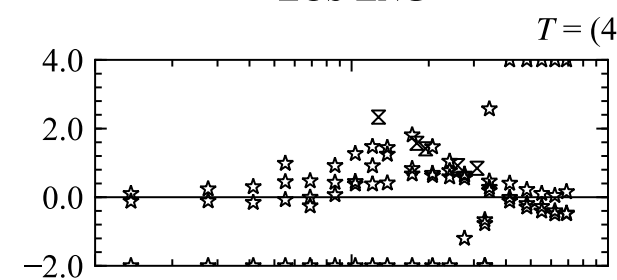

$T=(411-415) \mathrm{K}$
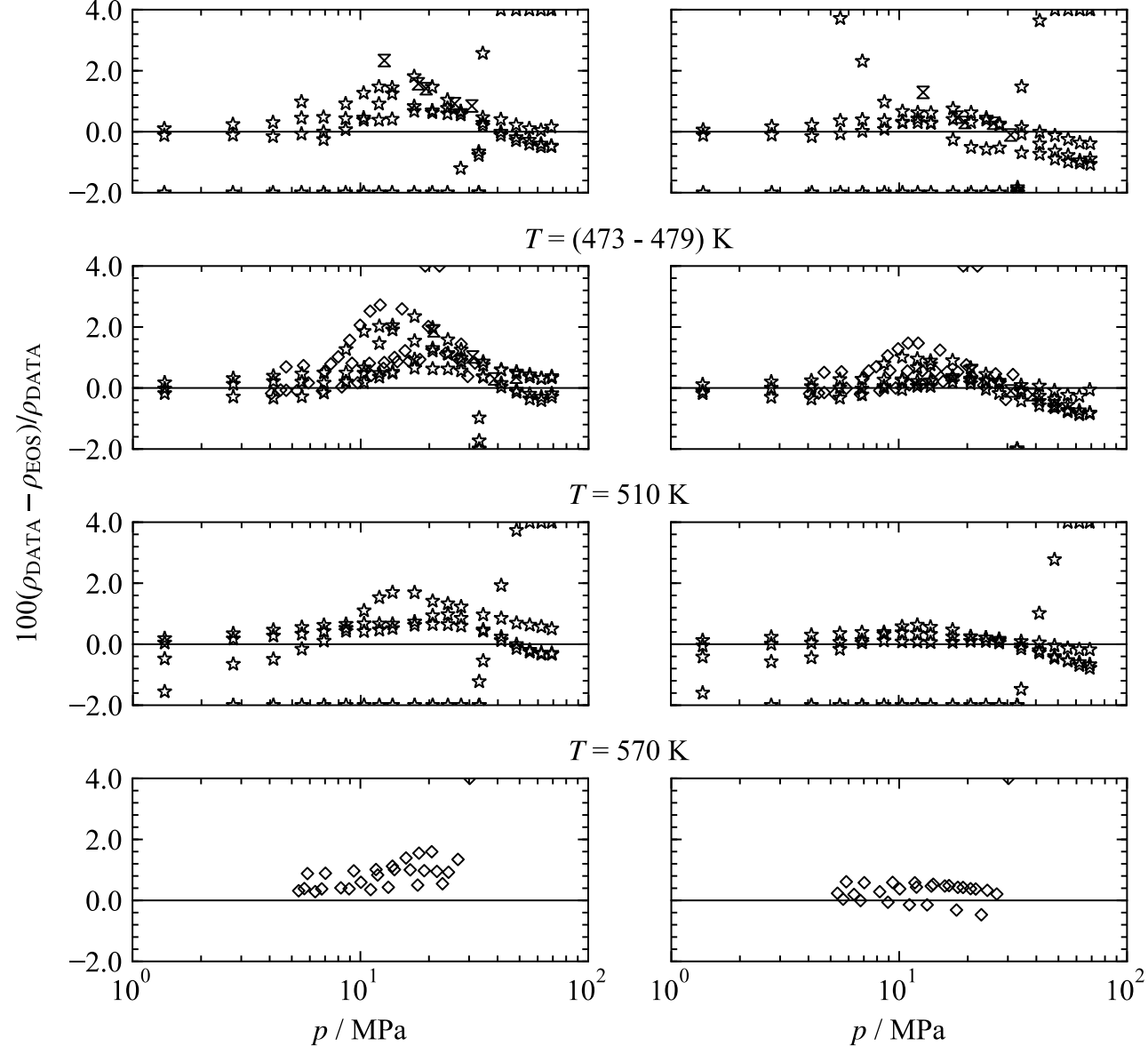

$\diamond$ Beattie et al. (1941)

\& Fenghour et al. (1999)

Fig. 8. Percentage deviations of homogeneous density data for the binary system $\mathrm{C}_{1} \mathrm{C}_{4}$ from the EOS-LNG (left) and the GERG-2008 (right) in selected temperature ranges above $400 \mathrm{~K}$.

Table 4. Average absolute relative deviations of bubble-point pressure data $\left(\mathrm{AARD}_{p \text { liq }} / \%\right)$ and average absolute deviations in terms of percentage mole fraction of methane in the saturated vapor phase $\left(\mathrm{AAD}_{y \mathrm{C} 1} / \%\right)$ ) for the binary system $\mathrm{C}_{1} \mathrm{C}_{4}$. $N$ denotes the total number of points in each publication except for pure-fluid measurements, whereas $N_{\mathrm{x}}$ and $N_{\mathrm{y}}$ indicate the number of bubble-point (index "x") and dew-point (index "y") pressure data. If $N_{\mathrm{x}}$ or $N_{\mathrm{y}}$ differ from $N$, state points were deleted from the numerical analysis for both models due to flash calculation errors or because they are outliers, which would distort the AARD or AAD.

\begin{tabular}{|c|c|c|c|c|c|c|c|c|c|}
\hline Author & $N$ & $N_{\mathrm{x}}$ & $N_{\mathrm{y}}$ & $\begin{array}{c}T_{\min }-T_{\max } / \\
\mathrm{K}\end{array}$ & $\begin{array}{c}p_{\min }-p_{\max } / \\
\mathrm{MPa}\end{array}$ & $\begin{array}{l}\mathrm{AARD}_{p l i q} \\
\text { (EOS-LNG) }\end{array}$ & $\begin{array}{c}\mathrm{AAD}_{y \mathrm{C} 1} \\
\text { (EOS- } \\
\mathrm{LNG} \text { ) }\end{array}$ & $\begin{array}{c}\text { AARD }_{p \text { liq }} \\
\text { (GERG- } \\
\text { 2008) }\end{array}$ & $\begin{array}{c}\mathrm{AAD}_{y \mathrm{Cl}} \\
\text { (GERG- } \\
\text { 2008) }\end{array}$ \\
\hline Chen et al. $(1974)^{89}$ & 167 & $a^{a}$ & 167 & $144-278$ & $0.1-12.9$ & - & 0.30 & - & 0.34 \\
\hline Elliot et al. $(1974)^{90}$ & 102 & 102 & 102 & $144-278$ & $0.1-12.6$ & 8.7 & 0.74 & 7.9 & 0.78 \\
\hline Fenghour et al. $(1999)^{76}$ & 5 & 5 & - & $336-382$ & $8.7-11.6$ & 3.8 & - & 1.7 & - \\
\hline Haynes $(1983)^{77}$ & 19 & 19 & - & $115-141$ & $0.1-0.6$ & 1.3 & - & 1.8 & - \\
\hline Kahre $(1974)^{91}$ & 70 & 70 & 70 & $166-284$ & $0.1-11.1$ & 7.2 & 0.15 & 6.4 & 0.13 \\
\hline May et al. $(2015)^{70}$ & 20 & 20 & 20 & $203-274$ & $1.3-10.2$ & 4.3 & 0.20 & 9.1 & 0.22 \\
\hline Nederbragt $(1938)^{92}$ & 9 & 9 & 9 & $252-317$ & $1.0-3.1$ & 4.1 & 1.2 & 6.4 & 1.4 \\
\hline Rigas et al. $(1958)^{93}$ & 7 & 7 & 7 & $310-311$ & $6.6-12.9$ & 4.3 & 1.1 & 5.9 & 2.0 \\
\hline
\end{tabular}




\begin{tabular}{|c|c|c|c|c|c|c|c|c|c|}
\hline Author & $N$ & $N_{\mathrm{x}}$ & $N_{\mathrm{y}}$ & $\begin{array}{c}T_{\min }-T_{\max } / \\
\mathrm{K}\end{array}$ & $\begin{array}{c}p_{\min }-p_{\max } / \\
\mathrm{MPa}\end{array}$ & $\begin{array}{c}\text { AARD }_{p l i q} \\
\text { (EOS-LNG) }\end{array}$ & $\begin{array}{c}\mathrm{AAD}_{y \mathrm{C} 1} \\
(\mathrm{EOS}- \\
\mathrm{LNG})\end{array}$ & $\begin{array}{c}\text { AARD }_{p l i q} \\
\text { (GERG- } \\
\text { 2008) }\end{array}$ & $\begin{array}{c}\mathrm{AAD}_{y \mathrm{C} 1} \\
\text { (GERG- } \\
2008)\end{array}$ \\
\hline Roberts et al. $(1962)^{94}$ & 75 & 75 & 72 & $210-411$ & $0.1-13.2$ & 10.0 & 2.0 & 7.5 & 3.1 \\
\hline Sage et al. $(1940)^{85}$ & 117 & 116 & $105^{b}$ & $294-395$ & $0.2-13.4$ & 1.7 & 2.7 & 2.5 & 3.1 \\
\hline Wang \& McKetta (1964) ${ }^{95}$ & 24 & 24 & 23 & $177-311$ & $0.5-11.8$ & 9.1 & 0.70 & 8.7 & 0.71 \\
\hline Wiese et al. $(1970)^{96}$ & 25 & 25 & 24 & $277-378$ & $1.3-13.3$ & 2.6 & 2.7 & 1.7 & 2.3 \\
\hline
\end{tabular}

${ }^{a}$ Only dew-point pressures were measured.

${ }^{b}$ Most of the state points, which are not included in the statistics, are measured at high pressures, which are significantly underestimated by the GERG-2008, $c f$. Fig. 10.

Table 4 lists a summary of the literature datasets for VLE compared with EOS-LNG and GERG-2008. ${ }^{11}$ Percentage deviations of these data from saturation-pressure values calculated with EOS-LNG, GERG-2008, ${ }^{11}$ and with the modification of Rowland et al. ${ }^{73}$ are presented in Fig. 9. For this system, the most comprehensive vapor-liquid equilibrium dataset was provided by Sage et al. ${ }^{85}$ Their data cover a temperature range from $294 \mathrm{~K}$ to $395 \mathrm{~K}$ with a maximum pressure of 13.4 MPa. Since the data were measured together with the homogeneous density data, they were used in this work to determine the location of the vapor-liquid equilibrium boundary. The overall AARD in terms of bubble-point pressures of EOS-LNG is $1.7 \%$ for this dataset, whereas GERG-2008 ${ }^{11}$ represents the dataset with an AARD of $2.5 \%$. This difference is mainly caused by the choice of the dataset that was fitted.

For the development of GERG-2008, ${ }^{11}$ the VLE data of Roberts et al. ${ }^{94}$ were favored. They state an uncertainty in their pressure measurements of $0.014 \mathrm{MPa}$, which is between $1 \%$ and more than $10 \%$ depending on the saturation pressure. Furthermore, it was found that the data of Roberts et al. ${ }^{94}$ and Wang and McKetta, ${ }^{95}$ which were measured with the same apparatus, significantly differ from other experiments, e.g., of Sage et al., ${ }^{85}$ Elliot et al. ${ }^{90}$ and May et al. ${ }^{70}$ (cf. Fig. 10, $T=244.3 \mathrm{~K}$, Elliot et al..$^{90}$ and May et al. ${ }^{70}$ ). Because the data of those three sources agree very well, the data of Elliot et al. ${ }^{90}(\mathrm{AARD}=8.7 \%)$ and May et al. ${ }^{70}(\mathrm{AARD}=4.3 \%)$ were used to model the vapor-liquid equilibrium of EOS-LNG at low temperatures down to $210 \mathrm{~K}$. The comparably high AARD for the data of Elliot et al. ${ }^{90}$ is mainly caused by the low pressure region. The most significant improvement was achieved in the high temperature region. Because GERG-2008 ${ }^{11}$ was fitted to the data of Roberts et al..$^{94}$ up to $411 \mathrm{~K}$, the data of Sage et al. ${ }^{85}$ are considerably underestimated in this region. Deviations of up to $-2 \mathrm{MPa}$ can be observed for GERG-2008 ${ }^{11}$ at $T=394.2 \mathrm{~K}$, which is far more accurately represented by EOSLNG (cf. Fig. 10). 

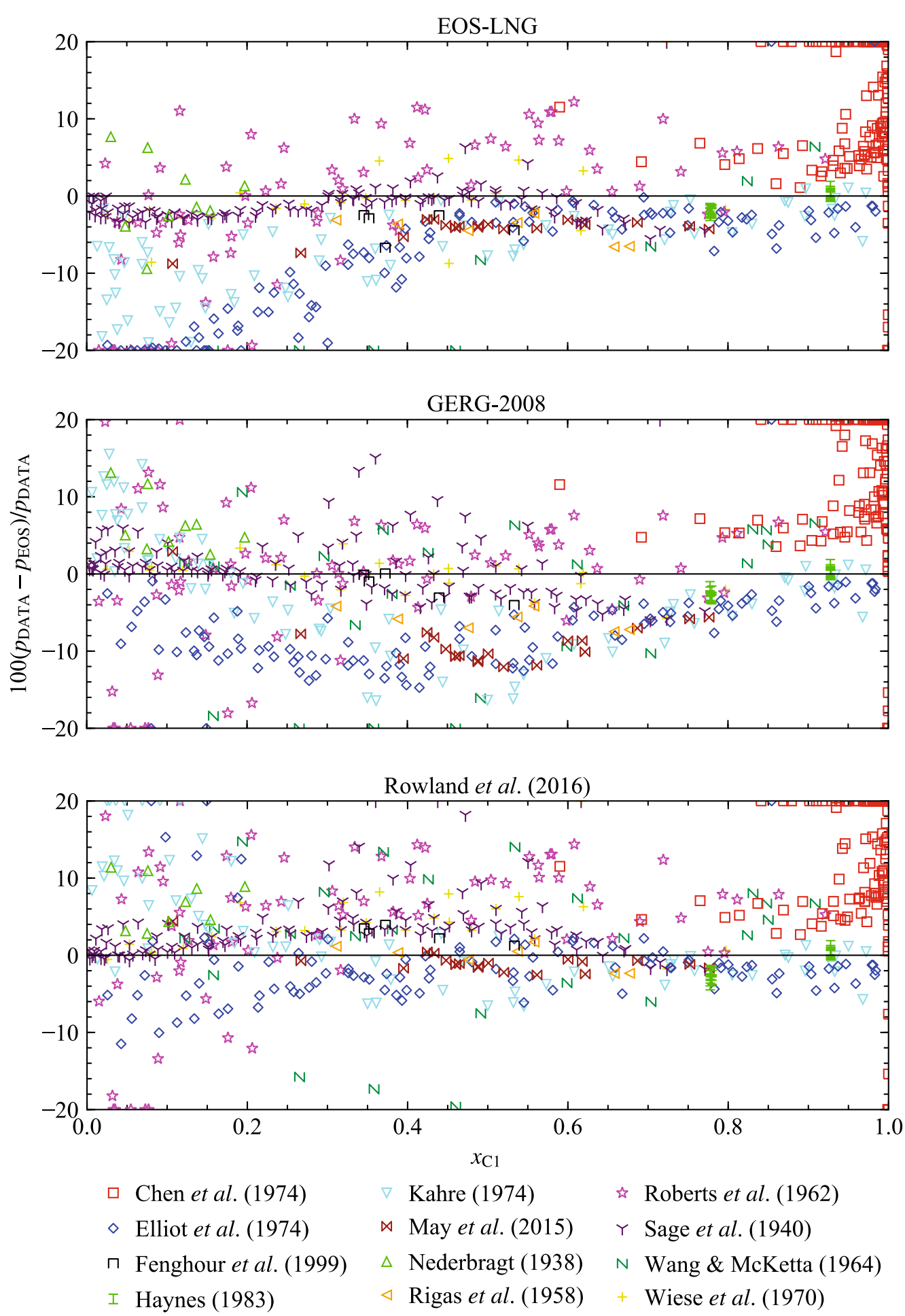

Fig. 9. Percentage deviations of bubble-point pressure data for the binary system $\mathrm{C}_{1} \mathrm{C}_{4}$ from the EOS-LNG (top), the GERG-2008 ${ }^{11}$ (center), and the modification of Rowland $e t a l .{ }^{73}$ as a function of the composition $x_{\mathrm{C} 1}$. 

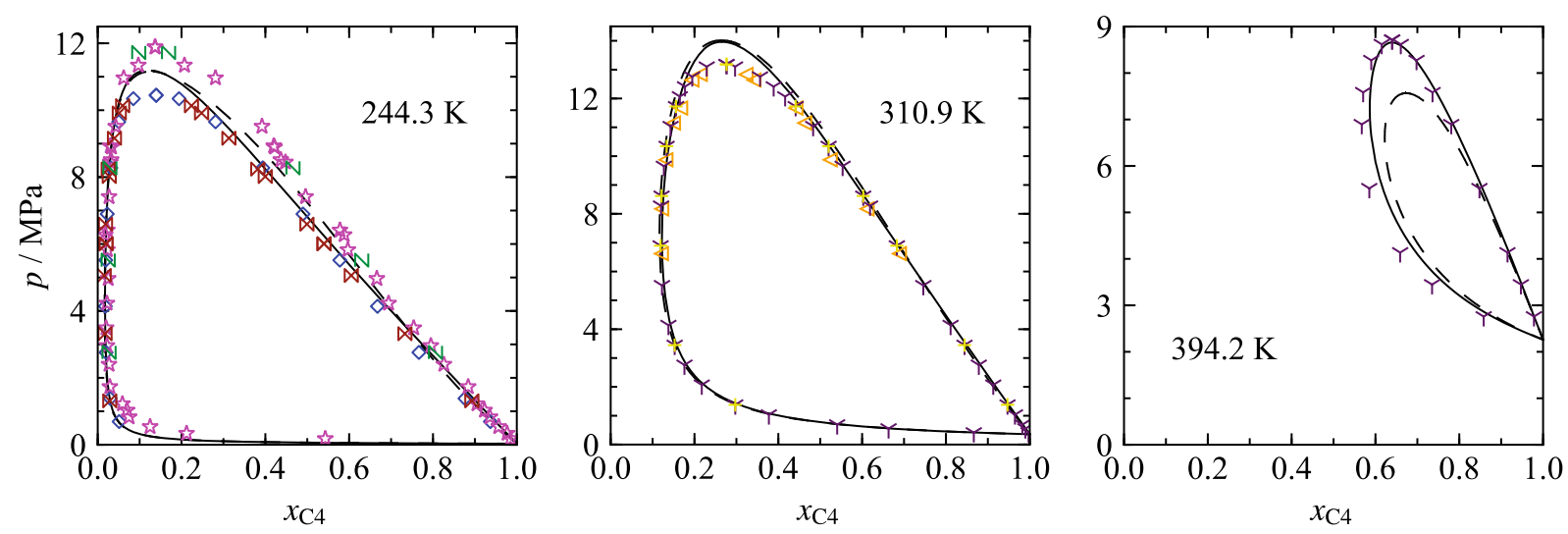

$\diamond$ Elliot et al. (1974)

is Roberts et al. (1962)

N Wang \& McKetta (1964)

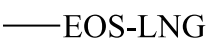

$\bowtie$ May et al. (2015)

Y Sage et al. (1940)

Wiese et al. (1970)

- -GERG-2008

$\checkmark$ Rigas et al. (1958)

Fig. 10. $p, x$-diagrams representing the vapor-liquid equilibrium data for the binary system $\mathrm{C}_{1} \mathrm{C}_{4}$.

With respect to caloric data, only one dataset each is available for speed of sound, for isobaric heat capacity, and for excess enthalpy. The speed of sound data of Plantier et al. ${ }^{83}$ are mostly scattered around the EOS-LNG and the other two models ${ }^{11,73}$ within $10 \%$. Excess enthalpies of Hutchings et al. ${ }^{84}$ deviate by up to $40 \%$, which is again similar for all three models. Significant differences among the three equations can only be observed for the isobaric heat capacities, $c f$. Fig. 11. The objective of Rowland et $a l .^{73}$ was to better represent the recent measurements of Syed et al., ${ }^{71}$ which are reproduced within $5 \%$ (AARD $=2.8 \%$ ), whereas GERG-2008 ${ }^{11}$ deviates by more than $10 \%$ (AARD $=9.1 \%$ ). With the new fitted parameters and departure function of the EOS-LNG, deviations are reduced to $3 \%$ (AARD $=1.8 \%$ ).

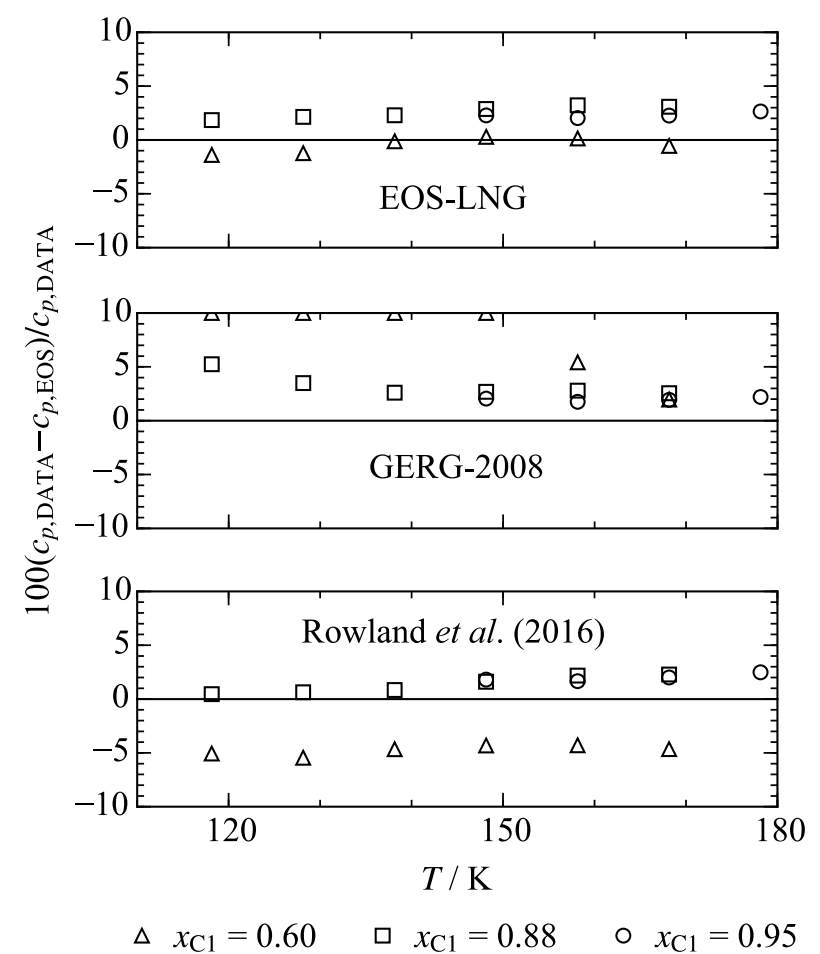

Fig. 11. Percentage deviations of isobaric heat capacity data of Syed et al. ${ }^{71}$ for the binary system $\mathrm{C}_{1} \mathrm{C}_{4}$ from EOSLNG (top), GERG-2008 ${ }^{11}$ (center), and the modification of Rowland et al..$^{73}$ 


\subsection{Methane + isobutane $\left(\mathrm{C}_{1} \mathrm{C}_{4 i}\right)$}

The available database for the binary system methane + isobutane is more restricted than for methane $+n$-butane. There are four datasets available for the homogeneous density and five datasets containing vapor-liquid equilibrium data. Except for new homogeneous liquid densities measured by Lentner et al. ${ }^{20,72}$, the density data were also available for the development of the GERG-2008. ${ }^{11}$ An overview of the performance of EOS-LNG and GERG-2008 ${ }^{11}$ in representing these data is given in Table 5 and shown in Figs. 12 and 13.

Table 5. Average absolute relative deviations (AARD / \%) of density data from values calculated with the new equation of state for the binary system $\mathrm{C}_{1} \mathrm{C}_{4 \mathrm{i}}$. For a better overview, comprehensive density $(p \rho T x)$ datasets are separated into different composition ranges for the data of Olds et al. ${ }^{52}$

\begin{tabular}{|c|c|c|c|c|c|c|}
\hline Author & $N$ & $\begin{array}{c}T_{\min }-T_{\max } \\
/ \mathrm{K}\end{array}$ & $\begin{array}{c}p_{\min }-p_{\max } \\
/ \mathrm{MPa}\end{array}$ & $\begin{array}{c}x_{\mathrm{C} 1 \text {,min }}- \\
x_{\mathrm{C} 1, \text { max }}\end{array}$ & $\begin{array}{c}\text { AARD } \\
\text { (EOS-LNG) }\end{array}$ & $\begin{array}{c}\text { AARD } \\
(\text { GERG-2008) }\end{array}$ \\
\hline & & Density $p \rho T$ & & & & \\
\hline Lentner et al. $(2018)^{20,72}$ & 47 & $100-180$ & $\begin{array}{c}0.2-9.31 \\
\text { and } p_{\text {liq }}\end{array}$ & 0.9701 & 0.010 & 0.12 \\
\hline Ellington $(1986)^{75}$ & 27 & $278-300$ & $0.7-6.30$ & 0.9576 & 0.16 & 0.17 \\
\hline $\begin{array}{lll}\begin{array}{l}\text { Rodosevich } \\
(1973)^{97}\end{array} & \& & \text { Miller } \\
\end{array}$ & 7 & $95-115$ & $p_{\text {liq }}$ & $0.915-0.947$ & 0.030 & 0.023 \\
\hline \multirow[t]{4}{*}{ Olds et al. $(1942)^{52}$} & 142 & $310-511$ & $1.3-34.5$ & 0.16 & 0.57 & 0.66 \\
\hline & 137 & $310-511$ & $1.3-34.5$ & 0.277 & 0.36 & 0.35 \\
\hline & 136 & $310-511$ & $1.3-34.5$ & 0.4681 & 0.28 & 0.16 \\
\hline & 140 & $310-511$ & $1.3-34.5$ & 0.7101 & 0.26 & 0.42 \\
\hline Overall & 555 & $310-511$ & $1.3-34.5$ & $0.160-0.711$ & 0.37 & 0.40 \\
\hline Haynes $(1983)^{77}$ & 13 & $110-140$ & $p_{\text {liq }}$ & $0.783-0.921$ & 0.057 & 0.049 \\
\hline Hiza et al. $(1977)^{78}$ & 4 & $115-130$ & $p_{\text {liq }}$ & 0.4869 & 0.068 & 0.96 \\
\hline
\end{tabular}

Figure 12 shows the low-temperature region covered by homogeneous density data. Lentner et al. $^{20,72}$ published data for six isotherms in the LNG region between $100 \mathrm{~K}$ and $180 \mathrm{~K}$. Modeling these data was challenging because the isotherms at higher temperatures approach the phase boundary in their low-pressure limit. If the available vapor-liquid equilibrium data are not consistent with the homogeneous density data, this offset has the largest effect near the phase boundary and it is only possible to accurately reproduce either the VLE or the homogeneous density data. The new density measurements were not available when the GERG$2008^{11}$ was developed. Therefore, the model was mainly fitted to represent the VLE and homogeneous density data of Olds et al. ${ }^{52}$ This gives rise to increasing deviations at increasing temperatures between the new density data ${ }^{72}$ and the GERG-2008 ${ }^{11}$ ( $c f$. Fig. 6, top panel), which leads to the assumption that the homogeneous density data of Olds et al. ${ }^{52}$ were overfitted in the development of GERG-2008. ${ }^{11}$ However, because no other data are available, EOS-LNG was fitted to ensure that the new data were represented as well as possible and that the accuracy of GERG-2008 ${ }^{11}$ for all other regions and properties was retained. Consequently, the density data by Lentner et al. ${ }^{20,72}$ are reproduced within their experimental uncertainty, except for three state points at the lower pressures of the isotherm $T=180 \mathrm{~K}, c f$. Fig. 12. The AARD was reduced from $0.12 \%$ (GERG-2008 ${ }^{11}$ ) to $0.01 \%$ (EOS-LNG). 

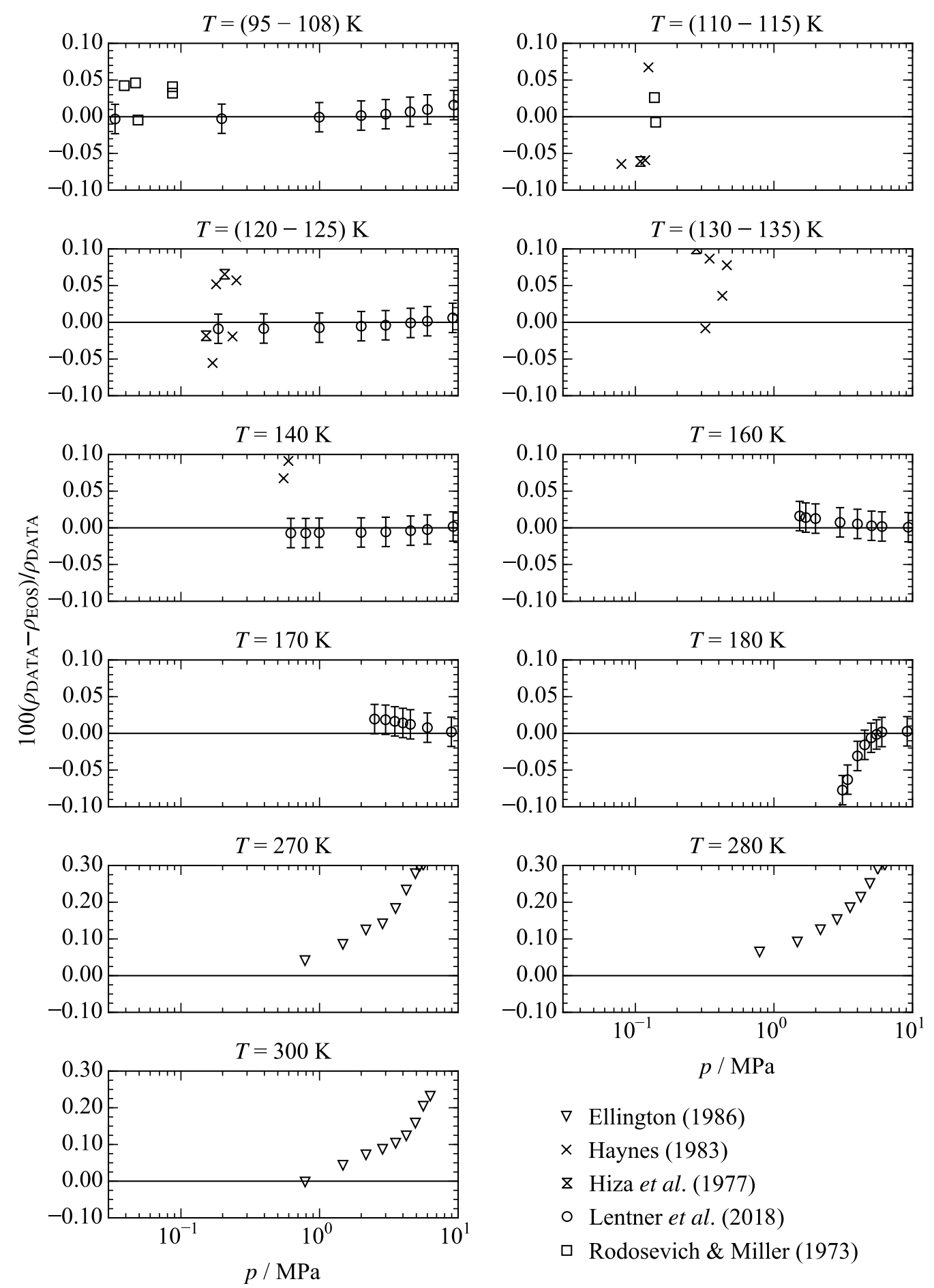

$\nabla$ Ellington (1986)

$\times$ Haynes (1983)

× Hiza et al. (1977)

○ Lentner et al. (2018)

Rodosevich \& Miller (1973)

Fig. 12. Percentage deviations of homogeneous density data in the low and medium temperature region from the EOS-LNG for the binary system $\mathrm{C}_{1} \mathrm{C}_{4 \mathrm{i}}$. The uncertainties of the data of Lentner et al ${ }^{20,72}$ are also shown. The scale of the $\mathrm{y}$-axis changes at $270 \mathrm{~K}$.

This improvement in the homogeneous liquid state at low temperatures resulted in an AARD of $0.057 \%\left(\mathrm{AARD}_{\mathrm{GERG}-2008}=0.049 \%\right)$ for the saturated liquid density data of Haynes ${ }^{77}$ and $0.068 \%\left(\mathrm{AARD}_{\mathrm{GERG}-2008}=0.96 \%\right.$ ) for the measurements of Hiza et al. ${ }^{78}$ As with $\mathrm{C}_{1} \mathrm{C}_{4}$, the experimental uncertainty of these datasets is approximately $0.12 \%$, and EOS-LNG reproduces all data within this value. For comparison, only one data point deviates by more than $0.1 \%$ for the systems $\mathrm{C}_{1} \mathrm{C}_{2}$ and $\mathrm{C}_{1} \mathrm{C}_{3}$. The dataset of Lentner et al. ${ }^{20,72}$ also includes saturated liquid 
density data at each measured temperature, which overlap the data of Haynes ${ }^{77}$ and Hiza et al. ${ }^{78}$ The data of Lentner et al..$^{20,72}$ are represented within their experimental uncertainty (less than $0.017 \%$ ) except for the state point at $T=180 \mathrm{~K}$, which deviates by $0.076 \%$. In the same temperature range, seven saturated liquid density data points were published by Rodosevich and Miller. ${ }^{97}$ Measurements were carried out with a special gas expansion system in a narrow temperature range for several binary mixtures including hydrocarbons and nitrogen. Deviations of these data with respect to EOS-LNG are less than $0.05 \%$, which is well within the experimental uncertainty of $0.1 \%$.

In the medium-temperature range, only three isotherms from one author are available. Because the data were disclosed as private communication from Ellington ${ }^{75}$ to Jaeschke and were later published in the supplementary material of a GERG report, ${ }^{61}$ no information on the measurement procedure or the accuracy is available. With increasing pressure, the data show increasing deviations of up to $0.3 \%(\mathrm{AARD}=0.16 \%)$. This matches the representation of the experimental data by the GERG-2008 ${ }^{11}(\mathrm{AARD}=0.17 \%)$.

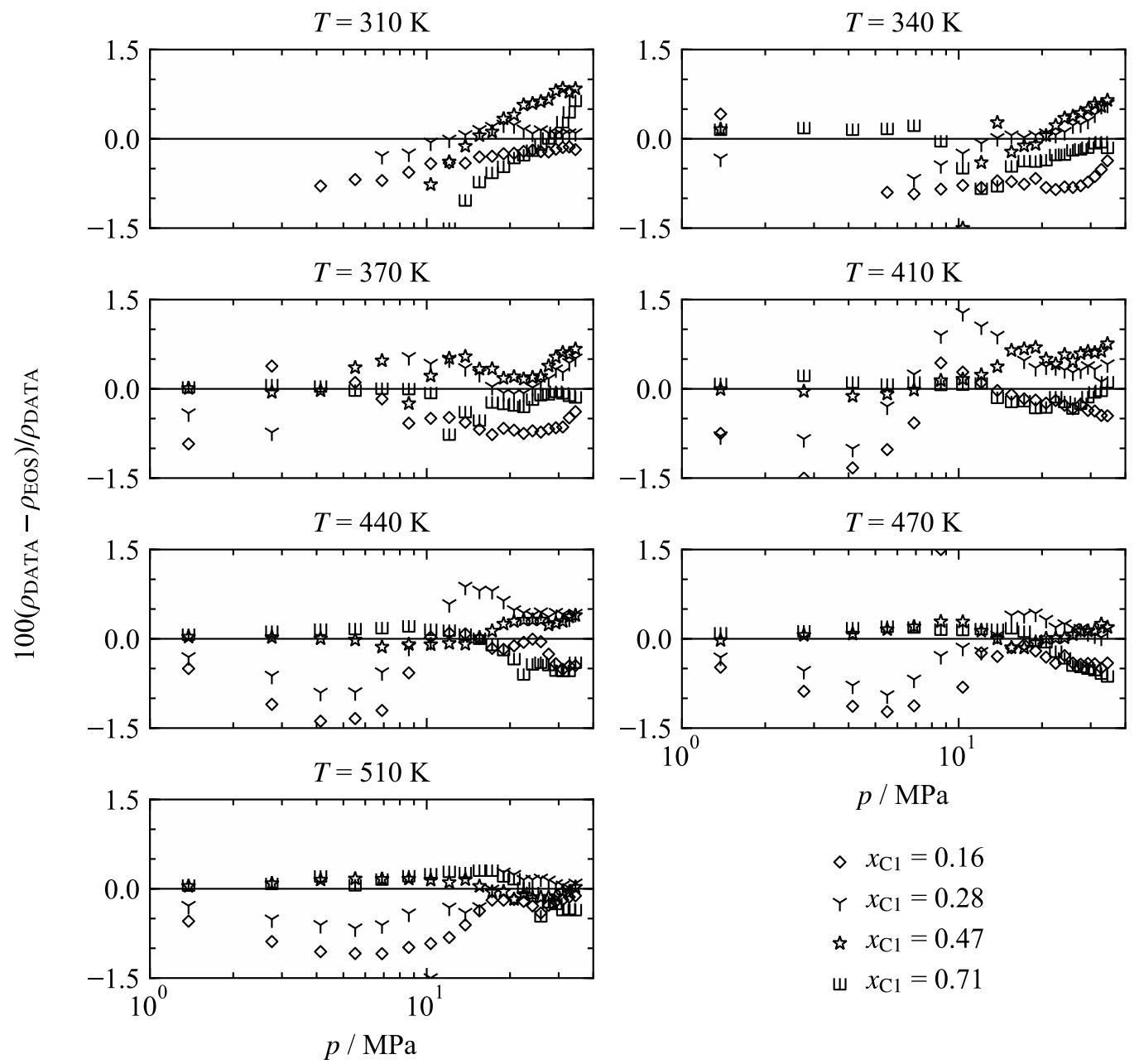

Fig. 13. Percentage deviations of homogeneous density data of Olds et al..$^{52}$ in the high-temperature region from the EOS-LNG for the binary system $\mathrm{C}_{1} \mathrm{C}_{4 \mathrm{i}}$. 
The high-temperature region $(310 \mathrm{~K}$ to $511 \mathrm{~K})$ was comprehensively investigated over a wide composition range by Olds et al. ${ }^{52}$ with data extending to a maximum pressure of 34.5 MPa. As illustrated in Fig. 13, deviations up to 1.5\% are obtained for the EOS-LNG, which is comparable to that for GERG-2008. ${ }^{11}$ The overall AARD is $0.37 \%$, whereas it is $0.40 \%$ for GERG-2008. ${ }^{11}$ As discussed in the introduction of Sec. 3, reliable experimental uncertainties of these data are not available. New measurements in this state region are desirable to accurately assess the data.

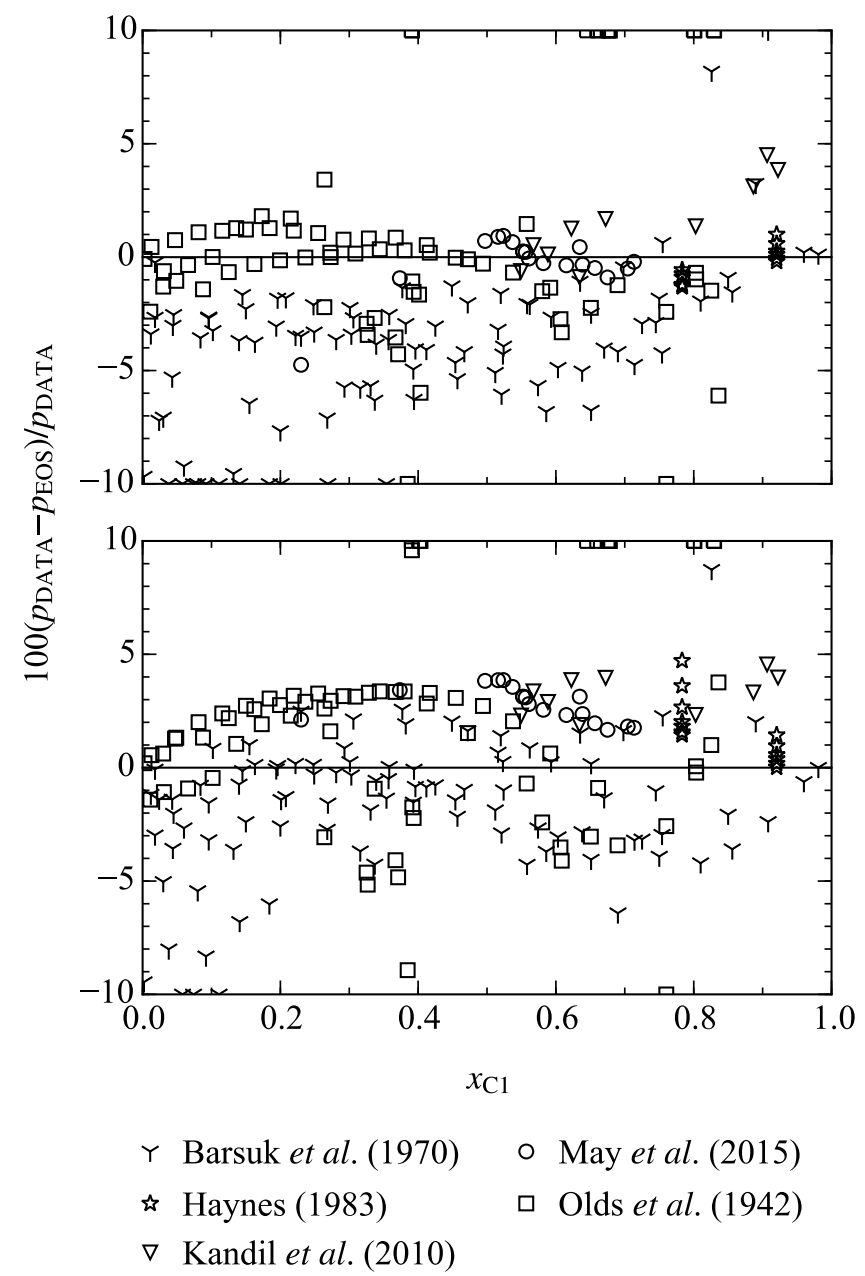

Fig. 14. Percentage deviations of bubble-point pressure data for the binary system $\mathrm{C}_{1} \mathrm{C}_{4 \mathrm{i}}$ from the EOS-LNG (top) and the GERG-2008 ${ }^{11}$ (bottom) as a function of the composition $x_{\mathrm{C} 1}$.

Figure 14 gives an overview of the percentage deviations of each VLE dataset from values calculated with EOS-LNG and GERG-2008, ${ }^{11}$ where the different choice of datasets used to develop the two models becomes apparent. The most extensive vapor-liquid equilibrium datasets available for this binary system are those of Barsuk et al. ${ }^{98}$ and Olds et al. ${ }^{52}$ The dewpoint pressure data of those two publications agree quite well, whereas the bubble-point pressure data of Barsuk et al. ${ }^{98}$ are systematically lower than the data of Olds et al. ${ }^{52}$ No reliable information on the uncertainty of the data were provided by the authors. Since the density data of Olds et al. ${ }^{52}$ were used to model the homogenous region, this dataset was also prioritized for 
the description of VLE data in this work. In this way, an inconsistency between the two properties is avoided. Furthermore, recent VLE measurements of May et al. ${ }^{70}$ confirm this approach. When fitting the VLE data of Olds et al., ${ }^{52}$ it is possible to reproduce the bubblepoint pressure data of May et al. ${ }^{70}$ within $0.9 \%$ (AARD $=0.73 \%$ ) except for one state point measured at the lowest methane mole fraction, $c f$. Fig. 14. For the development of the GERG$2008,{ }^{11}$ the data of Barsuk et al. ${ }^{98}$ were chosen as the reference dataset since the data of May et $a l . .^{70}$ were unavailable at the time of fitting. Consequently, the data of May et al. ${ }^{70}$ are systematically underpredicted by GERG-2008 ${ }^{11}$ and can only be reproduced with an AARD of 2.8\% . Additionally, 13 bubble-point pressure data measured by Haynes ${ }^{77}$ and 10 saturation pressure data measured by Kandil et al. ${ }^{99}$ are available. The data of Haynes ${ }^{77}$ are reproduced within $1.4 \%$ by the EOS-LNG ( $4.8 \%$ by the GERG-2008 ${ }^{11}$ ), whereas the data of Kandil et al..$^{99}$ exhibit positive deviations of up to $4.5 \%$ ( $4.6 \%$ by the GERG-2008 ${ }^{11}$ ). However, the data of Kandil et al. ${ }^{99}$ were measured with an earlier version of the apparatus used subsequently by May et $a l .{ }^{70}$ with poorer temperature control, and the experimental uncertainties estimated by Kandil et al. ${ }^{99}$ are much larger than those of May et al. ${ }^{70}$

Table 6. Average absolute relative deviations of bubble-point pressure data $\left(\mathrm{AARD}_{p l i q} / \%\right)$ and average absolute deviations in terms of percentage mole fraction of methane in the saturated vapor phase $\left.\left(\mathrm{AAD}_{y \mathrm{C} 1} / \%\right)\right)$ for the binary system $\mathrm{C}_{1} \mathrm{C}_{4 \mathrm{i}}$. $N$ denotes the total number of points in each publication except for pure-fluid measurements, whereas $N_{\mathrm{x}}$ and $N_{\mathrm{y}}$ indicate the number of bubble-point (index "x") and dew-point (index "y") pressure data. If $N_{\mathrm{x}}$ or $N_{\mathrm{y}}$ differ from $N$, state points were deleted from the numerical analysis for both models due to flash calculation errors or because they are outliers, which would distort the AARD or AAD.

\begin{tabular}{|c|c|c|c|c|c|c|c|c|c|}
\hline Author & $N$ & $N_{\mathrm{x}}$ & $N_{\mathrm{y}}$ & $\begin{array}{c}T_{\min }-T_{\max } / \\
\mathrm{K}\end{array}$ & $\begin{array}{c}p_{\min }-p_{\max } / \\
\mathrm{MPa}\end{array}$ & $\begin{array}{c}\mathrm{AARD}_{p \text { liq }} \\
\left(\mathrm{EOS}^{-L N G}\right)\end{array}$ & $\begin{array}{c}\mathrm{AAD}_{y \mathrm{C} 1} \\
(\mathrm{EOS}- \\
\mathrm{LNG})\end{array}$ & $\begin{array}{c}\text { AARD }_{p \text { liq }} \\
\text { (GERG- } \\
2008) \\
\end{array}$ & $\begin{array}{c}\mathrm{AAD}_{y \mathrm{C} 1} \\
\text { (GERG- } \\
2008)\end{array}$ \\
\hline Barsuk et al. $(1970)^{98}$ & 96 & 96 & 94 & $198-378$ & $0.4-12$ & 6.0 & 2.6 & 2.5 & 2.9 \\
\hline Haynes $(1983)^{77}$ & 13 & 13 & - & $110-141$ & $0.08-0.59$ & 0.70 & - & 1.7 & - \\
\hline Kandil et al. $(2010)^{99}$ & 10 & 10 & $7^{b}$ & $151-252$ & $1.0-8.4$ & 1.8 & 0.09 & 3.2 & 0.13 \\
\hline May et al. $(2015)^{70}$ & 18 & 18 & 18 & $203-274$ & $2.6-8.7$ & 0.73 & 0.15 & 2.8 & 0.32 \\
\hline Olds et al. $(1942)^{52}$ & 75 & $41^{a}$ & 75 & $310-378$ & $0.5-12$ & 0.83 & 1.3 & 2.2 & 1.7 \\
\hline
\end{tabular}

${ }^{a}$ For 34 state points out of 75 , no liquid-phase composition was measured.

${ }^{b}$ For 3 state points out of 10, no vapor-phase composition was measured. 


\subsection{Methane $+n$-pentane $\left(\mathrm{C}_{1} \mathrm{C}_{5}\right)$}

For the binary system methane $+n$-pentane, only a few data sources are available. Overviews are given in Tables 7 and 8 .

Table 7. Average absolute relative deviations (AARD / \%) for density and excess enthalpy data from values calculated with the new equation of state for the binary system $C_{1} C_{5}$. For a better overview, comprehensive density $(p \rho T x)$ datasets are separated into different composition ranges and the overall AARD is given.

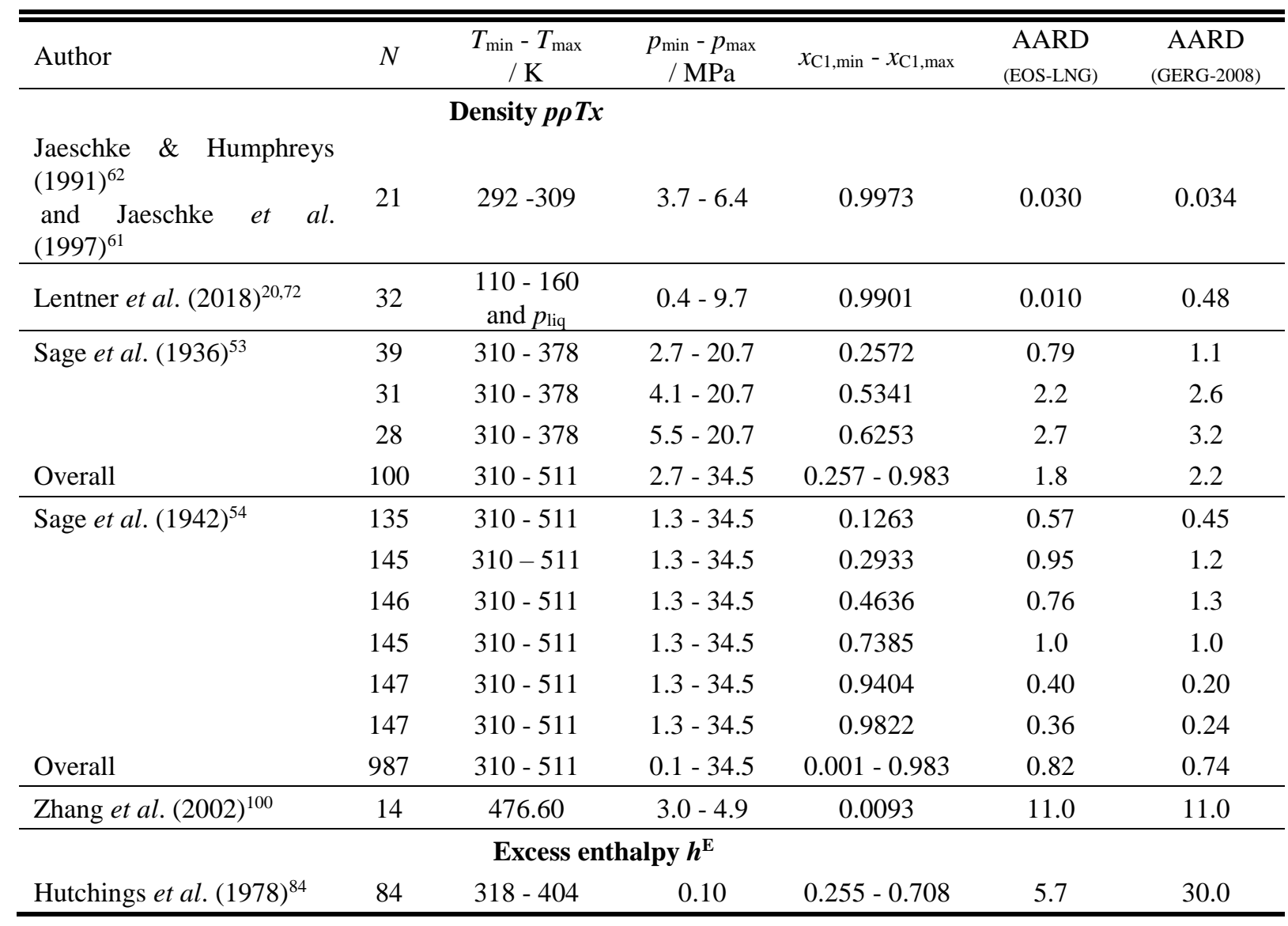

In Fig. 15, deviations of all available experimental density data from EOS-LNG are illustrated. Since the main focus of this work was the more accurate description of the LNG region, the new density data of Lentner et $a l^{20,72}$ were prioritized during the fit. The experimental uncertainty of the data is specified to be $0.02 \%$, which is reproduced by the EOSLNG.

As for the other binaries, the most comprehensive dataset for $\mathrm{C}_{1} \mathrm{C}_{5}$ was published by Sage et al..$^{53,54}$ They cover temperatures from $310 \mathrm{~K}$ to $511 \mathrm{~K}$ with a maximum pressure of $34.5 \mathrm{MPa}$ over the full composition range. The deviations of the data from Sage et al. ${ }^{53}$ from 1936 to both models are slightly higher than to those from $1942 .{ }^{54}$ For the EOS-LNG, the overall AARD amounts to $1.8 \%$, whereas the dataset of Sage et al. ${ }^{54}$ exhibits an AARD of $0.82 \%$. No temperature, pressure, or composition dependency could be observed, except for higher deviations in the vicinity of the critical points of each mixture. 

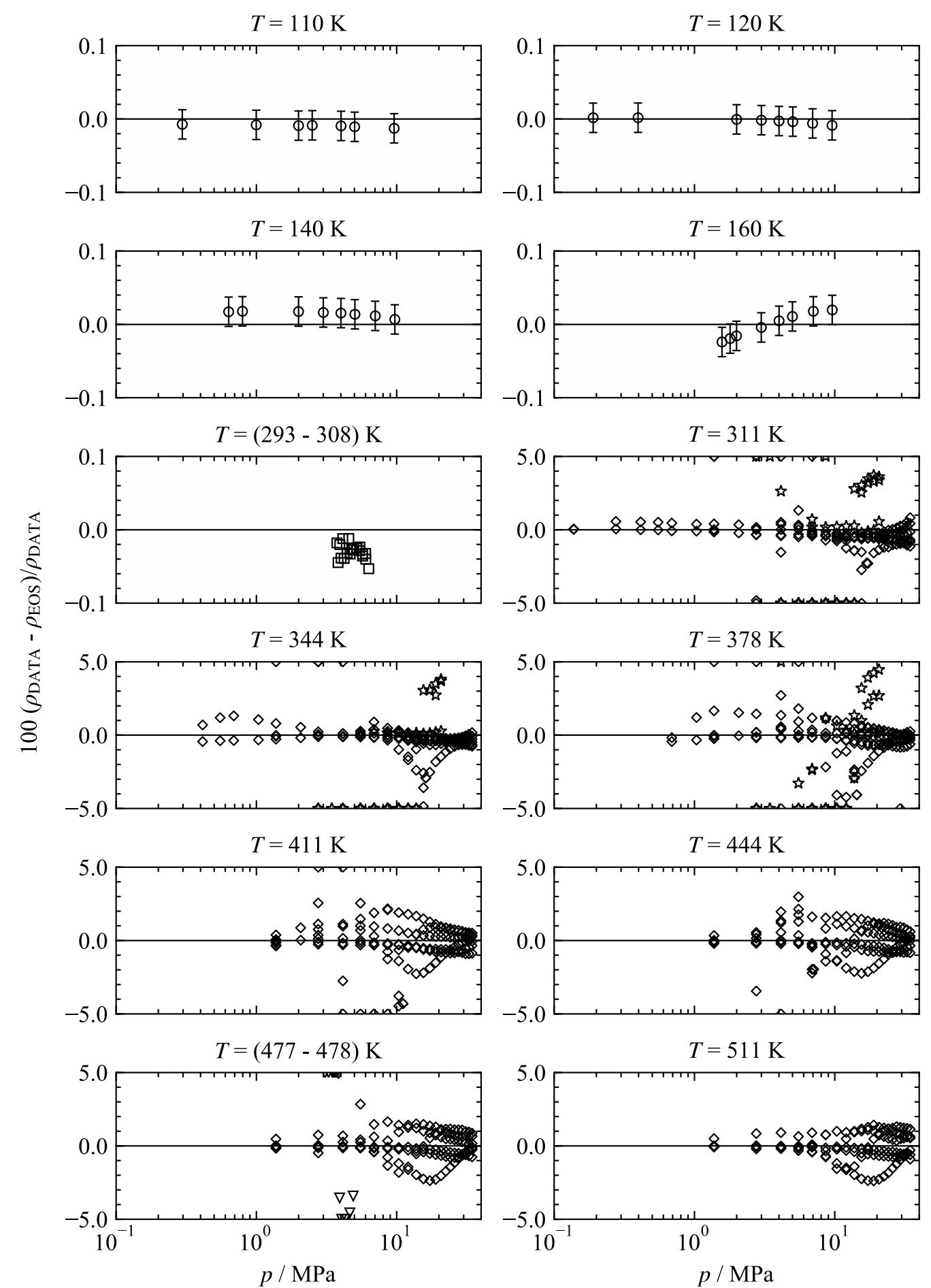

ㅁ Jaeschke \& Humphreys (1991) and Jaeschke et al. (1997)

$\diamond$ Sage et al. (1942)

$\Phi$ Lentner et al. (2018)

$\nabla$ Zhang et al. (2002)

* Sage et al. (1936)

Fig. 15. Percentage deviations of homogeneous density data from the EOS-LNG for the binary system $C_{1} C_{5}$. The scale of the $\mathrm{y}$-axis changes at $311 \mathrm{~K}$.

The most recent gas-phase density data for this binary were published by Jaeschke and Humphreys ${ }^{62}$ (and also Jaeschke et al. ${ }^{61}$ ) as part of a comprehensive measurement campaign of the GERG in the 1990s. Their reported uncertainty is less than $0.05 \%$, which agrees with the 
representation of the data by EOS-LNG. Only one data point deviates by $0.053 \%$, whereas all other state points differ by approximately $-0.03 \%$.

There is one dataset of Zhang et al. ${ }^{100}$ for a mixture with 99.07 mole percent pentane at $T=476.6 \mathrm{~K}$. These data exhibit large deviations with respect to the new equation of state as well as with respect to GERG-2008. ${ }^{11}$ Since the pure fluid experiments by Zhang et al. ${ }^{100}$ on $n$ pentane already deviate by up to $12 \%$, the measurement procedure may have been faulty, and their data were not considered further in this work.

In Table 8, comparisons of experimental vapor-liquid equilibrium data with values calculated from the EOS-LNG are listed. Separate comparisons are presented for states at the dew-point and bubble-point lines. Percentage deviations in terms of bubble-point pressure as a function of composition are depicted in Fig. 16.

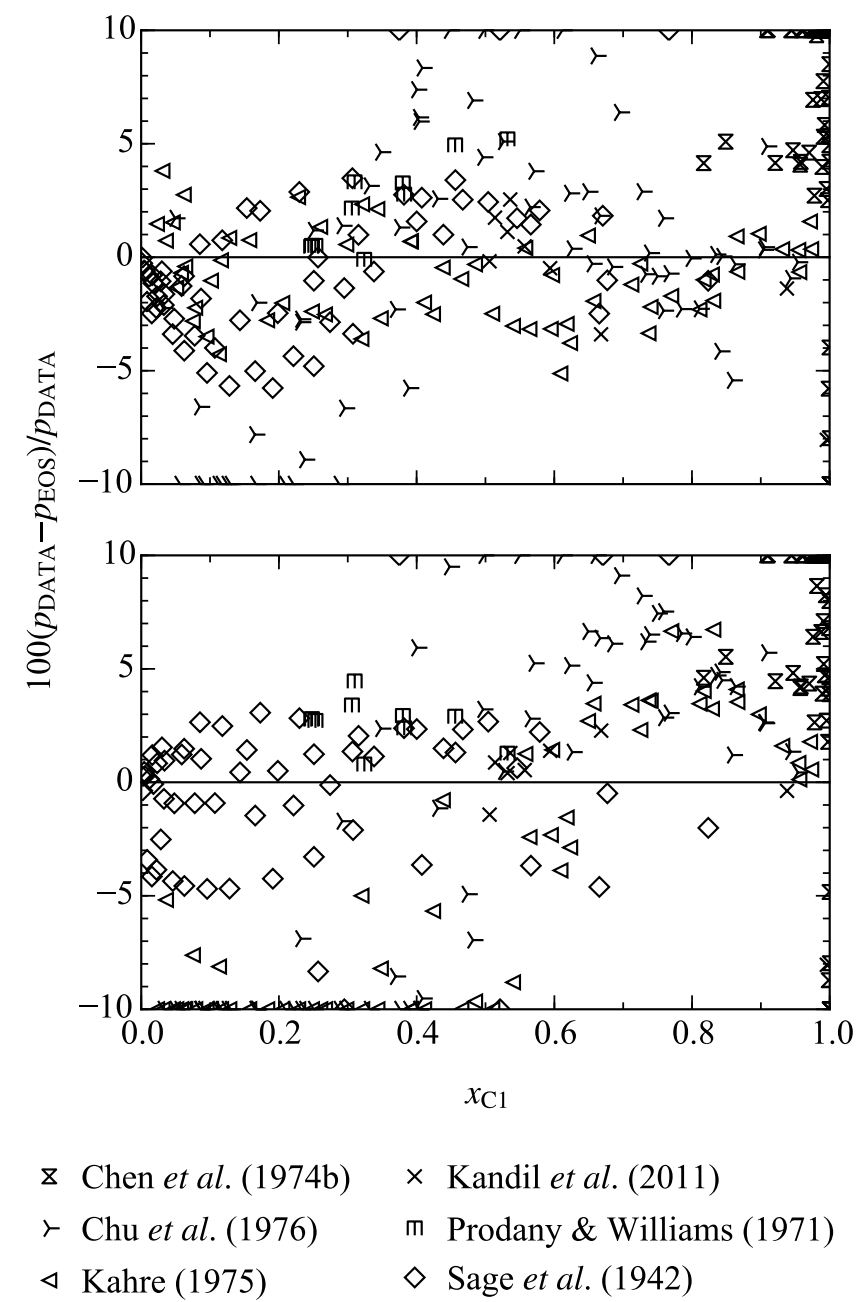

Fig. 16. Percentage deviations of vapor-liquid equilibrium pressure data for the binary system $\mathrm{C}_{1} \mathrm{C}_{5}$ from the EOSLNG (top) and the GERG-2008 ${ }^{11}$ (bottom) as a function of the composition $x_{\mathrm{C} 1}$. 
Table 8. Average absolute relative deviations of bubble-point pressure data $\left(\mathrm{AARD}_{p l i q} / \%\right)$ and average absolute deviations in terms of percentage mole fraction of methane in the saturated vapor phase $\left.\left(\mathrm{AAD}_{y \mathrm{C} 1} / \%\right)\right)$ for the binary system $\mathrm{C}_{1} \mathrm{C}_{5} . N$ denotes the total number of points in each publication except for pure-fluid measurements, whereas $N_{\mathrm{x}}$ and $N_{\mathrm{y}}$ indicate the number of bubble-point (index "x") and dew-point (index "y") pressure data. If $N_{\mathrm{x}}$ or $N_{\mathrm{y}}$ differ from $N$, state points were deleted from the numerical analysis for both models due to flash calculation errors or because they are outliers, which would distort the AARD or AAD.

\begin{tabular}{|c|c|c|c|c|c|c|c|c|c|}
\hline Author & $N$ & $N_{\mathrm{x}}$ & $N_{\mathrm{y}}$ & $\begin{array}{c}T_{\min }-T_{\max } \\
\quad / \mathrm{K}\end{array}$ & $\begin{array}{c}p_{\min }-p_{\max } \\
/ \mathrm{MPa}\end{array}$ & $\begin{array}{c}\mathrm{AARD}_{p \text { liq }} \\
(\text { EOS-LNG) }\end{array}$ & $\begin{array}{c}\mathrm{AAD}_{y \mathrm{C} 1} \\
(\mathrm{EOS}- \\
\mathrm{LNG}) \\
\end{array}$ & $\begin{array}{c}\text { AARD }_{p l i q} \\
\text { (GERG- } \\
\text { 2008) } \\
\end{array}$ & $\begin{array}{c}\mathrm{AAD}_{y \mathrm{C} 1} \\
(\mathrm{GERG}- \\
2008)\end{array}$ \\
\hline Chen et al. $(1974)^{101}$ & 118 & - & 112 & $173-274$ & $0.1-16$ & - & 3.9 & - & 10.0 \\
\hline Chu et al. $(1976)^{102}$ & 70 & 70 & $47^{a}$ & $176-274$ & $0.1-16$ & 5.8 & 0.06 & 18.0 & 0.10 \\
\hline Kahre $(1975)^{103}$ & 64 & 62 & 55 & $177-284$ & $0.3-16$ & 1.8 & 0.14 & 15.0 & 0.09 \\
\hline Kandil et al. $(2011)^{104}$ & 9 & 9 & 9 & $173-244$ & $2.4-8.0$ & 2.2 & 0.11 & 1.9 & 0.08 \\
\hline Prodany \& Williams $(1971)^{105}$ & 10 & 10 & 10 & 377.57 & $6.9-14$ & 2.3 & 0.12 & 2.6 & 0.10 \\
\hline Sage et al. $(1942)^{54}$ & 61 & 61 & 60 & $310-445$ & $0.1-17$ & 2.2 & 0.93 & 2.4 & 2.9 \\
\hline
\end{tabular}

${ }^{a}$ For 23 state points out of 70, no vapor-phase composition was measured.

Because the most comprehensive part of the homogeneous region was mainly fitted to the data of Sage et al. ${ }^{54}$ these data were also prioritized when fitting the vapor-liquid equilibrium. Moreover, these are the only data in the high-temperature region. The bubble-point pressure were fitted with an $\mathrm{AARD}_{p \text { liq }}$ of $2.2 \%$ and the dew-point line exhibits an $\mathrm{AAD}_{\mathrm{yC} 1}$ of $0.93 \%$ in terms of mole fraction of methane. In comparison to the GERG-2008, ${ }^{11}$ a significant improvement was achieved in the high-pressure region for both the dew-point and bubble-point lines.
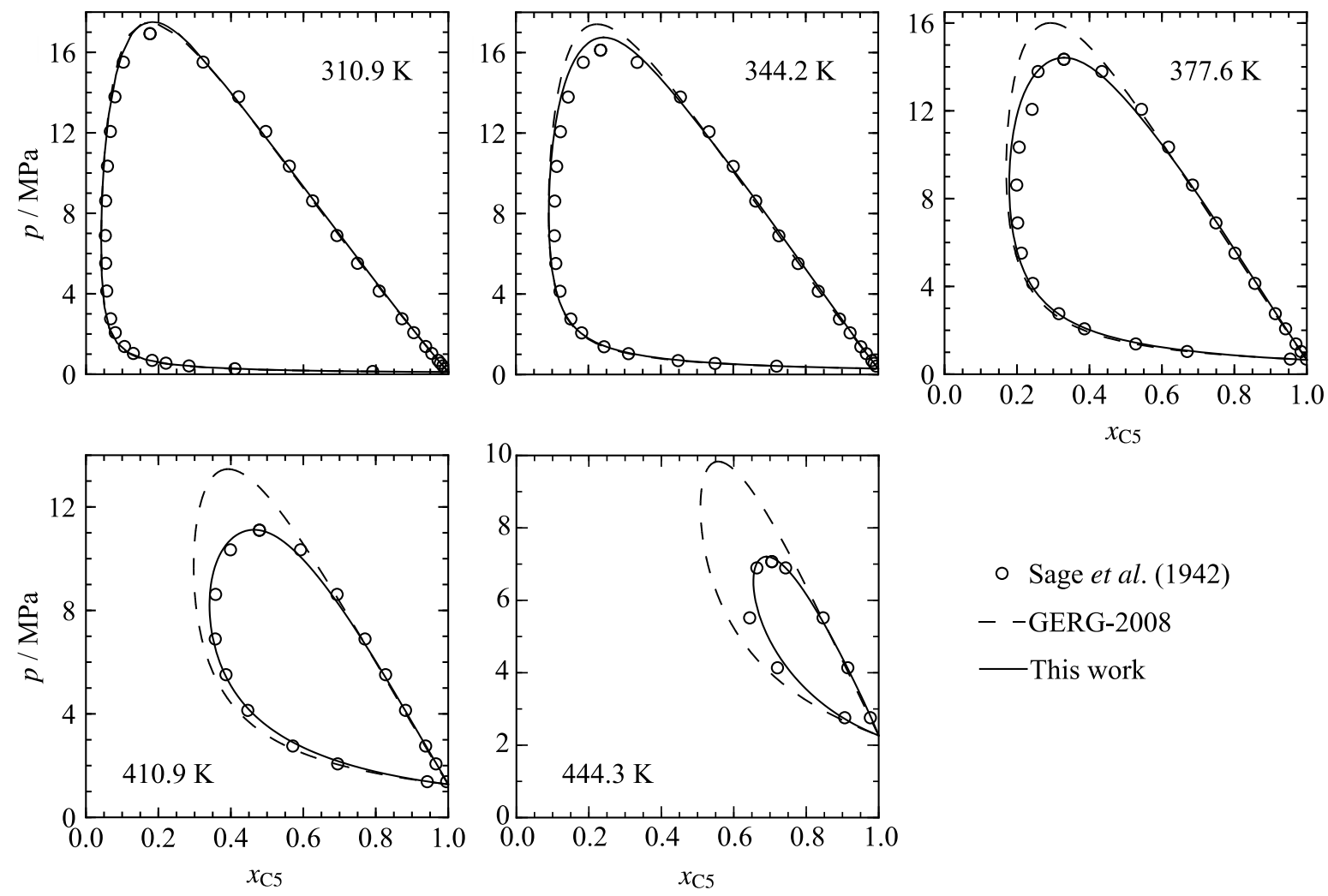

○ Sage et al. (1942)

- -GERG-2008

- This work

Fig. 17. $p, x$-diagrams representing the vapor-liquid equilibrium data of Sage et al. ${ }^{54}$ for the binary system $\mathrm{C}_{1} \mathrm{C}_{5}$. 
The $p, x$-diagrams shown in Fig. 17 exemplify this more accurate representation by EOSLNG. The GERG-2008 model ${ }^{11}$ overpredicts the VLE pressures. Deviations from the available experimental data of up to $3 \mathrm{MPa}$ are eliminated by the new equation of state. Similar to the preceding binary systems, the dew-point line passes through an infinite slope at higher pressures, which gives rise to large pressure deviations. However, Fig. 17 illustrates that the trend of the new equation of state matches the experimental data very well. In the lowtemperature region, significant improvement was achieved with respect to the representation of the bubble-point pressure data of $\mathrm{Kahre}^{103}\left(\mathrm{AARD}_{p \text { liq,EOS-LNG }}=1.8 \%\right.$ vs. $\mathrm{AARD}_{p \text { liq,GERG- }}$ $2008=15 \%)$ and $\mathrm{Chu}$ et al. ${ }^{102}\left(\mathrm{AARD}_{p \mathrm{liq}, \mathrm{EOS}-\mathrm{LNG}}=5.8 \%\right.$ vs. $\left.\mathrm{AARD}_{p \mathrm{liq}, \mathrm{GERG}-2008}=18 \%\right)$. The bubble-point pressure data of Prodany and Williams ${ }^{105}$ at $T=377.6 \mathrm{~K}$ are reproduced with an AARD of $2.3 \%$ by EOS-LNG, which is a slight improvement over GERG-2008. ${ }^{11}$ Both models represent the bubble-point pressure data of Kandil et al. ${ }^{104}$ well within their experimental uncertainty.

The experimental critical-point data measured by Sage et al. ${ }^{54}$ for this binary system present an opportunity to evaluate the predictions of the critical and cricondenbar lines by both models. In the upper panels of Fig. 18, $p, T$-phase diagrams calculated with EOS-LNG and GERG-2008 ${ }^{11}$ are presented. The methane $+n$-pentane system can be classified as a type I mixture with a pressure maximum on the critical line according to Deiters and Kraska. ${ }^{106}$ In their work, a comprehensive analysis of the critical line behavior is presented. However, no such analysis of the behavior of the cricondenbar line is available in the literature. Therefore, the new binary-specific function, which agrees well with the experimental critical points of Sage et al. ${ }^{54}$ is evaluated for that purpose. At first glance, the trend of the cricondenbar line appears to be suspicious due to the inflection point at approximately $8 \mathrm{MPa}$. Starting from the critical point of the more volatile component (methane), it follows the trend of the critical line with lower pressures until both lines meet at the same maximum. After passing this maximum and while approaching the less volatile component ( $n$-pentane), the cricondenbar line exhibits a steep negative slope resulting in a distinct change in curvature, which is more pronounced than for GERG-2008. ${ }^{11}$ Since there are no measurements available in the literature, it is not possible here to conclude if this behavior is correct. On the bottom of Fig. 18, three $p, x$ diagrams, which also contain the VLE data of Sage et al., ${ }^{54}$ are shown. The corresponding critical point of each isotherm is depicted as a solid, inverted triangle in the $p, T$-diagrams in the same color. The experimental critical points of Sage et al.$^{54}$ are reproduced better by EOS-LNG than by GERG-2008. ${ }^{11}$ For each of the critical points, the overall composition of the binary mixture was determined and the corresponding phase envelope is plotted as a dashed-dotted line. The calculated cricondenbar of each phase envelope is marked as a solid diamond and the calculated cricondentherm is illustrated with solid stars. For type I mixtures, the critical pressure is generally located between the pressure of the cricondenbar and the pressure of the cricondentherm. This is correctly modeled with both the EOS-LNG and the GERG-2008, ${ }^{11}$ 
except for the critical point at $444.3 \mathrm{~K}$. The phase envelope of the GERG-2008 ${ }^{11}$ would have to be shifted to lower pressures $\left(p_{\mathrm{c}}\left(T_{\mathrm{c}}=444.3 \mathrm{~K}\right) \approx 7.5 \mathrm{MPa}\right.$ instead of $\left.\approx 10 \mathrm{MPa}\right)$ to match this criterion as it was done for the EOS-LNG ( $c f$. Fig. 18, top left and bottom right panels). Since both models show the same behavior and the new model matches the VLE data of Sage et al., ${ }^{54}$ it appears that at least the qualitative behavior is correct for the cricondenbar line. Furthermore, additional investigations on methane + (propane to hexane) yielded the same results. However, additional measurements would be needed to provide a more reliable statement on the quantitative performance of the model.
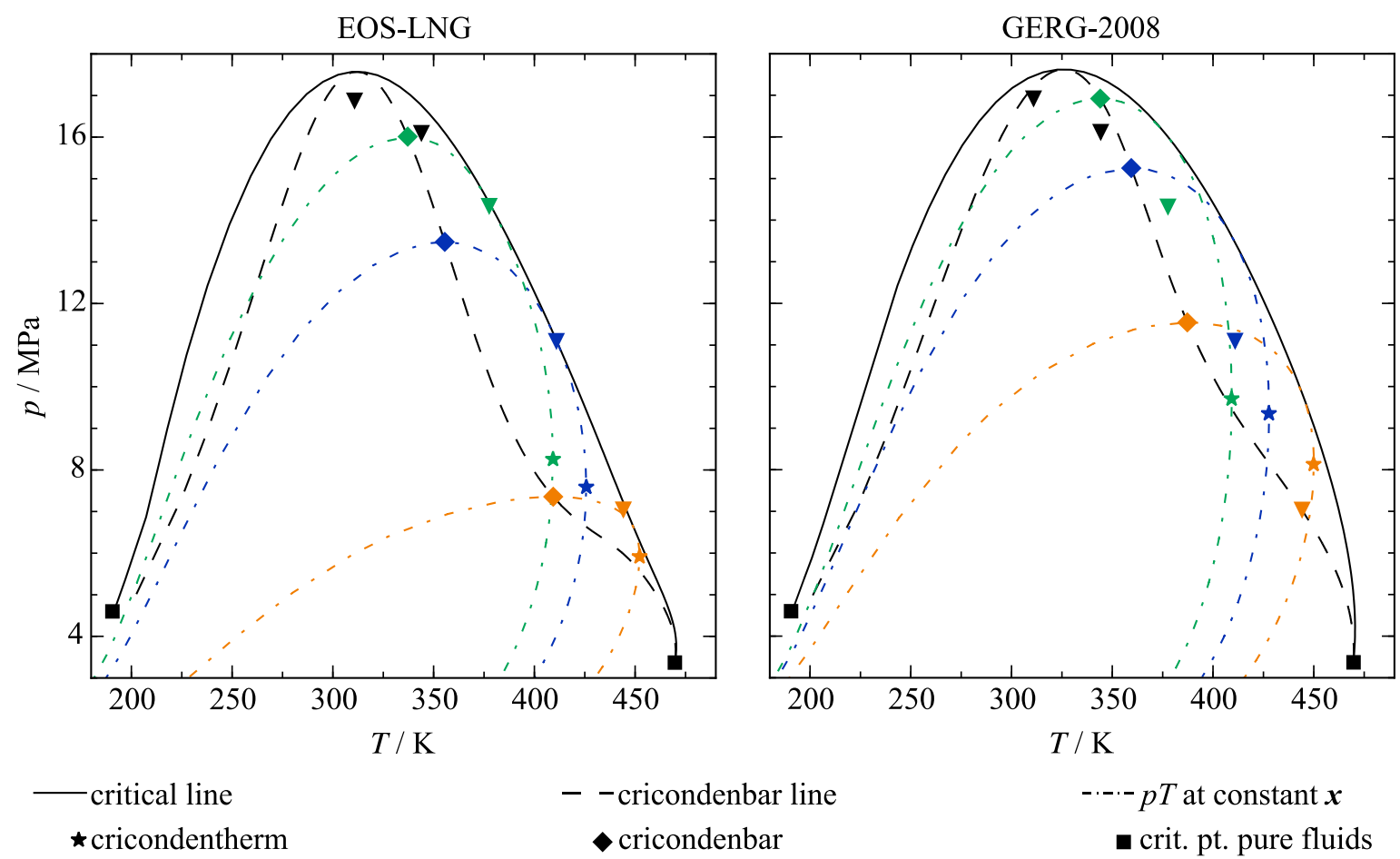

$$
\begin{aligned}
& - \text { - cricondenbar line } \\
& \text { cricondenbar }
\end{aligned}
$$

$-\cdots p T$ at constant $\boldsymbol{x}$

- crit. pt. pure fluids
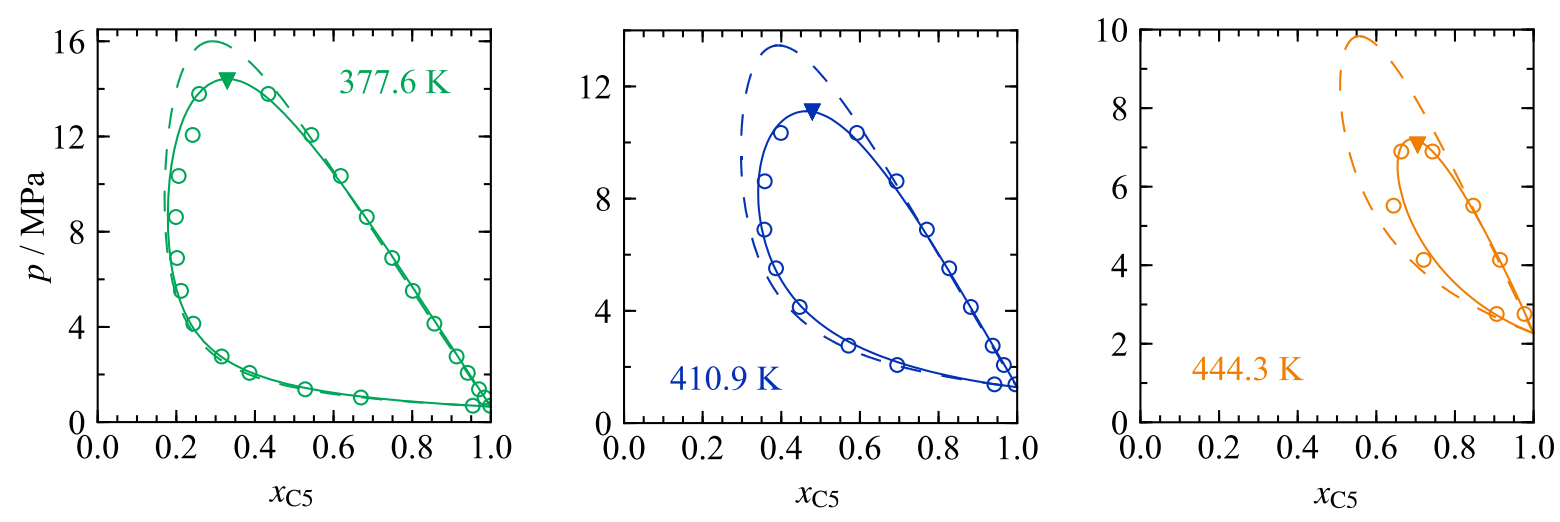

- Sage et al. (1942)

$\boldsymbol{\nabla}$ Sage et al. (1942), crit. pt.

-EOS-LNG

- -GERG-2008

Fig. 18. $p, T$-diagrams for the binary system $\mathrm{C}_{1} \mathrm{C}_{5}$ including the critical and cricondenbar lines calculated with EOS-LNG and GERG-2008 ${ }^{11}$ (top). The critical points of Sage et al. ${ }^{54}$ which are shown in the bottom panel, are included as solid, inverted triangles. The phase envelopes for the compositions of the critical points are shown as dashed-dotted lines in the same colors as in the bottom panel (green, blue, and orange), along with the cricondenbars and the cricondentherms. 


\subsection{Methane + isopentane $\left(\mathrm{C}_{1} \mathrm{C}_{5 \mathrm{i}}\right)$}

For the methane-isopentane binary system, only the two datasets of Amick et al. ${ }^{107}$ (homogeneous density and VLE) and Prodany and Williams ${ }^{105}$ (VLE) are available as shown in Tables 9 and 10.

Table 9. Average absolute relative deviations (AARD / \%) calculated with the new equation of state for the binary system $\mathrm{C}_{1} \mathrm{C}_{5 \mathrm{i}}$. For a better overview, the dataset is separated into different composition ranges and the overall AARD is given.

\begin{tabular}{|c|c|c|c|c|c|c|}
\hline Author & $N$ & $\begin{array}{c}T_{\min }-T_{\max } \\
/ \mathrm{K}\end{array}$ & $\begin{array}{c}p_{\min }-p_{\max } \\
/ \mathrm{MPa}\end{array}$ & $x_{\mathrm{C} 1, \min }-x_{\mathrm{C} 1, \max }$ & $\begin{array}{c}\text { AARD } \\
\text { (EOS-LNG) }\end{array}$ & $\begin{array}{c}\text { AARD } \\
\text { (GERG-2008) }\end{array}$ \\
\hline \multirow[t]{5}{*}{ Amick et al. $(1952)^{107}$} & 20 & $460-478$ & $3.4-5.52$ & 0.15 & 2.8 & 5.9 \\
\hline & 37 & $449-478$ & $2.0-9.05$ & 0.3339 & 2.2 & 2.4 \\
\hline & 78 & $377-478$ & $1.3-10.4$ & 0.4976 & 1.0 & 1.0 \\
\hline & 92 & $360-478$ & $1.3-10.4$ & 0.6175 & 0.76 & 0.36 \\
\hline & 102 & $344-478$ & $1.3-8.96$ & 0.7949 & 0.46 & 0.21 \\
\hline Overall & 329 & $344-478$ & $1.3-10.4$ & $0.15-0.795$ & 1.0 & 1.0 \\
\hline
\end{tabular}

For the determination of the homogeneous density data, Amick et al. ${ }^{107}$ used an apparatus similar to the one modified by Kay. ${ }^{108}$ A known mass of a mixture was loaded into a glass bulb sealed at one end. At the other end, mercury was used to change the volume and pressure of the sample, which was kept at constant temperature. The samples that were used (99.7 mole percent pure methane and 99.7 mole percent pure isopentane) were further refined, but no information is available on the final sample purity. The measured densities were then graphically smoothed. On average, the smoothed data can be reproduced within $1.5 \%$ by EOS-LNG as illustrated in Fig. 19. The deviations are similar to those calculated for GERG-2008. ${ }^{11}$

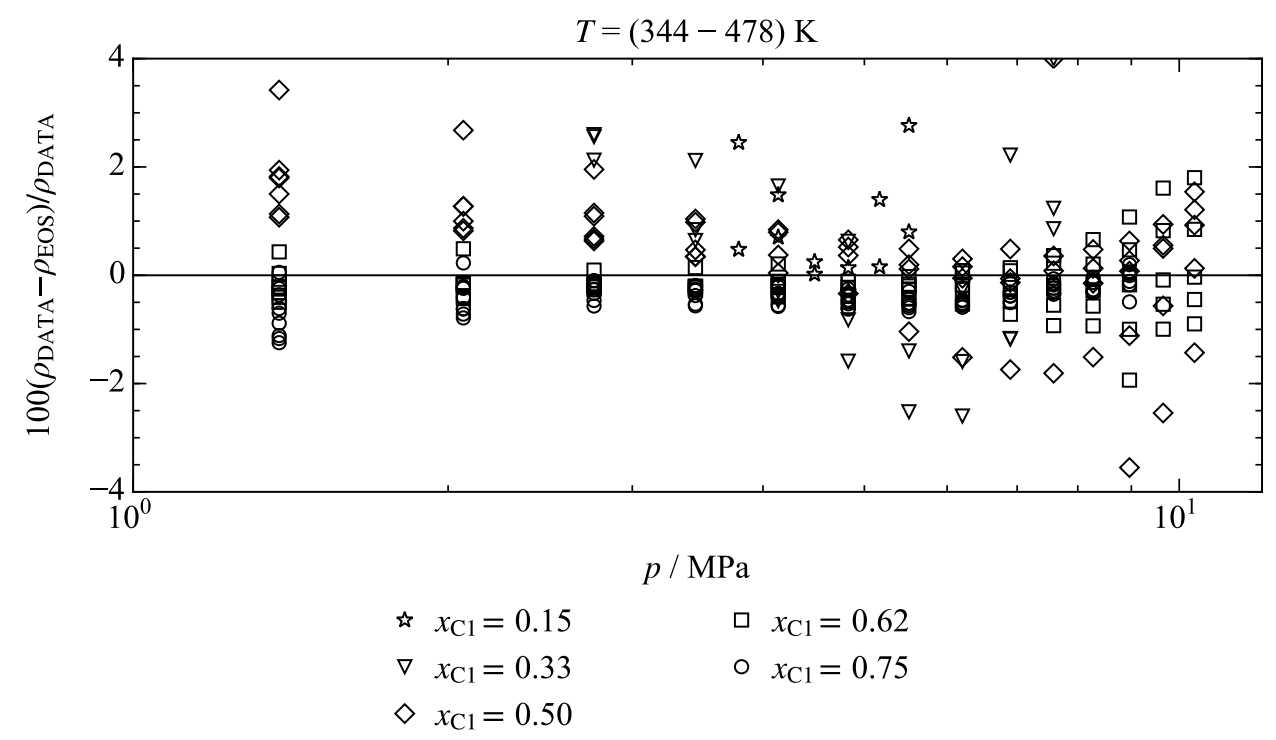

Fig. 19. Percentage deviations of homogeneous density data of Amick et al. ${ }^{107}$ from EOS-LNG for the binary system $\mathrm{C}_{1} \mathrm{C}_{5 \mathrm{i}}$. 
Table 10. Average absolute relative deviations of bubble-point pressure data $\left(\mathrm{AARD}_{p l i q} / \%\right)$ and average absolute deviations in terms of percentage mole fraction of methane in the saturated vapor phase $\left.\left(\mathrm{AAD}_{y \mathrm{C} 1} / \%\right)\right)$ for the binary system $\mathrm{C}_{1} \mathrm{C}_{5 \mathrm{i}}$. $N$ denotes the total number of points in each publication except for pure-fluid measurements, whereas $N_{\mathrm{x}}$ and $N_{\mathrm{y}}$ indicate the number of bubble-point (index "x") and dew-point (index "y") pressure data. If $N_{\mathrm{x}}$ or $N_{\mathrm{y}}$ differ from $N$, state points were deleted from the numerical analysis for both models due to flash calculation errors or because they are outliers, which would distort the AARD or AAD.

\begin{tabular}{lccccccccc}
\hline \hline \multirow{2}{*}{ Author } & \multirow{2}{*}{$N_{\mathrm{x}}$} & $N_{\mathrm{y}}$ & $\begin{array}{c}T_{\min }- \\
T_{\max } / \mathrm{K}\end{array}$ & $\begin{array}{c}p_{\min }-p_{\max } \\
/ \mathrm{MPa}\end{array}$ & $\begin{array}{c}\mathrm{AARD}_{p l i q} \\
\text { (EOS-LNG) }\end{array}$ & $\begin{array}{c}\mathrm{AAD}_{y \mathrm{C} 1} \\
\text { (EOS-LNG) }\end{array}$ & $\begin{array}{c}\mathrm{AARD}_{p l i q} \\
\text { (GERG-2008) }\end{array}$ & $\begin{array}{c}\mathrm{AAD}_{y \mathrm{C} 1} \\
\text { (GERG-2008) }\end{array}$ \\
\hline Amick et al. $(1952)^{107}$ & 29 & 29 & 29 & $344-450$ & $2.7-6.9$ & 14.5 & 5.8 & 11.0 & 3.2 \\
Prodany \& Williams (1971) & 2105 & 20 & 21 & $344-411$ & $3.4-15.2$ & 1.8 & 2.6 & 6.5 & 3.1 \\
\hline
\end{tabular}
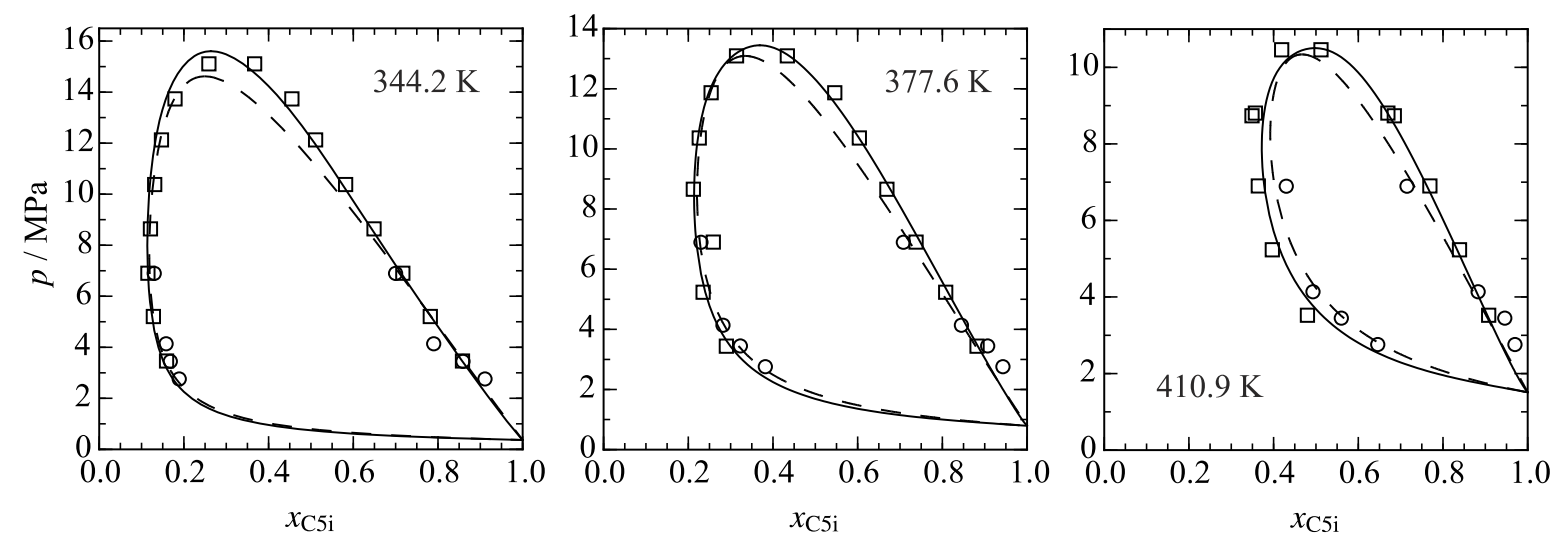

○ Amick et al. (1952) - EOS-LNG

Prodany \& Williams (1971) - -GERG-2008

Fig. 20. $p, x$-diagrams representing the vapor-liquid equilibrium data for the binary system $\mathrm{C}_{1} \mathrm{C}_{5 \mathrm{i}}$.

Improvements were made in the representation of the vapor-liquid equilibrium measurements. The bubble-point pressure data of Prodany and Williams, ${ }^{105}$ whose measurements for the system $\mathrm{C}_{1} \mathrm{C}_{5}$ are in good agreement with the data of Sage et al. ${ }^{54}$ are represented with an $\mathrm{AARD}=1.8 \%\left(\mathrm{AARD}_{\mathrm{x}, \mathrm{GERG}-2008}=6.5 \%\right)$. The three isotherms investigated by Prodany and Williams ${ }^{105}$ are depicted in Fig. 20. For all temperatures, the bubble-point lines calculated with EOS-LNG match the data better than those calculated with GERG-2008. ${ }^{11}$ The dew-point lines were already accurately represented by GERG-2008 ${ }^{11}$ except those at the highest isotherm. At this temperature, the deviations with respect to the data of Prodany and Williams ${ }^{105}$ were also reduced by EOS-LNG as compared with those from GERG-2008. ${ }^{11}$ These plots show that the vapor-liquid equilibrium data of Amick et al. ${ }^{107}$ deviate significantly from the data of Prodany and Williams ${ }^{105}$ and, thus, they were not utilized in the development of the new equation of state.

Since the only two available datasets for this binary are rather old and inconsistent, it would be valuable to further investigate this system experimentally. Accurate density data are needed over the entire fluid surface. In particular, the possible existence of liquid-liquid equilibrium for $\mathrm{C}_{1} \mathrm{C}_{5 \mathrm{i}}$ should be investigated given that it does exist for methane $+n$-heptane $\left(\mathrm{C}_{1} \mathrm{C}_{7}\right),{ }^{109}$ and it was also suspected during the experiments on $\mathrm{C}_{1} \mathrm{C}_{5}$ by Lentner et al. ${ }^{20,72}$ and Kandil et al. ${ }^{104}$ 
Figure 21 shows the locus of the liquid-liquid equilibrium on a $T, x$-plane as can be traced with modern phase-equilibrium algorithms such as proposed by Bell and Deiters. ${ }^{110}$ This binary system can be categorized as a type II mixture according to Deiters and Kraska, ${ }^{106}$ therefore, the LLE temperature at a given overall composition is nearly independent of the pressure. The GERG-2008 ${ }^{11}$ equation of state illustrates that even for typical methane-rich LNG mixtures (more than 90 mole percent methane), liquid-liquid equilibrium might occur in the lowtemperature region. New measurements must take this into account because such a phase equilibrium can perturb the stability of the signal observed with densimeters, as might have happened during the LNG measurements for the binary systems $\mathrm{C}_{1} \mathrm{C}_{4 \mathrm{i}}$ and $\mathrm{C}_{1} \mathrm{C}_{5}{ }^{20,72}$ The EOSLNG also predicts the occurrence of liquid-liquid phase equilibrium, but the shape and equilibrium temperature are completely different from those predicted with GERG-2008. ${ }^{11}$ Simpler equations such as the Peng-Robinson ${ }^{1,2} \quad\left(k_{i j}=0\right)$ or Soave-Redlich-Kwong ${ }^{3,4}$ $\left(k_{i j}=0.007\right)^{111}$ equations do not indicate liquid-liquid phase equilibrium. Since there is no conclusive experimental information available, it is not possible to state here which model is correct.
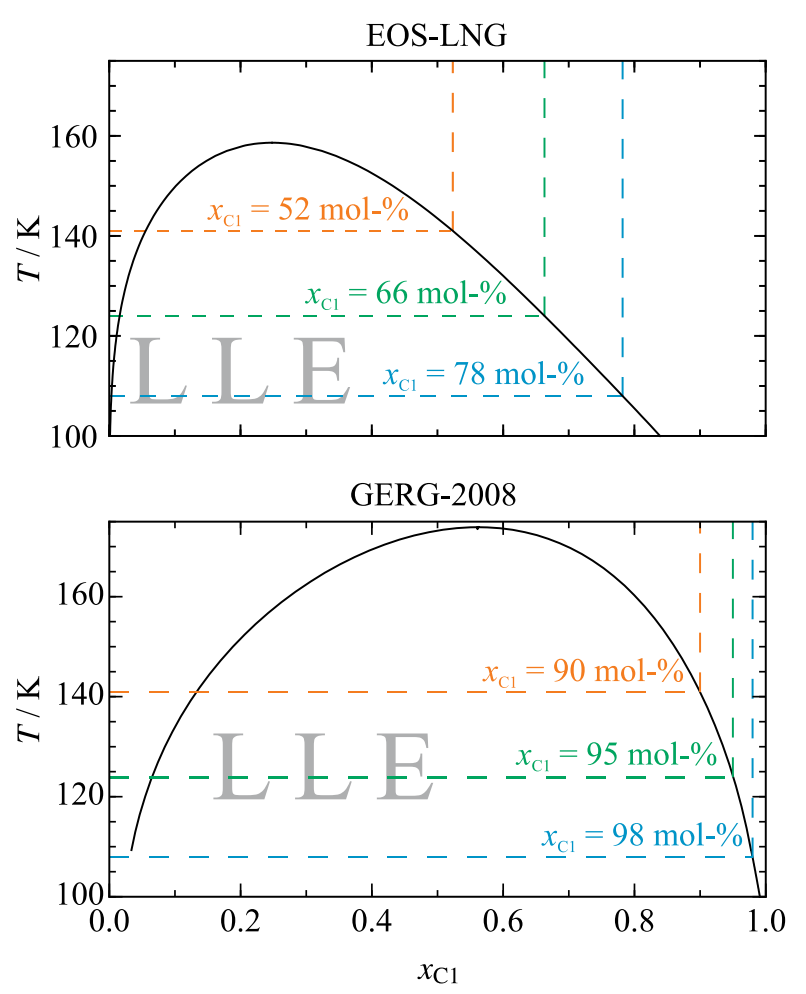

Fig. 21. $T, x$-diagram at $p=0.1 \mathrm{MPa}$ for the binary system $\mathrm{C}_{1} \mathrm{C}_{5 \mathrm{i}}$ with the liquid-liquid equilibrium phase boundary calculated with EOS-LNG (top) and GERG-2008 ${ }^{11}$ (bottom). The indicated equilibrium temperatures are the same in both plots and the compositions shown are those for the lower-density (methane rich) liquid phase at the temperatures $141 \mathrm{~K}$ (orange), $124 \mathrm{~K}$ (green), and $108 \mathrm{~K}$ (blue). 


\section{Representation of Multicomponent Mixtures}

After fitting the parameters of EOS-LNG to represent the available experimental data for the four binary mixtures described previously, while ensuring no degradation in performance relative to GERG-2008, ${ }^{11}$ the new model's performance was tested with the use of data for multicomponent mixtures for LNG-like systems available in the literature. The functions for the binary mixtures other than the four binaries discussed in Sec. 3 are taken from the GERG2008 model. ${ }^{11}$ In Fig. 22, deviations of density data for three multicomponent mixtures ${ }^{19,49}$ from values calculated with GERG-2008 ${ }^{11}$ and EOS-LNG are presented. Each of these synthetic mixtures, which are representative of three commercial LNGs from three different regions, mainly consists of methane and ethane with small quantities of propane, $n$-butane, and nitrogen, cf. Table 11.

Table 11. Molar compositions of the three multicomponent mixtures labeled as Libya, Norway, and Oman. ${ }^{19,49}$

\begin{tabular}{lccc}
\hline \hline & Libya & Norway & Oman \\
\hline $\boldsymbol{x}_{\mathbf{C} 1} /$ mol-\% & $\mathbf{8 1 . 5 6 2 6}$ & $\mathbf{9 1 . 7 9 8}$ & $\mathbf{8 7 . 8 8 5 4}$ \\
$x_{\mathrm{C} 2} /$ mol-\% & 13.3744 & 5.698 & 7.2738 \\
$x_{\mathrm{C} 3} /$ mol-\% & 3.6793 & 1.303 & 2.9257 \\
$\boldsymbol{x}_{\mathbf{C} 4} /$ mol-\% & $\mathbf{0 . 6 8 8 4}$ & $\mathbf{0 . 3 9 6}$ & $\mathbf{1 . 5 6 4 7}$ \\
$x_{\mathrm{N} 2} /$ mol- $\%$ & 0.6953 & 0.805 & 0.3504 \\
\hline
\end{tabular}

In comparison to the GERG-2008 model, ${ }^{11}$ only the new departure function developed for $\mathrm{C}_{1} \mathrm{C}_{4}$ has changed for the representation of these three multicomponent mixtures. This emphasizes the importance of this binary system for the representation of multicomponent LNG mixtures. For Libya and Norway, the amount of $n$-butane in the system is rather low. Therefore, deviations from GERG-2008 ${ }^{11}$ are less than $0.06 \%$, which is almost within the range of the accuracy targeted in this work. The new departure function for $\mathrm{C}_{1} \mathrm{C}_{4}$ reduces these deviations to approximately $0.03 \%$ in the case of LNG Libya and even to $0.02 \%$ for LNG Norway. In contrast, the $n$-butane content of the LNG Oman mixture is more than twice that of the other two mixtures. The deviations with respect to the GERG- $2008^{11}$ are $0.13 \%$, which is much larger than the experimental uncertainty of the data. The new binary mixture model for $\mathrm{C}_{1} \mathrm{C}_{4}$ used in EOS-LNG reduces these deviations to less than $0.04 \%$, achieving the target accuracy of $0.05 \%$ with respect to the representation of the multicomponent data. These results show that the binary system $\mathrm{C}_{1} \mathrm{C}_{4}$ has a significant influence on the representation of multicomponent density data. Since there were no experimental data available in the homogeneous LNG region for the development of the new binary-specific function, additional measurements of density in the LNG region for this system would help to improve the representation of multicomponent mixtures in future work. 


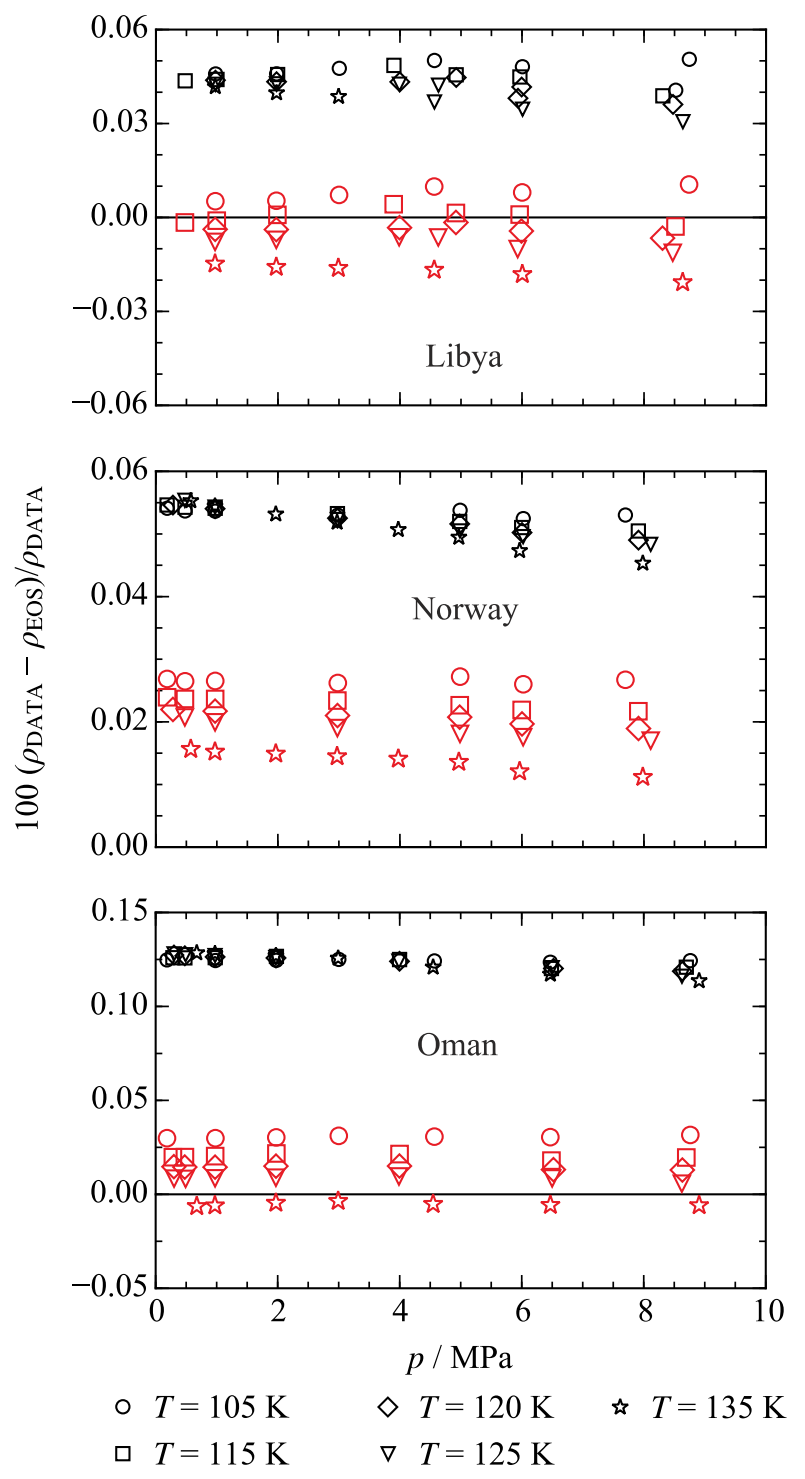

Fig. 22. Percentage deviations of the density data of three multicomponent LNG mixtures ${ }^{19,49}$ from the EOS-LNG (red symbols) and the GERG-2008 ${ }^{11}$ (black symbols).

Table 12. Molar compositions of the three multicomponent mixtures LNG 2, LNG 5, and LNG 7. ${ }^{19}$

\begin{tabular}{lccc}
\hline \hline & LNG 2 & LNG 5 & LNG 7 \\
\hline$x_{\mathrm{C} 1} /$ mol-\% & $\mathbf{8 4 . 6 3 6 2}$ & $\mathbf{8 7 . 9 7 1 6}$ & $\mathbf{9 7 . 8 8 9 8}$ \\
$x_{\mathrm{C} 2} /$ mol-\% & 12.8000 & 7.24000 & 0.99900 \\
$x_{\mathrm{C} 3} /$ mol-\% & 1.49900 & 2.90000 & 0.49710 \\
$x_{\mathrm{C} 4} /$ mol-\% & $\mathbf{0 . 2 0 9 3 0}$ & $\mathbf{0 . 6 9 1 7 0}$ & $\mathbf{0 . 2 0 9 2 0}$ \\
$\boldsymbol{x}_{\mathrm{C} 4 \mathrm{i}} /$ mol-\% & $\mathbf{0 . 2 1 9 9 0}$ & $\mathbf{0 . 6 4 2 8 0}$ & $\mathbf{0 . 1 7 7 1 0}$ \\
$\boldsymbol{x}_{\mathrm{C} 5} /$ mol-\% & $\mathbf{0 . 0 3 0 1 0}$ & $\mathbf{0 . 1 0 0 4 0}$ & $\mathbf{0 . 0 1 6 1 7}$ \\
$\boldsymbol{x}_{\mathrm{C} 5 \mathrm{1}} /$ mol-\% & $\mathbf{0 . 0 2 0 1 0}$ & $\mathbf{0 . 1 1 0 0 0}$ & $\mathbf{0 . 0 1 8 3 3}$ \\
$x_{\mathrm{N} 2} /$ mol-\% & 0.58540 & 0.34350 & 0.19330 \\
\hline
\end{tabular}



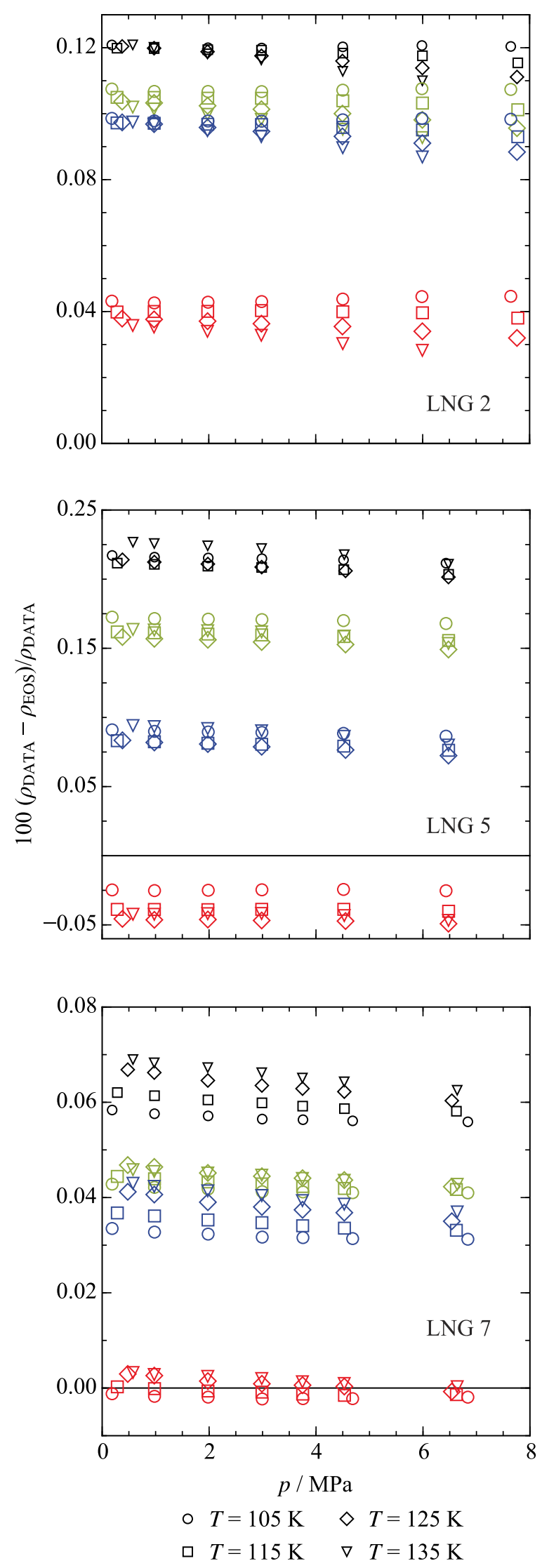

Fig. 23. Percentage deviations of the density data of three multicomponent LNG mixtures ${ }^{19}$ from the EOS-LNG (red symbols) and the GERG-2008 ${ }^{11}$ (black symbols). The green symbols show deviations calculated with the GERG-2008 ${ }^{11}$ and the adjusted binary function only for $\mathrm{C}_{1} \mathrm{C}_{4}$, whereas the blue symbols depict the deviations calculated with the GERG-2008 ${ }^{11}$ and the adjusted binary function only for $\mathrm{C}_{1} \mathrm{C}_{5 \mathrm{i}}$. 
Lentner et al. ${ }^{19}$ also published measurements for multicomponent LNG mixtures including $n$-butane, isobutane, $n$-pentane, and isopentane as shown in Table 12. Figure 23 shows that deviations of these density data from predictions calculated with GERG-2008 ${ }^{11}$ (black symbols) are within $0.22 \%$, whereas the EOS-LNG (red symbols) is able to represent all of the mixture data within $0.05 \%$. The green symbols in Fig. 23 show only the contribution of the new departure function for $\mathrm{C}_{1} \mathrm{C}_{4}$ to the improved performance of EOS-LNG. For these three multicomponent LNGs, the $\mathrm{C}_{1} \mathrm{C}_{4}$ departure function is responsible for $10 \%$ to $35 \%$ of the change in the deviations between the GERG-2008 ${ }^{11}$ and EOS-LNG models. Figure 23 also shows the contribution in the improvement (blue symbols) due to the new version of the $\mathrm{C}_{1} \mathrm{C}_{5 \mathrm{i}}$ departure function, which accounts for $20 \%$ to $65 \%$ of the change for these multicomponent mixtures. The biggest impact of the $\mathrm{C}_{1} \mathrm{C}_{5 \mathrm{i}}$ departure function occurs for LNG 5, which has more than five times the isopentane content of the other two LNG mixtures. Tests on the other two binary functions showed that their influence is not as significant as those of $\mathrm{C}_{1} \mathrm{C}_{4}$ and $\mathrm{C}_{1} \mathrm{C}_{5 \mathrm{i}}$.

Clearly, the improvement of the two departure functions for $\mathrm{C}_{1} \mathrm{C}_{4}$ and $\mathrm{C}_{1} \mathrm{C}_{5 \mathrm{i}}$ has a significant impact on the ability of EOS-LNG to represent the data of Lentner et al. ${ }^{19}$ within $0.05 \%$. However, as shown in Sec. 3.5, the departure function for $\mathrm{C}_{1} \mathrm{C}_{5 \mathrm{i}}$ and the binary parameters in the new EOS-LNG are tuned to a very limited database with no binary data available at conditions directly relevant to LNG. Therefore, new measurements of homogeneous densities and vapor-liquid (maybe also liquid-liquid) equilibrium data are needed to further improve the $\mathrm{C}_{1} \mathrm{C}_{5 \mathrm{i}}$ binary function.

During the analysis of the multicomponent data of Lentner et al. ${ }^{19}$ and Richter et al..${ }^{49}$ an interesting observation was made. In Fig. 24, deviations of the experimental data ${ }^{19,49}$ are illustrated for the original GERG-2008 equation of state ${ }^{11}$ (black symbols) and for a modified version of the GERG-2008 ${ }^{11}$ that used the Lorentz-Berthelot combining rule (no departure function) for the system methane + nitrogen $\left(\mathrm{C}_{1} \mathrm{~N}_{2}\right)$ instead of the original adjusted interaction parameters combined with the departure function. Although the binary-specific function for $\mathrm{C}_{1} \mathrm{~N}_{2}$ of the GERG-2008 ${ }^{11}$ is one of the most accurate mixture models in the literature, density deviations of the investigated multicomponent LNG mixtures (see Tables 12 and 13) are lower when applying the Lorentz-Berthelot combining rule. In the case of the LNG Norway and LNG Libya mixtures (the mixtures with higher nitrogen contents), the deviations decreased from $0.05 \%$ to $0.02 \%$. This effect is related to the parameters of the reducing functions in Eqs. (8) and (9). Because the amount of nitrogen is rather low in the multicomponent systems investigated here, the correct modeling of the transition from the binary mixture to the pure fluids $\left(x_{\mathrm{C} 1} \rightarrow 0\right.$ or 1 ), in particular at the methane pure-fluid limit, is very important. The influence of the departure function vanishes in this region. Therefore, the departure function is not needed here and the mixture behavior seems to be mainly related to the reducing parameters. During the development of binary mixture functions, it is common practice to simultaneously adjust the reducing parameters and the departure function. This can result in models where the 
interaction parameters can be set to anything if the departure function is developed to account for any change resulting from the interaction parameters. This can result in models where the interaction parameters are not optimal if the departure function is developed to account for deficiencies of the interaction parameters. Therefore, it is most likely that for $\mathrm{C}_{1} \mathrm{~N}_{2}$ the reducing parameters were fitted so that they joined in a way with the departure function to meet the uncertainties in the data over the entire composition range but do not necessarily behave correctly in the pure-fluid limits in multicomponent systems. When fitting departure functions, it might be favorable to first adjust the reducing parameters to experimental data where $x_{\mathrm{C} 1} \rightarrow 0$ or 1 , and then adjust the departure function to experimental data with concentrations between those limits. Conversely, measurements at $\mathrm{LNG}$ conditions for the binary system $\mathrm{C}_{1} \mathrm{~N}_{2}$ with very high methane contents $\left(x_{\mathrm{C} 1}=0.97 \text { and } 0.99\right)^{72}$ are accurately reproduced within $0.02 \%$ ( $0.25 \%$ with the Lorentz Berthelot combining rule), which leads to the assumption that the choice of the reducing parameters is less important for the binary systems but crucial for the interaction of binary functions in a multicomponent system.

Several tests not only on $\mathrm{C}_{1} \mathrm{~N}_{2}$ but also on the four binary systems adjusted for the EOSLNG showed that $\beta_{v}$ and $\gamma_{v}$ are the most sensitive parameters when modeling densities. However, this has to be investigated in more detail in future work.

Since there is no conclusive answer to the correct choice of reducing parameters, the binary-specific function for $\mathrm{C}_{1} \mathrm{~N}_{2}$ of the GERG-2008 model, ${ }^{11}$ which is the most accurate model available for that system, should still be applied for the calculation of natural gas properties. 


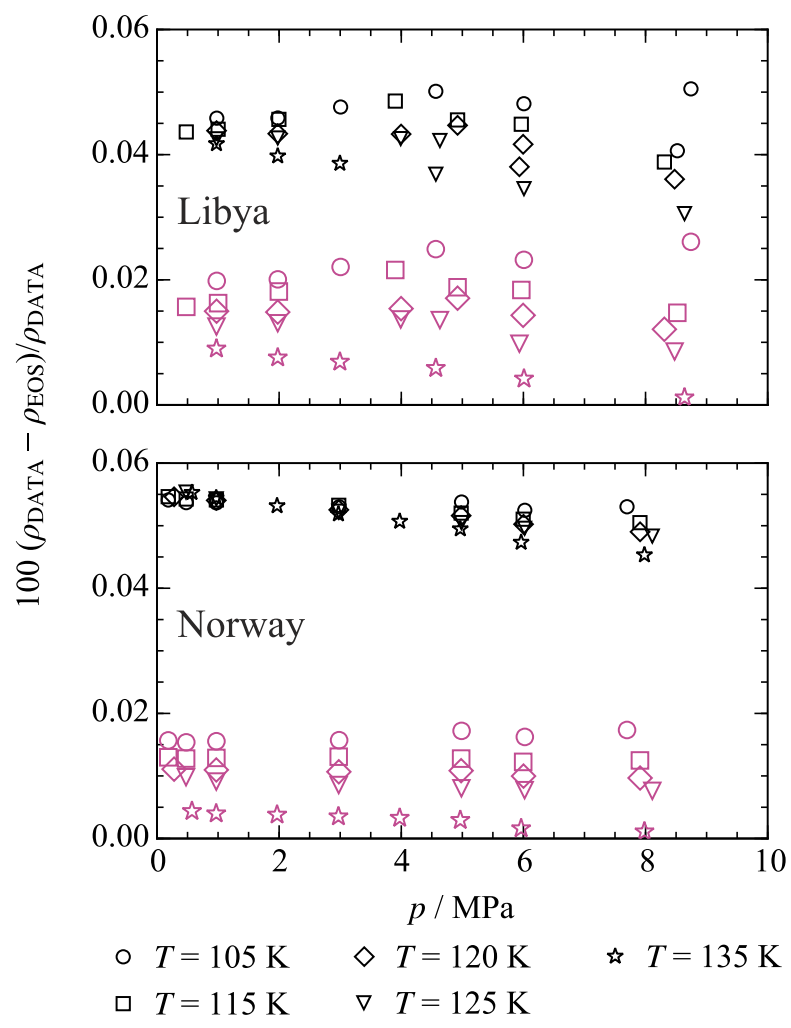

Fig. 24. Percentage deviations of the experimental density data of two multicomponent LNG mixtures ${ }^{19,49}$ from the GERG-2008 ${ }^{11}$ (black symbols) and the GERG-2008 mode ${ }^{11}$ with the Lorentz-Berthelot combining rule for the binary system methane + nitrogen (magenta symbols).

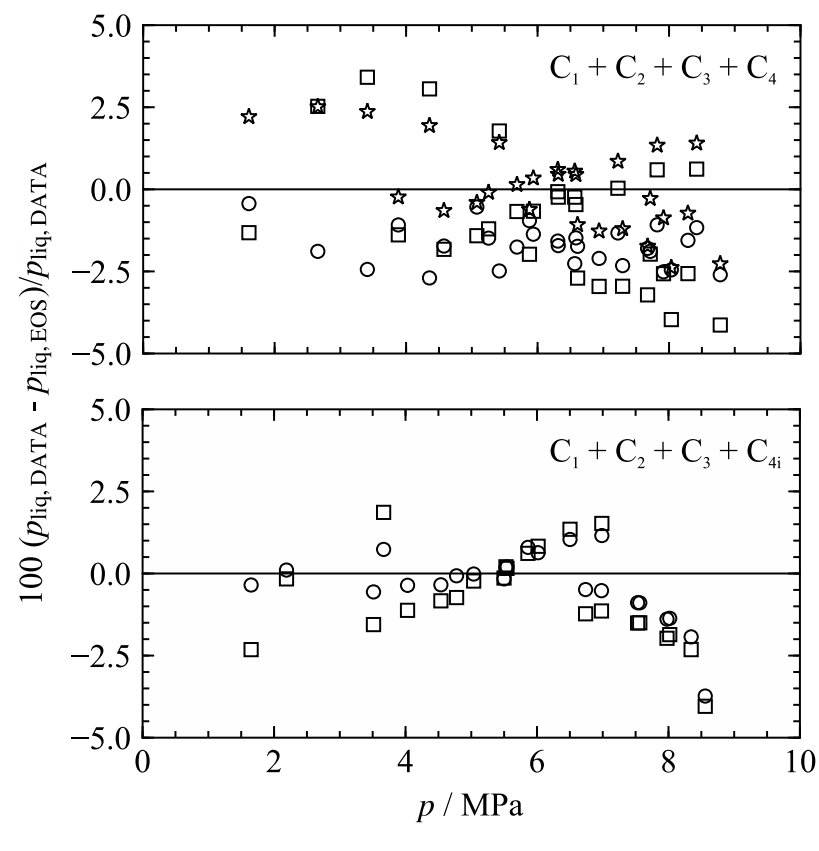

$\square$ EOS-LNG ○ GERG-2008 ¿ Rowland et al. (2016)

Fig. 25. Percentage deviations of the experimental vapor-liquid equilibrium data of Hughes et al. ${ }^{112}$ from the EOSLNG $\left(\mathrm{C}_{1} \mathrm{C}_{4}\right.$ and $\left.\mathrm{C}_{1} \mathrm{C}_{4 \mathrm{i}}\right)$, the GERG-2008 ${ }^{11}\left(\mathrm{C}_{1} \mathrm{C}_{4}\right.$ and $\left.\mathrm{C}_{1} \mathrm{C}_{4 \mathrm{i}}\right)$, and the modification of Rowland et al. ${ }^{73}\left(\mathrm{C}_{1} \mathrm{C}_{4}\right)$. Temperatures range from $200 \mathrm{~K}$ to $275 \mathrm{~K}$. 
Comparison with the multi-component VLE data reported by Hughes et al. ${ }^{112}$ for mixtures containing $n$-butane and isobutane are shown in Fig. 25 . The representation of these data is similar for the EOS-LNG, GERG-2008, ${ }^{11}$ and the modification of Rowland et al. ${ }^{73}$

Significant improvements are observed for the representation of the heat capacity data (multicomponent mixture of methane, ethane, propane, $n$-butane, and nitrogen) measured by Syed et al. ${ }^{71}$ While the GERG-2008 mode $1^{11}$ exhibits deviations of up to $14.6 \%$, the EOS-LNG and the modification of Rowland et al. ${ }^{73}$ deviate by not more than 6.5\%, cf. Fig. 26.

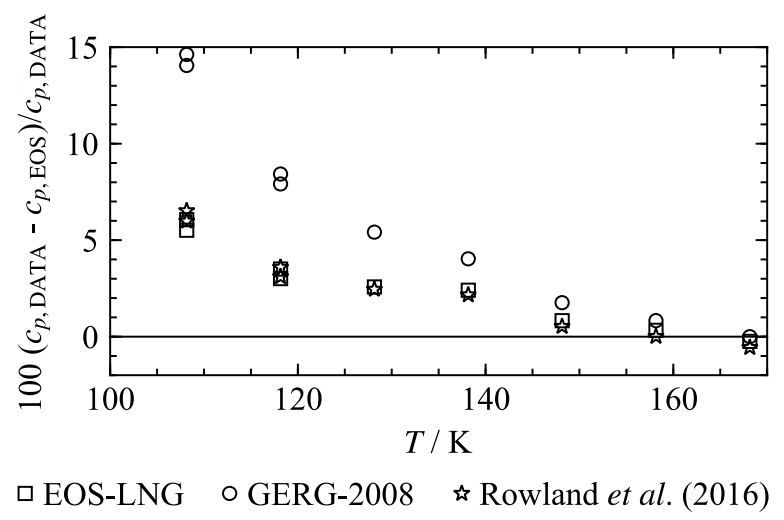

Fig. 26. Percentage deviations of the experimental isobaric heat capacity data of Syed et al. ${ }^{71}$ from the EOS-LNG, the GERG-2008,${ }^{11}$ and the modification of Rowland et al. ${ }^{73}$ at pressures of $1 \mathrm{MPa}$ and $5 \mathrm{MPa}$.

Although the main focus was given to the accurate representation of the subcooled liquid state, the gaseous and supercritical regions, which are important for the calculation of natural gas properties at pipeline conditions, were monitored to ensure that properties predicted in this region with the EOS-LNG are of comparable quality to predictions made with the GERG2008. ${ }^{11}$ In contrast to the liquid state, there is a significant amount of data available in this region, which were carefully evaluated and analyzed in the GERG Technical Monograph No. $15 .^{23}$ Based on these datasets, comparisons between the EOS-LNG and GERG-2008 ${ }^{11}$ were carried out. The results are presented in Tables A1 and A2 in Appendix A. Due to the number of data, graphical evaluation of the results is not presented here. Since the mole fractions of the four components investigated in this work are generally rather small in the systems listed in Tables A1 and A2, no significant differences between the representation of the data by the two equations of state are observed. Only the datasets of Jaeschke and Schley ${ }^{113}$ and of Watson and Millington ${ }^{114}$ (RNG1 to RNG7 in the table) contain a significant amount of butanes or pentanes and can, therefore, be used as a baseline for comparisons with the EOS-LNG. In general, these data are now reproduced more accurately than with the GERG-2008. ${ }^{11}$ One remarkable result, which is in line with the analysis of the corresponding binary mixtures, is the improved representation of the saturated liquid density data of Hiza and Haynes ${ }^{115}$ (M7 to M10 in the table) and Haynes ${ }^{116}$ (M1 to M17 in the table). For example, the deviations of samples containing more than 4 mol\% $n$-butane (M8 - Hiza and Haynes, ${ }^{115}$ M1 and M2 - Haynes ${ }^{116}$ ) are reduced by a factor of approximately five. 


\section{Conclusion}

In this paper, a new fundamental equation of state in terms of the Helmholtz energy is presented for accurately representing properties of multicomponent natural gas mixtures in the liquid state region (EOS-LNG). The general mathematical form and most of the binary functions are adopted from GERG-2008, ${ }^{11}$ which is the reference model for natural gases in the literature. Based on new experimental data and new fitting techniques, binary-specific functions for methane $+n$-butane, methane + isobutane, methane $+n$-pentane, and methane + isopentane were developed. In comparison to GERG-2008, ${ }^{11}$ different density data were chosen for the fitting procedure and new data in the liquefied natural gas region were applied. This results in a significantly better representation of the homogeneous density data in the LNG region and for vapor-liquid equilibrium states. The representation of caloric properties (e.g., heat capacities and excess enthalpies) was also improved.

By combining the four new binary-specific functions developed in this work with the remaining functions of GERG-2008, ${ }^{11}$ deviations with respect to density data of six exemplary multicomponent mixtures could be reduced from $0.22 \%$ calculated with GERG-2008 ${ }^{11}$ to $0.05 \%$ with EOS-LNG. For further improvements, new experimental data (e.g., density, speed of sound, and vapor-liquid equilibrium) are required, in particular for the systems methane $+n$ butane and methane + isopentane. The representation of multicomponent vapor-liquid equilibrium data with the EOS-LNG is similar to GERG-2008, ${ }^{11}$ whereas deviations from heat capacity data are reduced by a factor of approximately 2.5 .

Although the main focus was given to the temperature, pressure, and composition range of liquefied natural gases, the representation of all other binary mixture data that were available for the four adjusted systems is better or at least similar to GERG-2008. ${ }^{11}$ Therefore, the new model is not only valid in the liquefied-natural-gas region but also in any other fluid state and is available in common software packages such as TREND, ${ }^{117}$ REFPROP,${ }^{118}$ and CoolProp. ${ }^{119}$ Test values for computer implementation are given in Appendix B. 


\section{Acknowledgments}

We gratefully acknowledge helpful discussions with Ian H. Bell and Jadran Vrabec throughout the development of the models. Furthermore, we thank Sven Pohl for his assistance during data evaluation and Robin Fingerhut for providing the figures of the molecular models in the graphical abstract.

Funding: This work was part of the Joint Research Project "Metrological support for LNG custody transfer and transport fuel applications" (JRP: ENG60 LNGII) and was carried out as part of the European Metrology Research Program (EMRP), which was jointly funded under the researcher grant contract no. ENG60-REG3 by the EMRP participating countries within the European Association of National Metrology Institutes (EURAMET). The authors thank the German Academic Exchange Service (DAAD) for funding the international collaboration between the groups at Ruhr-Universität Bochum and The University of Western Australia. Eric F. May is grateful for the support of the Ruhr-University Research School PLUS, funded by Germany's Excellence Initiative [DFG GSC 98/3]. EFM also acknowledges the support of the Australian Research Council Industrial Transformation Training Centre for LNG Futures (IC150100019). 


\section{References}

1 D.-Y. Peng and D. B. Robinson, Ind. Eng. Chem. Fundam. 15, 59 (1976).

2 D. B. Robinson and D.-Y. Peng, The Characterization of the Heptanes and Heavier Fractions for the GPA Peng-Robinson Programs (Research report: Gas Processors Association, 1978).

3 O. Redlich and J. N. S. Kwong, Chem. Rev. 44, 233 (1949).

${ }^{4}$ G. Soave, Chem. Eng. Sci. 27, 1197 (1972).

5 B. I. Lee and M. G. Kesler, AIChE J. 21, 510 (1975).

${ }^{6}$ U. Plöcker, H. Knapp, and J. M. Prausnitz, Ind. Eng. Chem. Proc. Des. Dev. 17, 324 (1978).

${ }^{7}$ R. Klimeck, R. Span, R. Kleinrahm, and W. Wagner, Fundamental Equation for Calorific Properties. Collecting of Data and Test of Existing Equations. (Final report to GERG WG 1.3; Bochum, Germany, 1996).

8 F. Dauber and R. Span, Appl. Energy 97, 822 (2012).

9 D. George, Development of Accurate Methods for Predicting Hydrocarbon Dew Points (Final report to United States Minerals Management Service; San Antonio, Texas, USA, 2007).

10 AGA Transmission Measurement Committee, Thermodynamic Properties of Natural Gas and Related Gases: DETAIL and GROSS Equations of State (AGA Report No. 8, Part I, 3rd ed.; Washington, D.C., 2017).

11 O. Kunz and W. Wagner, J. Chem. Eng. Data 57, 3032 (2012).

12 AGA Transmission Measurement Committee, Thermodynamic Properties of Natural Gas and Related Gases: GERG-2008 Equation of State (AGA Report No. 8, Part II, 3rd ed.; Washington, D.C., 2017).

13 E. W. Lemmon, Better Defining the Uncertainties for the AGA 8 Equation (Catalog No. PR-381-12604-R01, 2013).

14 AGA Transmission Measurement Committee https://pages.nist.gov/AGA8/, Computer Code in Fortran, C++, and Visual Basic along with a Spreadsheet for Quick Calculations of Properties for Both Models.

15 G. H. Thomson, K. R. Brobst, and R. W. Hankinson, AIChE J. 28, 671 (1982).

16 Groupe International des Importateurs de Gaz Naturel Liquéfié (GIIGNL), LNG Custody Transfer Handbook; Paris, 2017).

17 R. D. McCarty, J. Chem. Thermodyn. 14, 837 (1982). 
18 C. Tietz, M. Richter, R. Kleinrahm, and R. Span, Fuel Process. Technol. 165, 19 (2017).

19 R. Lentner, M. Richter, R. Kleinrahm, and R. Span, J. Chem. Thermodyn. 112, 68 (2017).

${ }^{20}$ R. Lentner, M. Richter, R. Kleinrahm, P. Eckmann, and R. Span, J. Chem. Thermodyn., to be submitted (2019).

${ }^{21}$ E. W. Lemmon, Dissertation, University of Idaho, 1996.

${ }^{22}$ R. Klimeck, Dissertation, Ruhr-Universität Bochum, 2000.

${ }^{23}$ O. Kunz, R. Klimeck, W. Wagner, and M. Jaeschke, The GERG-2004 Wide-Range Equation of State for Natural Gases and Other Mixtures (GERG Technical Monograph No. 15; Düsseldorf, Germany, 2007).

24 I. H. Bell and E. W. Lemmon, J. Chem. Eng. Data 61, 3752 (2016).

25 E. W. Lemmon and M. O. McLinden, Method for Estimating Mixture Equation of State Parameters in Conference on Thermophysical Properties of New Refrigerants, edited by International Institute of Refrigeration, Commission B1, 2001, pp. 23-30.

${ }^{26}$ E. W. Lemmon and R. Tillner-Roth, Fluid Phase Equilib. 165, 1 (1999).

${ }^{27}$ R. Span, Multiparameter Equations of State: An Accurate Source of Thermodynamic Property Data (Springer, Berlin, 2000).

${ }^{28}$ E. W. Lemmon and R. T. Jacobsen, Int. J. Thermophys. 20, 825 (1999).

${ }^{29}$ L. Haar, J. S. Gallagher, and G. S. Kell, Proc. 8th Symp. Thermophys. Prop. 8, 298 (1982).

${ }^{30}$ U. Setzmann and W. Wagner, J. Phys. Chem. Ref. Data 20, 1061 (1991).

31 I. H. Bell, K. Gao, and E. W. Lemmon, J. Phys. Chem. Ref. Data, to be published (2019).

${ }^{32}$ L. F. S. Souza, S. Herrig, R. Span, and J. P. M. Trusler, Applied Energy, to be published (2019).

33 T. Neumann, M. Thol, I. H. Bell, E. W. Lemmon, and R. Span, Fluid Phase Equilib., to be published (2019).

${ }^{34}$ G. M. Kontogeorgis, E. C. Voutsas, I. V. Yakoumis, and D. P. Tassios, Ind. Eng. Chem. Res. 35, 4310 (1996).

35 W. G. Chapman, K. E. Gubbins, G. Jackson, and M. Radosz, Fluid Phase Equilib. 52, 31 (1989).

36 W. G. Chapman, K. E. Gubbins, G. Jackson, and M. Radosz, Ind. Eng. Chem. Res. 29, 1709 (1990).

37 S. H. Huang and M. Radosz, Ind. Eng. Chem. Res. 29, 2284 (1990).

38 S. H. Huang and M. Radosz, Ind. Eng. Chem. Res. 30, 1994 (1991).

39 A. Jäger, I. H. Bell, and C. Breitkopf, Fluid Phase Equilib. 469, 56 (2018). 
40 A. Jäger, E. Mickoleit, and C. Breitkopf, Fluid Phase Equilib. 476, 147 (2018).

41 J. G. Gernert and R. Span, J. Chem. Thermodyn. 93, 274 (2016).

${ }^{42}$ R. Span, H.-J. Collmann, and W. Wagner, Int. J. Thermophys. 19, 491 (1998).

43 E. W. Lemmon and R. T. Jacobsen, J. Phys. Chem. Ref. Data 34, 69 (2005).

${ }^{44}$ E. W. Lemmon, M. O. McLinden, and W. Wagner, J. Chem. Eng. Data 54, 3141 (2009).

45 M. Thol, G. Rutkai, A. Köster, R. Span, J. Vrabec, and R. Lustig, J. Phys. Chem. Ref. Data 45, 023101 (2016).

${ }^{46}$ M. Thol and E. W. Lemmon, Int. J. Thermophys. 37, 28 (2016).

47 K. Gao, J. Wu, P. Zhang, and E. W. Lemmon, J. Chem. Eng. Data 61, 2859 (2016).

48 V. D. Arp, J. M. Persichetti, and G.-b. Chen, J. Fluids Eng. 106, 193 (1984).

49 M. Richter, R. Kleinrahm, R. Lentner, and R. Span, J. Chem. Thermodyn. 93, 205 (2016).

50 B. H. Sage and W. N. Lacey, Trans. Am. Inst. Mining, Metall. Pet. Eng. 136, 136 (1940).

51 B. H. Sage, R. A. Budenholzer, and W. N. Lacey, Ind. Eng. Chem. 32, 1262 (1940).

52 R. H. Olds, B. H. Sage, and W. N. Lacey, Ind. Eng. Chem. 34, 1008 (1942).

53 B. H. Sage, D. C. Webster, and W. N. Lacey, Ind. Eng. Chem. 28, 1045 (1936).

54 B. H. Sage, H. H. Reamer, R. H. Olds, and W. N. Lacey, Ind. Eng. Chem. 34, 1108 (1942).

55 H. H. Reamer, B. H. Sage, and W. N. Lacey, J. Chem. Eng. Data 5, 44 (1960).

56 B. H. Sage and W. N. Lacey, Ind. Eng. Chem. 32, 992 (1940).

57 B. H. Sage and W. N. Lacey, Ind. Eng. Chem. 31, 1497 (1939).

58 W. Blanke and R. Weiss, Int. J. Thermophys. 16, 643 (1995).

59 A. E. Hoover, Dissertation, Rice University, 1965.

${ }^{60}$ H. Hou, J. C. Holste, K. R. Hall, K. N. Marsh, and B. E. Gammon, J. Chem. Eng. Data 41, 344 (1996).

${ }^{61}$ M. Jaeschke, H.-M. Hinze, and A. E. Humphreys, Supplement to the GERG Databank of High-Accuracy Compression Factor Measurements (GERG Technical Monograph No. 7; Düsseldorf, Germany, 1996).

62 M. Jaeschke and A. E. Humphreys, The GERG Databank of High Accuracy Compressibility Factor Measurements (Fortschr.-Ber. Reihe 6: Energieerzeugung No. 251; Düsseldorf, Germany, 1991).

63 O. Wöll and T. El Hawary, personal communication to Oliver Kunz (2003).

${ }^{64}$ A. Karimi, T. J. Hughes, M. Richter, and E. F. May, J. Chem. Eng. Data 61, 2782 (2016).

${ }^{65}$ H. H. Reamer, B. H. Sage, and W. N. Lacey, Ind. Eng. Chem. 42, 534 (1950). 
${ }^{66}$ E. T. S. Huang, G. W. Swift, and F. Kurata, AIChE J. 13, 846 (1967).

67 K. Arai and R. Kobayashi, Adv. Cryog. Eng. 25, 640 (1980).

68 W. Wagner, R. Kleinrahm, H. W. Lösch, J.T.R. Watson, V. Majer, A.A.H. Pádua, L. A. Woolf, J. C. Holste, A. M. de Figueiredo Palavra, K. Fujii, and J. W. Stansfeld, Density in Experimental Thermodynamics, edited by A. R. H. Goodwin, K. N. Marsh, W. A. Wakeham (Elsevier, Amsterdam, Boston), 2003, Vol. 6, pp. 125-235.

69 B. H. Sage, W. N. Lacey, and J. G. Schaafsma, Ind. Eng. Chem. 26, 214 (1934).

${ }^{70}$ E. F. May, J. Y. Guo, J. H. Oakley, T. J. Hughes, B. F. Graham, K. N. Marsh, and S. H. Huang, J. Chem. Eng. Data 60, 3606 (2015).

71 T. H. Syed, T. J. Hughes, K. N. Marsh, and E. F. May, J. Chem. Eng. Data 59, 968 (2014).

${ }^{72}$ R. Lentner, Dissertation, Ruhr-Universität Bochum, 2018.

73 D. Rowland, T. J. Hughes, and E. F. May, J. Chem. Thermodyn. 97, 206 (2016).

74 J. A. Beattie, W. H. Stockmayer, and H. G. Ingersoll, J. Chem. Phys. 9, 871 (1941).

75 R. T. Ellington, personal communication to Jaeschke et al. reported in Ref. 50 (1986).

76 A. Fenghour, J. P. M. Trusler, and W.A. Wakeham, Fluid Phase Equilib. 163, 139 (1999).

77 W. M. Haynes, J. Chem. Thermodyn. 15, 903 (1983).

78 M. J. Hiza, W. M. Haynes, and W. R. Parrish, J. Chem. Thermodyn. 9, 873 (1977).

79 J. Kestin and J. Yata, J. Chem. Phys. 49, 4780 (1968).

${ }^{80}$ W. P. Pan, M. H. Mady, and R. C. Miller, AIChE J. 21, 283 (1975).

81 H. H. Reamer, K. J. Korpl, B. H. Sage, and W. N. Lacey, Ind. Eng. Chem. 39, 206 (1947).

82 J. R. Tomlinson, NGPA Techn. Publ., 1 (1985).

${ }^{83}$ F. Plantier, A. Danesh, M. Sohrabi, J.-L. Daridon, F. Gozalpour, and A. C. Todd, J. Chem. Eng. Data 50, 673 (2005).

${ }^{84}$ D. J. Hutchings, E. J. Lewis, and C. J. Wormald, J. Chem. Thermodyn. 10, 559 (1978).

85 R. H. Sage, B. L. Hicks, and W. N. Lacey, Ind. Eng. Chem. 32, 1085 (1940).

86 W. Wagner and R. Kleinrahm, Metrologia 41, S24-S39 (2004).

87 M. O. McLinden, Chapter 2. Experimental Techniques 1: Direct Methods in Volume Properties, edited by E. Wilhelm and T. Letcher (Royal Society of Chemistry, Cambridge), 2014, pp. 73-99.

${ }^{88}$ M. O. McLinden, Meas. Sci. Technol. 17, 2597 (2006).

89 R. J. J. Chen, P. S. Chappelear, and R. Kobayashi, J. Chem. Eng. Data 19, 53 (1974).

90 D. G. Elliot, R. J. J. Chen, P. S. Chappelear, and R. Kobayashi, J. Chem. Eng. Data 19, 71 (1974). 
91 L. C. Kahre, J. Chem. Eng. Data 19, 67 (1974).

92 G. W. Nederbragt, Ind. Eng. Chem. 30, 587 (1938).

93 T. J. Rigas, D. F. Mason, and G. Thodos, Ind. Eng. Chem. 50, 1297 (1958).

${ }^{94}$ L. R. Roberts, R. H. Wang, A. Azarnoosh, and J. J. McKetta, J. Chem. Eng. Data 7, 484 (1962).

95 R. H. Wang and J. J. McKetta, J. Chem. Eng. Data 9, 30 (1964).

96 H. C. Wiese, J. Jacobs, and B. H. Sage, J. Chem. Eng. Data 15, 82 (1970).

97 J. B. Rodosevich and R. C. Miller, AIChE J. 19, 729 (1973).

98 S. D. Barsuk, V. G. Skripka, and O. A. Benyaminovich, Gazov. Promst. 15, 38 (1970).

99 M. E. Kandil, E. F. May, B. F. Graham, K. N. Marsh, M. A. Trebble, R. D. Trengove, and S. H. Huang, J. Chem. Eng. Data 55, 2725 (2010).

100 X. Zhang, L. Gao, Z. Liu, J. He, J. Zhang, and B. Han, J. Supercrit. Fluids 23, 233 (2002).

101 R. J. J. Chen, P. S. Chappelear, and R. Kobayashi, J. Chem. Eng. Data 19, 58 (1974).

102 T.-C. Chu, R. J. J. Chen, P. S. Chappelear, and R. Kobayashi, J. Chem. Eng. Data 21, 41 (1976).

103 L. C. Kahre, J. Chem. Eng. Data 20, 363 (1975).

104 M. E. Kandil, M. J. Thoma, T. Syed, J. Y. Guo, B. F. Graham, K. N. Marsh, S. H. Huang, and E. F. May, J. Chem. Eng. Data 56, 4301 (2011).

105 N. W. Prodany and B. Williams, J. Chem. Eng. Data 16, 1 (1971).

106 U. K. Deiters and T. Kraska, High-Pressure Fluid Phase Equilibria: Phenomenology and Computation (Elsevier, Amsterdam, Netherlands, 2012).

107 E. H. Amick, W. B. Johnson, and B. F. Dodge, Chem. Eng. Prog. Symp. Ser. 48, 65 (1952).

108 W. B. Kay, Ind. Eng. Chem. 28, 1014 (1936).

109 H. L. Chang, L. J. Hurt, and R. Kobayashi, AIChE J. 12, 1212 (1966).

110 I. H. Bell and U. K. Deiters, AIChE J. 64, 2745 (2018).

111 G. Soave, S. Gamba, and L. A. Pellegrini, Fluid Phase Equilib. 299, 285 (2010).

112 T. J. Hughes, J. Y. Guo, C. J. Baker, D. Rowland, B. F. Graham, K. N. Marsh, S. H. Huang, and E. F. May, J. Chem. Thermodyn. 113, 81 (2017).

113 M. Jaeschke and P. Schley, Compression Factor Measurements on Rich Natural Gases (Final Report to Gas Research Institute, Contract No. 5095-260-3557; Chicago, 1998).

114 J. T. R. Watson and B. Millington, The Density of Rich Natural Gas Mixtures. A Joint Industrial Project. (NEL, Project No. DRG001 Report No. 110/97, 1998). 
115 M. J. Hiza and W. M. Haynes, J. Chem. Thermodyn. 12, 1 (1980).

116 W. M. Haynes, J. Chem. Thermodyn. 14, 603 (1982).

117 R. Span, R. Beckmüller, T. Eckermann, S. Herrig, S. Hielscher, A. Jäger, T. Neumann, S. Pohl, B. Semrau, and M. Thol, TREND. Thermodynamic Reference and Engineering Data 4.0 (Lehrstuhl für Thermodynamik, Ruhr-Universität Bochum, Bochum, Germany, 2019).

118 E. W. Lemmon, I. H. Bell, M. L. Huber, and M. O. McLinden, NIST Standard Reference Database 23: Reference Fluid Thermodynamic and Transport Properties-REFPROP, Version 10.0 (National Institute of Standards and Technology, Gaithersburg, USA, 2018).

119 I. H. Bell, J. Wronski, S. Quoilin, and V. Lemort, Ind. Eng. Chem. Res. 53, 2498 (2014). 


\section{APPENDIX - A}

In Tables A1 and A2, numerical results for the AARD are presented for the multicomponent data in the pipeline region, which were used for the validation of the GERG2008. ${ }^{11}$ Comparisons are made with both the GERG-2008 ${ }^{11}$ and EOS-LNG models.

Table A1. Average absolute relative deviations (AARD/\%) of the experimental multicomponent data in the homogeneous state that were available for the development of the GERG-2008 ${ }^{11}$ and which contain butanes or pentanes. The AARD was calculated with EOS-LNG and GERG-2008 ${ }^{11}$ for comparison. The listed mole fractions indicate only the fractions of the components studied in this work (methane: $x_{\mathrm{C} 1}, n$-butane: $x_{\mathrm{C} 4}$, isobutane: $x_{\mathrm{C} 4 \mathrm{i}}, n$ pentane: $x_{\mathrm{C} 5}$, isopentane: $x_{\mathrm{C} 5 \mathrm{i}}$ ). For information on the complete composition and the designation of the mixtures, see the GERG Technical Monograph No. $15 .{ }^{23}$

\begin{tabular}{|c|c|c|c|c|c|c|c|c|c|c|}
\hline Author/Designation & $N$ & $T_{\min }-T_{\max }$ & $\begin{array}{c}p_{\min }- \\
p_{\max }\end{array}$ & $x_{\mathrm{C} 1}$ & $x_{\mathrm{C} 4}$ & $x_{\mathrm{C} 4 \mathrm{i}}$ & $x_{\mathrm{C} 5}$ & $x_{\mathrm{C} 5 \mathrm{i}}$ & $\begin{array}{c}\text { AARD } \\
\text { (EOS- } \\
\text { LNG) }\end{array}$ & $\begin{array}{c}\text { AARD } \\
\text { (GERG- } \\
2008 \text { ) }\end{array}$ \\
\hline & & $\mathrm{K}$ & $\mathrm{MPa}$ & mol- \% & mol- $\%$ & mol- \% & mol- $\%$ & mol- \% & $\%$ & $\%$ \\
\hline & & & Density & $p \rho T x$ & & & & & & \\
\hline D16(BUR) & 49 & $273-314$ & $0.4-31$ & 84.7831 & 1.2374 & - & - & - & 0.034 & 0.053 \\
\hline D17(OPT) & 168 & $273-314$ & $0.4-29$ & 84.7831 & 1.2374 & - & - & - & 0.027 & 0.026 \\
\hline D19(OPT) & 284 & $275-350$ & $0.3-29$ & 88.602 & 0.3 & 0.194 & 0.005 & 0.021 & 0.067 & 0.061 \\
\hline D20(OPT) & 153 & $290-350$ & $0.4-28$ & 88.652 & 0.3 & 0.194 & 0.005 & 0.021 & 0.044 & 0.041 \\
\hline D22(OPT), GU1 & 279 & $275-350$ & $0.4-28$ & 81.441 & 0.104 & 0.1 & - & - & 0.012 & 0.013 \\
\hline D23(GDM), GU1 & 13 & 299.99 & $0.5-5.0$ & 81.441 & 0.104 & 0.1 & - & - & 0.007 & 0.007 \\
\hline D24(BUR), GU1 & 78 & $250-325$ & $0.1-11$ & 81.299 & 0.1 & 0.101 & - & - & 0.012 & 0.013 \\
\hline D25(PYC), GU1 & 91 & $225-350$ & $3.4-60$ & 81.299 & 0.1 & 0.101 & - & - & 0.074 & 0.075 \\
\hline D26(BUR), GU1 & 65 & $226-350$ & $1.9-35$ & 81.299 & 0.1 & 0.101 & - & - & 0.021 & 0.023 \\
\hline D27(BUR), GU1 & 155 & $273-324$ & $0.1-34$ & 81.441 & 0.104 & 0.1 & - & - & 0.045 & 0.046 \\
\hline D28(IBU), GU1 & 64 & $242-274$ & $0.6-4.1$ & 81.441 & 0.104 & 0.1 & - & - & 0.019 & 0.019 \\
\hline D29(OPT), GU2 & 269 & $275-350$ & $0.4-28$ & 81.212 & 0.152 & 0.151 & - & - & 0.019 & 0.019 \\
\hline D30(GDM), GU2 & 13 & 299.99 & $0.5-8.0$ & 81.212 & 0.152 & 0.151 & - & - & 0.012 & 0.011 \\
\hline D31(BUR), GU2 & 85 & $250-325$ & $0.1-12$ & 81.202 & 0.155 & 0.148 & - & - & 0.018 & 0.018 \\
\hline D32(PYC), GU2 & 89 & $225-350$ & $3.3-60$ & 81.202 & 0.155 & 0.148 & - & - & 0.089 & 0.089 \\
\hline D33(BUR), GU2 & 70 & $225-350$ & $1.7-34$ & 81.202 & 0.155 & 0.148 & - & - & 0.025 & 0.025 \\
\hline D34(BUR), GU2 & 119 & $273-324$ & $0.3-36$ & 81.212 & 0.152 & 0.151 & - & - & 0.037 & 0.037 \\
\hline D35(BUR), RG2 & 18 & 299.99 & $0.2-23$ & 85.9063 & 0.3506 & 0.3486 & 0.048 & 0.0509 & 0.012 & 0.011 \\
\hline D36(OPT), RG2 & 275 & $275-350$ & $0.4-28$ & 85.9063 & 0.3506 & 0.3486 & 0.048 & 0.0509 & 0.034 & 0.023 \\
\hline D37(GDM), RG2 & 9 & 299.99 & $0.5-6.1$ & 85.9063 & 0.3506 & 0.3486 & 0.048 & 0.0509 & 0.013 & 0.009 \\
\hline D38(BUR), RG2 & 61 & $274-325$ & $0.1-11$ & 85.898 & 0.347 & 0.351 & 0.053 & 0.051 & 0.019 & 0.017 \\
\hline D39(PYC), RG2 & 87 & $225-350$ & $2.7-60$ & 85.898 & 0.347 & 0.351 & 0.053 & 0.051 & 0.265 & 0.216 \\
\hline D40(BUR), RG2 & 65 & $225-350$ & $1.9-33$ & 85.898 & 0.347 & 0.351 & 0.053 & 0.051 & 0.088 & 0.065 \\
\hline D41(OPT), NIST1 & 280 & $275-350$ & $0.4-28$ & 96.5222 & 0.1007 & 0.0977 & 0.0324 & 0.0473 & 0.016 & 0.026 \\
\hline D42(GDM), NIST1 & 15 & 299.99 & $0.5-8.1$ & 96.5222 & 0.1007 & 0.0977 & 0.0324 & 0.0473 & 0.005 & 0.006 \\
\hline D43(BUR), NIST1 & 77 & $250-325$ & $0.1-11$ & 96.579 & 0.102 & 0.099 & 0.032 & 0.047 & 0.012 & 0.013 \\
\hline D44(PYC), NIST1 & 82 & $225-350$ & $3.4-57$ & 96.579 & 0.102 & 0.099 & 0.032 & 0.047 & 0.135 & 0.107 \\
\hline D45(BUR), NIST1 & 66 & $225-350$ & $1.9-35$ & 96.579 & 0.102 & 0.099 & 0.032 & 0.047 & 0.022 & 0.022 \\
\hline D46(IBU), NIST1 & 64 & $242-274$ & $0.5-4.2$ & 96.5222 & 0.1007 & 0.0977 & 0.0324 & 0.0473 & 0.035 & 0.036 \\
\hline D47(OPT), NIST2 & 278 & $274-350$ & $0.4-28$ & 90.6724 & 0.1563 & 0.1037 & 0.0443 & 0.0321 & 0.014 & 0.015 \\
\hline D48(GDM), NIST2 & 11 & 299.99 & $0.5-3.8$ & 90.6724 & 0.1563 & 0.1037 & 0.0443 & 0.0321 & 0.008 & 0.007 \\
\hline
\end{tabular}




\begin{tabular}{|c|c|c|c|c|c|c|c|c|c|c|}
\hline Author/Designation & $N$ & $T_{\min }-T_{\max }$ & $\begin{array}{c}p_{\min }- \\
p_{\max }\end{array}$ & $x_{\mathrm{C} 1}$ & $x_{\mathrm{C} 4}$ & $x_{\mathrm{C} 4 \mathrm{i}}$ & $x_{\mathrm{C} 5}$ & $x_{\mathrm{C} 5 \mathrm{i}}$ & $\begin{array}{c}\text { AARD } \\
\text { (EOS- } \\
\text { LNG) }\end{array}$ & $\begin{array}{c}\text { AARD } \\
\text { (GERG- } \\
\text { 2008) }\end{array}$ \\
\hline & & K & $\mathrm{MPa}$ & mol- $\%$ & mol- $\%$ & mol-\% & mol- $\%$ & mol- $\%$ & $\%$ & $\%$ \\
\hline D49(BUR), NIST2 & 78 & $250-325$ & $0.1-9.6$ & 90.643 & 0.156 & 0.1 & 0.045 & 0.03 & .020 & 0.021 \\
\hline D50(PY & 66 & $25-350$ & $3.3-59$ & 90.643 & 0.156 & 0.1 & 0.045 & 0.03 & .167 & 0.146 \\
\hline D51(BUR), NIST2 & 67 & $5-350$ & $1.9-35$ & 90.643 & 0.156 & 0.1 & 0.045 & 0.03 & 0.031 & 0.028 \\
\hline D52(BUR), NIST2 & 135 & $273-324$ & $0.1-39$ & 90.6724 & 0.1563 & 0.1037 & 0.0443 & 0.0321 & 0.081 & 0.077 \\
\hline D53(IBU), NIST2 & 40 & $242-274$ & $1.1-4.2$ & 90.6724 & 0.1563 & 0.1037 & 0.0443 & 0.0321 & 0.049 & 0.051 \\
\hline D54(BUR) & 33 & $298-324$ & $0.1-16$ & 88.269 & 0.989 & - & - & - & 0.026 & 0.023 \\
\hline D55(BUR) & 35 & $290-324$ & $0.1-17$ & 80.079 & 1.75 & - & - & - & 0.108 & 0.088 \\
\hline D58(DEH) & 13 & 9.84 & $1.1-5.3$ & 96.5 & 0 . & 0.1 & 0.1 & 0.1 & 0.013 & 0.012 \\
\hline D59(DEH) & 32 & $288-300$ & $1.1-6.3$ & 90.66 & 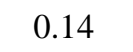 & 0.1 & 0.02 & 0.03 & 0.026 & 0.028 \\
\hline N1 (DEH) & 18 & $273-294$ & $1.9-7.0$ & 84.3346 & 0.6463 & 0.3381 & 0.0903 & 0.0922 & 0.066 & 0.058 \\
\hline N2 (DEH) & 18 & $273-294$ & $2.0-7.0$ & 95.534 & 0.0892 & 0.0619 & 0.0276 & 0.0311 & 0.024 & 0.024 \\
\hline N3 (DEH) & 18 & $273-294$ & $2.0-7.0$ & 85.1473 & 0.3232 & 0.1841 & 0.0801 & 0.0648 & 0.055 & 0.05 \\
\hline N4 (DEH) & 18 & $273-294$ & $2.0-7.0$ & 85.4814 & 0.5668 & 0.3027 & 0.0986 & 0.0905 & 0.039 & 0.045 \\
\hline N5 (DEH) & 24 & $273-304$ & $2.0-7.0$ & 80.1984 & 0.3454 & 0.2003 & 0.0618 & 0.0539 & 0.035 & 0.033 \\
\hline N6 (DEH) & 24 & $273-304$ & $2.0-7.0$ & 82.1692 & 0.3586 & 0.2081 & 0.0621 & 0.0554 & 0.018 & 0.019 \\
\hline N7 (DEH) & 24 & $273-304$ & $2.0-7.0$ & 73.6405 & 0.1482 & 0.0974 & .0451 & 0.0293 & 39 & 0.04 \\
\hline N8 (DEH) & 23 & $273-304$ & $2.0-7.0$ & 78.7092 & 0.1631 & 0.1073 & 0.0464 & 0.0315 & 0.045 & 0.045 \\
\hline N9 (BUR) & 67 & -294 & $0.1-8.6$ & 95.5192 & 0.0896 & 0.0622 & 0.0283 & 0.0308 & 0.030 & 0.030 \\
\hline N10 (BUR) & 68 & $273-294$ & $0.1-8.7$ & 84.4678 & 0.6304 & 0.3364 & 0.1005 & 0.0994 & 0.016 & 0.021 \\
\hline N11 (BUR) & 69 & $273-294$ & $0.1-8.6$ & 85.1666 & 0.3216 & 0.1845 & 0.0804 & 0.0647 & 0.016 & 0.019 \\
\hline N12 (BUR) & 69 & $273-294$ & $0.1-8.7$ & 85.4915 & 0.5683 & 0.3026 & 0.0 & 0.0907 & 0.024 & 0.032 \\
\hline N13 (OPT) & 74 & $273-294$ & $0.1-7.8$ & 95.5192 & 0.0896 & 0.0622 & 0.0283 & 0.0308 & 0.021 & 0.022 \\
\hline N14 (OPT) & 74 & $273-294$ & $0.1-7.8$ & 84.4678 & 0.6304 & 0.3364 & 0.1005 & 0.0994 & 0.059 & 0.072 \\
\hline N15 & 73 & $273-294$ & $0.1-7.8$ & 85.1666 & 0.3216 & 0.1845 & 0.0804 & 0.0647 & 0.053 & 0.052 \\
\hline N16 (OPT) & 74 & $273-294$ & $0.1-7.8$ & 85.4915 & 0.5683 & 0.3026 & 0.0995 & 0.0907 & 0.047 & 0.053 \\
\hline N17 & 76 & $273-294$ & $0.09-7.8$ & & & 0.0612 & & 0.0308 & 0.044 & 0.045 \\
\hline N18 (OPT) & 68 & -294 & $0.1-8.0$ & 84.4333 & 0.6311 & 0.3386 & 0.1015 & 0.0996 & 0.039 & 0.041 \\
\hline N19 (C & 73 & $273-294$ & $0.1-7.7$ & 85.1784 & 0.3226 & 0.1845 & 0.0804 & 0.0647 & 0.042 & 0.04 \\
\hline N20 (OPT) & 77 & $273-294$ & $0.1-7.9$ & 85.462 & 0.5688 & 0.3024 & 0.099 & 0.0912 & 0.037 & 0.042 \\
\hline N21 (BUR) & 12 & $273-292$ & $0.3-7.1$ & 92.2794 & 0.2498 & 0.1863 & 0.0792 & 0.0691 & 0.127 & 0.124 \\
\hline N22 (BUR) & 15 & $273-295$ & $0.2-11$ & 93.0357 & 0.1468 & 0.1348 & 0.0729 & 0.0426 & 0.080 & 0.078 \\
\hline N23 (DEH) & 18 & $278-299$ & $2.0-7.0$ & 81.2125 & 0.067 & 0.0622 & 0.0321 & 0.0233 & 0.068 & 0.068 \\
\hline N24 (DEH) & 12 & $278-299$ & $2.0-7.0$ & 90.8251 & 0.061 & 0.0519 & 0.0027 & 0.0204 & 0.061 & 0.06 \\
\hline N25 (DEH) & 10 & $288-294$ & $1.0-4.5$ & 83.952 & 0.627 & 0.362 & 0.105 & 0.104 & 0.053 & 0.058 \\
\hline N26 (DEH) & 5 & $283-284$ & $1.0-4.5$ & 83.8681 & 0.619 & 0.357 & 0.1029 & 0.102 & 0.103 & 0.101 \\
\hline N27 (DEH) & 5 & $278-279$ & $1.0-4.5$ & 83.75 & 0.613 & 0.355 & 0.0996 & 0.1 & 0.122 & 0.119 \\
\hline N28 (DEH) & 64 & $279-300$ & $3.7-6.5$ & 88.965 & 0.33 & 0.183 & 0.105 & 0.058 & 0.024 & 0.026 \\
\hline N29 (DEH) & 53 & $280-300$ & $3.7-6.5$ & 75.72 & 0.085 & 0.058 & 0.047 & 0.026 & 0.023 & 0.022 \\
\hline N30 (DEH) & 52 & $281-300$ & $3.7-6.5$ & 87.981 & 0.17 & 0.144 & 0.103 & 0.052 & 0.021 & 0.02 \\
\hline N31 (DEH) & 53 & $279-300$ & $3.7-6.5$ & 92.722 & 0.056 & 0.047 & 0.086 & 0.021 & 0.038 & 0.037 \\
\hline N32 (DEH) & 54 & $280-300$ & $3.7-6.5$ & 88.802 & 0.169 & 0.13 & 0.072 & 0.05 & 0.026 & 0.024 \\
\hline N33 (DEH) & 64 & $9-300$ & $3.7-6.5$ & 68.714 & 0.117 & 0.085 & 0.056 & 0.043 & 0.03 & 0.034 \\
\hline
\end{tabular}




\begin{tabular}{|c|c|c|c|c|c|c|c|c|c|c|}
\hline Author/Designation & $N$ & $T_{\min }-T_{\max }$ & $\begin{array}{c}p_{\min }- \\
p_{\max }\end{array}$ & $x_{\mathrm{C} 1}$ & $x_{\mathrm{C} 4}$ & $x_{\mathrm{C} 4 \mathrm{i}}$ & $x_{\mathrm{C} 5}$ & $x_{\mathrm{C} 5 \mathrm{i}}$ & $\begin{array}{c}\text { AARD } \\
\text { (EOS- } \\
\text { LNG) }\end{array}$ & $\begin{array}{c}\text { AARD } \\
\text { (GERG- } \\
\text { 2008) }\end{array}$ \\
\hline & & $\mathrm{K}$ & MPa & mol-\% & mol- $\%$ & mol-\% & mol- $\%$ & mol- $\%$ & $\%$ & $\%$ \\
\hline N34 (DEH) & 52 & $280-300$ & $3.7-6.5$ & 80.876 & 0.145 & 0.094 & 0.073 & .048 & .038 & 0.04 \\
\hline N35 (DEH) & 55 & $280-300$ & $7-6.5$ & 65.686 & 0.115 & 0.086 & 0.057 & 0.045 & 0.075 & 0.08 \\
\hline N36 (DEH) & 55 & $280-300$ & $3.7-6.5$ & 86.646 & 0.245 & 0.158 & 0.09 & 0.054 & 0.021 & 0.02 \\
\hline N37 (DEH) & 64 & $279-301$ & $3.7-6.5$ & 84.005 & 0.703 & 0.376 & 0.147 & 0.132 & 0.049 & 0.044 \\
\hline N38 (DEH) & 65 & $279-300$ & $3.7-6.6$ & 79.318 & 0.077 & 0.051 & 0.026 & 0.028 & 0.069 & 0.069 \\
\hline N39 (DEH) & 55 & $280-300$ & $3.7-6.5$ & 87.97 & 0.306 & 0.186 & 0.102 & 0.062 & 0.04 & 0.047 \\
\hline N40 (DEH) & 54 & $281-301$ & $3.7-6.5$ & 79.615 & 0.137 & 0.096 & 0.065 & 039 & 0.060 & 0.060 \\
\hline N41 (DEH) & 16 & $279-294$ & $3.7-5.5$ & 81.592 & 0.08 & 0.07 & 0.044 & .027 & 0.077 & 0.077 \\
\hline N42 (DEH) & 44 & $279-300$ & $3.7-6.5$ & 81.478 & 0.079 & 0.069 & 0.04 & 028 & 0.085 & 0.085 \\
\hline N43 (DEH) & 66 & $279-301$ & $3.7-6.6$ & 86.445 & 0.179 & 0.152 & 0.089 & 0.054 & 0.042 & 0.045 \\
\hline N44 (DEH) & 66 & $279-300$ & $3.7-6.5$ & 92.321 & 0.113 & 0.072 & 0.066 & 0.034 & 0.036 & 0.036 \\
\hline N45 (DEH) & 66 & $279-301$ & $3.7-6.5$ & 90.44 & 0.158 & 0.126 & 0.068 & 0.051 & 0.046 & 0.048 \\
\hline N46 (DEH) & 65 & $279-301$ & $3.7-6.5$ & 75.105 & 0.014 & 0.005 & 0.003 & 0.009 & 0.093 & 0.093 \\
\hline N47 (DEH) & 65 & $279-301$ & $3.7-6.5$ & 70.317 & 0.014 & 0.005 & 0.003 & 0.008 & 0.083 & 0.083 \\
\hline N48 (DEH) & 65 & $279-301$ & $3.7-6.6$ & 45.236 & 0.011 & 0.002 & 0.001 & 0.007 & 0.055 & 0.055 \\
\hline N49 (DEH) & 33 & $279-287$ & $3.8-6.4$ & 88.048 & & 0.313 & 0.076 & 076 & 03 & 0.113 \\
\hline N50 (DEH) & 22 & $279-284$ & $3.7-6.5$ & 81.55 & 0.072 & 0.072 & 0.0325 & 0.0325 & 0.071 & 0.070 \\
\hline N51 (BUR) & 31 & $273-314$ & $0.5-31$ & 85.4915 & 0.5683 & 0.3026 & 0.0995 & 0.0907 & 0.059 & 0.084 \\
\hline N52 (OPT) & 54 & 3.14 & $0.3-28$ & 85.4915 & 0.5683 & 0.3026 & 0.0995 & 0.0907 & 0.031 & 0.065 \\
\hline N53 (BUR) & 47 & $273-354$ & $0.4-31$ & 85.462 & 0.5688 & 0.3024 & 0.099 & 0.0912 & 0.025 & 0.042 \\
\hline N54 (OPT) & 113 & -354 & $0.3-29$ & 85.462 & 0.5688 & 0.3024 & 0.099 & 0.0912 & 0.024 & 0.036 \\
\hline N55 ( & 98 & -330 & $0.3-28$ & 85.3453 & 0.5864 & 0.3111 & 0.0902 & 0.0843 & 0.022 & 0.035 \\
\hline & 175 & $270-330$ & -30 & 85.3453 & 0.5864 & 0.3111 & 0.0902 & 0.0843 & 0.023 & 0.054 \\
\hline N57 & 30 & 90.00 & $0.4-26$ & 94.6077 & 0.0422 & 0.034 & 0.0122 & 0.0122 & 0.009 & 0.01 \\
\hline N58 (OPT) & 116 & $280-290$ & $0.5-29$ & 94.6077 & 0.0422 & .034 & 0.0122 & 0.0122 & 0.025 & 0.028 \\
\hline N59 ( & 34 & 0000 & $0.3-27$ & 82.5198 & 0.1543 & 0.0996 & & 0.0333 & 0.024 & 0.025 \\
\hline N60 (OPT) & 342 & $270-350$ & $0.4-30$ & 82.5198 & 0.1543 & 0.0996 & 0.0413 & 0.0333 & 0.039 & 0.044 \\
\hline N61 (BUR) & 36 & $309-310$ & $0.2-27$ & 98.2722 & 0.0334 & 0.0258 & 0.0068 & 0.0089 & 0.009 & 0.010 \\
\hline N62 (OPT) & 311 & $270-350$ & $0.3-29$ & 98.2722 & 0.0334 & 0.0258 & 0.0068 & 0.0089 & 0.023 & 0.025 \\
\hline N63 (BUR) & 62 & $309-330$ & $0.2-27$ & 89.4525 & 0.0043 & 0.0021 & 0.0011 & 0.0009 & 0.012 & 0.012 \\
\hline N64 (OPT) & 336 & $270-350$ & $0.5-29$ & 89.4525 & 0.0043 & 0.0021 & 0.0011 & 0.0009 & 0.020 & 0.020 \\
\hline N65 (BUR) & 60 & $275-280$ & $0.3-27$ & 85.4541 & 0.5947 & 0.3004 & 0.0848 & 0.0825 & 0.028 & 0.041 \\
\hline N66 (OPT) & 333 & $270-350$ & $0.3-29$ & 85.4541 & 0.5947 & 0.3004 & 0.0848 & 0.0825 & 0.042 & 0.035 \\
\hline N67 (BUR) & 68 & $273-304$ & $0.4-9.2$ & 82.1692 & 0.3586 & 0.2081 & 0.0621 & 0.0554 & 0.043 & 0.046 \\
\hline N68 (BUR) & 69 & $273-304$ & $0.4-9.2$ & 80.1984 & 0.3454 & 0.2003 & 0.0618 & 0.0539 & 0.018 & 0.019 \\
\hline N69 (BUR) & 70 & $273-304$ & $0.3-9.3$ & 73.6405 & 0.1482 & 0.0974 & 0.0451 & 0.0293 & 0.010 & 0.010 \\
\hline N70 (BUR) & 68 & $273-304$ & $0.4-9.2$ & 82.2373 & 0.353 & 0.2067 & 0.062 & 0.0554 & 0.042 & 0.045 \\
\hline N71 (BUR) & 70 & $273-304$ & $0.3-9.3$ & 80.1543 & 0.3468 & 0.2012 & 0.0613 & 0.0538 & 0.016 & 0.016 \\
\hline N72 (BUR) & 67 & $273-304$ & $0.4-9.3$ & 73.5015 & 0.1483 & 0.0975 & 0.0447 & 0.0293 & 0.013 & 0.012 \\
\hline N73 (BUR) & 31 & 309.99 & $0.4-27$ & 73.5015 & 0.1483 & 0.0975 & 0.0447 & 0.0293 & 0.012 & 0.011 \\
\hline N74 (OPT) & 341 & $270-350$ & $0.4-29$ & 73.5015 & 0.1483 & 0.0975 & 0.0447 & 0.0293 & 0.023 & 0.023 \\
\hline N75 (OPT) & 331 & $270-350$ & $0.4-29$ & 85.9284 & 0.4604 & 0.2381 & 0.063 & 0.0588 & 0.057 & 0.040 \\
\hline
\end{tabular}




\begin{tabular}{|c|c|c|c|c|c|c|c|c|c|c|}
\hline Author/Designation & $N$ & $T_{\min }-T_{\max }$ & $\begin{array}{l}p_{\min }- \\
p_{\max }\end{array}$ & $x_{\mathrm{C} 1}$ & $x_{\mathrm{C} 4}$ & $x_{\mathrm{C} 4 \mathrm{i}}$ & $x_{\mathrm{C} 5}$ & $x_{\mathrm{C} 5 \mathrm{i}}$ & $\begin{array}{c}\text { AARD } \\
\text { (EOS- } \\
\text { LNG) }\end{array}$ & $\begin{array}{c}\text { AARD } \\
\text { (GERG- } \\
\text { 2008) }\end{array}$ \\
\hline & & $\mathrm{K}$ & $\mathrm{MPa}$ & mol- $\%$ & mol- $\%$ & mol- $\%$ & mol- \% & mol- $\%$ & $\%$ & $\%$ \\
\hline N76 (DMA) & 135 & $273-324$ & $0.1-8.1$ & 84.3769 & 0.6574 & 0.3448 & 0.0896 & 0.0916 & 0.01 & 0.022 \\
\hline N77 (DEH) & 11 & $296-297$ & $3.7-7.2$ & 81.314 & 0.075 & 0.065 & 0.038 & 0.024 & 0.059 & 0.059 \\
\hline N78 (DEH) & 19 & $295-298$ & $3.6-6.6$ & 88.221 & 0.377 & 0.212 & 0.034 & 0.059 & 0.074 & 0.082 \\
\hline N79 (DEH) & 21 & $296-297$ & $3.0-5.5$ & 83.4177 & 0.6588 & 0.3777 & 0.0895 & 0.0933 & 0.045 & 0.036 \\
\hline N80 (DEH) & 44 & $280-294$ & $3.7-6.5$ & 65.6961 & 0.1185 & 0.086 & 0.0571 & 0.0424 & 0.078 & 0.083 \\
\hline N81 (DEH) & 42 & $280-294$ & $3.8-6.5$ & 80.8753 & 0.1457 & 0.0943 & 0.0733 & 0.0488 & 0.055 & 0.059 \\
\hline N82 (BUR) & 57 & $309-330$ & $0.5-27$ & 84.4872 & 0.3287 & 0.1802 & 0.0555 & 0.0502 & 0.013 & 0.012 \\
\hline N83 (OPT) & 353 & $270-350$ & $0.3-29$ & 84.4872 & 0.3287 & 0.1802 & 0.0555 & 0.0502 & 0.028 & 0.022 \\
\hline N84 (DEH) & 37 & $283-314$ & $1.0-8.1$ & 57.693 & 0.072 & 0.073 & 0.018 & 0.024 & 0.057 & 0.059 \\
\hline N85 (DEH) & 48 & $280-299$ & $2.8-7.5$ & 85.961 & - & 0.668 & - & 0.122 & 0.037 & 0.044 \\
\hline N86 (EXP) & 10 & 303.11 & $1.0-16$ & 82.71 & - & 0.12 & - & 0.01 & 0.080 & 0.079 \\
\hline N87 (DEH) & 7 & 288.71 & $4.9-5.3$ & 96.5016 & - & 0.1999 & - & 0.2 & 0.031 & 0.036 \\
\hline N88 (DEH) & 40 & $283-314$ & $1.0-6.0$ & 95.022 & - & 0.19 & - & 0.092 & 0.049 & 0.047 \\
\hline N89 (DEH) & 42 & $283-313$ & $1.5-6.6$ & 87.432 & - & 0.05 & - & 0.028 & 0.022 & 0.022 \\
\hline N90 (DEH) & 35 & $283-314$ & $1.5-5.6$ & 93.62 & - & 0.21 & - & 0.095 & 0.045 & 0.043 \\
\hline N91 (DEH) & 32 & $282-314$ & $1.0-5.1$ & 85.297 & - & 0.5 & - & 0.172 & 0.045 & 0.042 \\
\hline N92 (DEH) & 26 & $283-313$ & $1.0-4.0$ & 95.616 & - & 0.014 & - & 0.006 & 0.025 & 0.025 \\
\hline N94 (DEH) & 26 & $286-287$ & $2.9-7.9$ & 85.923 & - & 0.664 & - & 0.121 & 0.009 & 0.015 \\
\hline N95 (DEH) & 44 & $280-299$ & $2.9-7.2$ & 8 & - & 0.669 & - & 22 & 0.037 & 0.040 \\
\hline N96 (DEH) & 48 & $280-299$ & $2.8-7.7$ & 75.203 & - & 0.018 & - & 0.013 & 0.063 & 0.063 \\
\hline N97 (BUR) & 33 & 309.99 & $0.3-26$ & 64.8023 & 0.3716 & 0.1885 & 0.0541 & 0.0501 & 0.021 & 0.016 \\
\hline N98 (OPT) & 306 & $270-350$ & $0.4-29$ & 64.8023 & 0.3716 & 0.1885 & 0.0541 & 0.0501 & 0.052 & 0.055 \\
\hline N99 (BUR) & 15 & 290 & $0.6-27$ & 59.0265 & 0.1229 & 0.0768 & 0.0346 & 0.0266 & 0.018 & 0.019 \\
\hline N100 (OPT) & 285 & $270-350$ & $0.3-28$ & 59.0265 & 0.1229 & 0.0768 & 0.0346 & 0.0266 & 0.043 & 0.043 \\
\hline N101 (OPT) & 338 & $270-350$ & $0.4-29$ & 47.2554 & 0.098 & 0.0612 & 0.0262 & 0.0203 & 0.019 & 0.019 \\
\hline N102 (BUR) & 33 & 290 & $0.4-27$ & 82.4733 & 0.5448 & 0.2775 & 0.0772 & 0.0752 & 0.019 & 0.023 \\
\hline N103 (OPT) & 336 & $270-350$ & $0.4-29$ & 82.4733 & 0.5448 & 0.2775 & 0.0772 & 0.0752 & 0.046 & 0.055 \\
\hline N104 (OPT) & 223 & $270-350$ & $0.5-28$ & 76.337 & 0.3974 & 0.2033 & 0.0486 & 0.0472 & 0.106 & 0.084 \\
\hline N105 (BUR) & 33 & 329.99 & $0.3-27$ & 65.847 & 0.171 & 0.107 & 0.0442 & 0.0318 & 0.055 & 0.059 \\
\hline N106 (OPT) & 220 & $270-350$ & $0.4-29$ & 65.847 & 0.171 & 0.107 & 0.0442 & 0.0318 & 0.105 & 0.113 \\
\hline N107 (OPT) & 460 & $265-350$ & $0.5-30$ & 79.3693 & 0.0179 & 0.0135 & 0.0104 & 0.0062 & 0.031 & 0.031 \\
\hline N108 (OPT) & 187 & $270-350$ & $0.5-20$ & 79.95 & 0.2598 & 0.1345 & 0.0348 & 0.0324 & 0.020 & 0.024 \\
\hline N109 (OPT) & 322 & $265-350$ & $0.5-31$ & 80.042 & 0.0564 & 0.0356 & 0.014 & 0.011 & 0.054 & 0.056 \\
\hline N110 (OPT) & 360 & $270-350$ & $0.5-31$ & 27.9285 & 0.015 & 0.002 & 0.0073 & 0.0007 & 0.067 & 0.067 \\
\hline N111 (OPT) & 90 & $270-350$ & $0.4-4.9$ & 70.7555 & 0.1034 & 0.132 & 0.0078 & 0.0083 & 0.042 & 0.043 \\
\hline N112 (OPT) & 100 & $270-350$ & $0.4-6.9$ & 81.0253 & 3.0997 & 0.0866 & 0.0367 & 0.0289 & 0.049 & 0.047 \\
\hline N113 (OPT) & 173 & $270-350$ & $0.4-15$ & 79.5699 & 0.1202 & 0.0849 & 0.0357 & 0.0293 & 0.015 & 0.015 \\
\hline N114 (OPT) & 125 & $270-350$ & $0.4-8.5$ & 76.845 & 0.104 & 0.077 & 0.0333 & 0.0267 & 0.041 & 0.042 \\
\hline N115 (OPT) & 342 & $270-350$ & $0.5-29$ & 81.5264 & 0.208 & 0.0001 & 0.072 & 0.0004 & 0.018 & 0.018 \\
\hline N116 (OPT) & 345 & $270-350$ & $0.5-29$ & 28.8898 & 0.071 & - & 0.0271 & 0.0003 & 0.024 & 0.024 \\
\hline $\begin{array}{l}\text { Capla et al. (2002), } \\
\text { M1 }\end{array}$ & 28 & $253-324$ & $0.9-16$ & 98.352 & 0.031 & 0.021 & 0.011 & 0.008 & 0.023 & 0.023 \\
\hline Capla et al. (2002), & 28 & $253-324$ & $1.0-16$ & 90.362 & 0.169 & 0.301 & 0.029 & 0.059 & 0.096 & 0.092 \\
\hline
\end{tabular}




\begin{tabular}{|c|c|c|c|c|c|c|c|c|c|c|}
\hline Author/Designation & $N$ & $T_{\min }-T_{\max }$ & $\begin{array}{l}p_{\min }- \\
p_{\max }\end{array}$ & $x_{\mathrm{C} 1}$ & $x_{\mathrm{C} 4}$ & $x_{\mathrm{C} 4 \mathrm{i}}$ & $x_{\mathrm{C} 5}$ & $x_{\mathrm{C} 5 \mathrm{i}}$ & $\begin{array}{c}\text { AARD } \\
\text { (EOS- } \\
\text { LNG) }\end{array}$ & $\begin{array}{c}\text { AARD } \\
\text { (GERG- } \\
2008)\end{array}$ \\
\hline & & $\mathrm{K}$ & $\mathrm{MPa}$ & mol- $\%$ & mol- $\%$ & mol- $\%$ & mol- \% & mol- $\%$ & $\%$ & $\%$ \\
\hline \multicolumn{11}{|l|}{ M2 } \\
\hline $\begin{array}{l}\text { Capla et al. (2002), } \\
\text { M3 }\end{array}$ & 28 & $253-324$ & $1.0-16$ & 92.436 & 0.046 & 0.041 & 0.014 & 0.015 & 0.020 & 0.020 \\
\hline Duschek et al. (1989) & 135 & $273-324$ & $0.1-8.1$ & 84.382 & 0.6589 & 0.3466 & 0.091 & 0.0897 & 0.010 & 0.023 \\
\hline $\begin{array}{l}\text { Guo et al. (1990a), } \\
\text { M1 }\end{array}$ & 8 & 299.99 & $0.5-3.8$ & 90.672 & 0.26 & - & 0.076 & - & 0.008 & 0.008 \\
\hline $\begin{array}{l}\text { Guo et al. (1990a), } \\
\text { M2 }\end{array}$ & 40 & $273-294$ & $0.1-12$ & 85.8933 & 0.4483 & 0.23 & 0.0531 & 0.0519 & 0.043 & 0.033 \\
\hline $\begin{array}{l}\text { Guo et al. (1990a), } \\
\text { M3 }\end{array}$ & 14 & 299.99 & $0.5-8.0$ & 81.212 & 0.303 & - & - & - & 0.014 & 0.013 \\
\hline $\begin{array}{l}\text { Guo et al. (1990a), } \\
\text { M4 }\end{array}$ & 15 & 299.99 & $0.5-8.1$ & 96.5222 & 0.1984 & - & 0.0797 & - & 0.005 & 0.005 \\
\hline $\begin{array}{l}\text { Guo et al. (1990a), } \\
\text { M5 }\end{array}$ & 57 & $273-294$ & $0.1-13$ & 82.1255 & 0.1434 & 0.0968 & 0.0354 & 0.0307 & 0.088 & 0.087 \\
\hline $\begin{array}{l}\text { Guo et al. (1990b), } \\
\text { M1 }\end{array}$ & 10 & 299.99 & $0.5-5.0$ & 81.441 & 0.204 & - & - & - & 0.006 & 0.006 \\
\hline $\begin{array}{l}\text { Guo et al. (1990b), } \\
\text { M2 }\end{array}$ & 9 & 299.99 & $0.5-6.1$ & 85.8988 & 0.7119 & - & 0.096 & - & 0.015 & 0.011 \\
\hline $\begin{array}{l}\text { Guo et al. (1993), } \\
\text { M1 }\end{array}$ & 8 & 283.15 & $2.7-9.6$ & 81.7329 & 0.183 & 0.097 & 0.0286 & 0.026 & 0.026 & 0.026 \\
\hline $\begin{array}{l}\text { Guo et al. (1993), } \\
\text { M2 }\end{array}$ & 8 & 283.15 & $2.2-7.8$ & 83.3243 & 0.146 & 0.087 & 0.0285 & 0.0245 & 0.081 & 0.085 \\
\hline $\begin{array}{l}\text { Guo et al. (1993), } \\
\text { M3 }\end{array}$ & 17 & $273-294$ & $2.3-11$ & 83.1821 & 0.1092 & 0.0804 & 0.0339 & 0.0282 & 0.088 & 0.089 \\
\hline $\begin{array}{l}\text { Guo et al. (1993), } \\
\text { M4 }\end{array}$ & 16 & $273-294$ & $2.2-8.3$ & 85.4917 & 0.4817 & 0.241 & 0.07 & 0.0638 & 0.024 & 0.010 \\
\hline $\begin{array}{l}\text { Guo et al. (1993), } \\
\text { M5 }\end{array}$ & 17 & $273-294$ & $2.3-10$ & 88.0605 & 0.2515 & 0.1568 & 0.0636 & 0.0479 & 0.192 & 0.199 \\
\hline $\begin{array}{l}\text { Guo et al. (1993), } \\
\text { M6 }\end{array}$ & 8 & 283.15 & $2.7-9.5$ & 98.4435 & 0.0358 & 0.0281 & 0.0046 & 0.0064 & 0.016 & 0.017 \\
\hline $\begin{array}{l}\text { Kleinrahm et } \quad \text { al. } \\
(1996), \text { M1 }\end{array}$ & 31 & $273-294$ & $0.6-8.2$ & 84.8802 & 0.4632 & 0.2342 & 0.0636 & 0.0604 & 0.038 & 0.052 \\
\hline $\begin{array}{l}\text { Kleinrahm et } \\
(1996), \text { M2 }\end{array}$ & 14 & 283.15 & $2.4-8.6$ & 84.4668 & 0.1291 & 0.0868 & 0.0392 & 0.0338 & 0.093 & 0.094 \\
\hline $\begin{array}{l}\text { Jaeschke and Schley } \\
\text { (1998), RNG1 }\end{array}$ & 268 & $280-350$ & $0.1-29$ & 59.0129 & 5.9958 & - & - & - & 0.050 & 0.122 \\
\hline $\begin{array}{l}\text { Jaeschke and Schley } \\
\text { (1998), RNG2 }\end{array}$ & 327 & $280-350$ & $0.1-30$ & 58.9863 & 4.9978 & - & - & - & 0.065 & 0.082 \\
\hline $\begin{array}{l}\text { Jaeschke and Schley } \\
\text { (1998), RNG3 }\end{array}$ & 247 & $280-350$ & $0.1-28$ & 58.9976 & 3.2996 & - & 0.4947 & - & 0.106 & 0.038 \\
\hline $\begin{array}{l}\text { Jaeschke and Schley } \\
\text { (1998), RNG4 }\end{array}$ & 249 & $280-350$ & $0.2-29$ & 60.0063 & 4.2898 & - & 0.5058 & - & 0.139 & 0.047 \\
\hline $\begin{array}{l}\text { Jaeschke and Schley } \\
\text { (1998), RNG5 }\end{array}$ & 256 & $280-350$ & $0.2-29$ & 63.9757 & 3.3144 & - & 0.5074 & - & 0.072 & 0.063 \\
\hline $\begin{array}{l}\text { Jaeschke and Schley } \\
\text { (1998), RNG6 }\end{array}$ & 251 & $280-350$ & $0.1-29$ & 57.9945 & 3.2983 & - & 0.4994 & - & 0.070 & 0.181 \\
\hline $\begin{array}{l}\text { Jaeschke and Schley } \\
\text { (1998), RNG7 }\end{array}$ & 250 & $280-350$ & $0.1-29$ & 51.981 & 3.3027 & - & 0.4948 & - & 0.151 & 0.261 \\
\hline Watson and & & & & & & & & & & \\
\hline $\begin{array}{l}\text { Millington (1998), } \\
\text { RNG1 }\end{array}$ & 39 & $318-354$ & $10-18$ & 59.0013 & 5.9822 & - & - & - & 0.041 & 0.154 \\
\hline Watson & 48 & $314-354$ & $7.8-18$ & 59.0055 & 4.979 & - & - & - & 0.044 & 0.094 \\
\hline
\end{tabular}




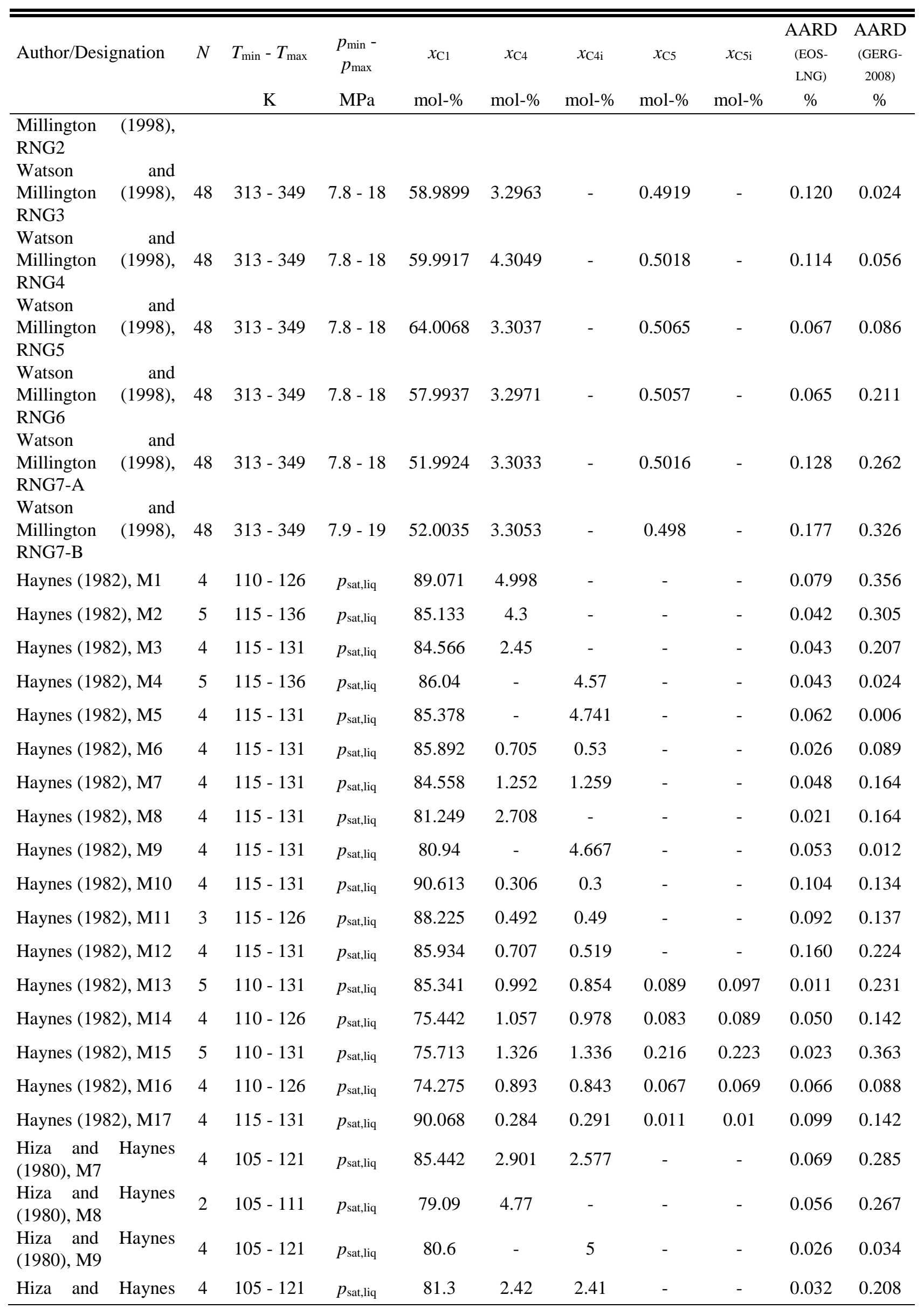




\begin{tabular}{|c|c|c|c|c|c|c|c|c|c|c|}
\hline \multirow[t]{2}{*}{ Author/Designation } & $N$ & $T_{\min }-T_{\max }$ & $\begin{array}{l}p_{\min }- \\
p_{\max }\end{array}$ & $x_{\mathrm{C} 1}$ & $x_{\mathrm{C} 4}$ & $x_{\mathrm{C} 4 \mathrm{i}}$ & $x_{\mathrm{C} 5}$ & $x_{\mathrm{C} 5 \mathrm{i}}$ & $\begin{array}{l}\text { AARD } \\
\text { (EOS- } \\
\text { LNG) }\end{array}$ & $\begin{array}{c}\text { AARD } \\
\text { (GERG- } \\
\text { 2008) }\end{array}$ \\
\hline & & $\mathrm{K}$ & $\mathrm{MPa}$ & mol- $\%$ & mol- $\%$ & mol- $\%$ & mol- \% & mol- $\%$ & $\%$ & $\%$ \\
\hline \multicolumn{11}{|l|}{ (1980), M10 } \\
\hline \multicolumn{11}{|c|}{ Speed of sound $w$} \\
\hline $\begin{array}{l}\text { Blanke and Weiß } \\
\text { (1986), M1 }\end{array}$ & 24 & $273-304$ & $\begin{array}{c}<0.01- \\
6.0\end{array}$ & 89.6788 & 0.2849 & 0.141 & 0.0527 & 0.0466 & 0.195 & 0.194 \\
\hline $\begin{array}{l}\text { Blanke and Weiß } \\
\text { (1986), M2 }\end{array}$ & 24 & $273-304$ & $\begin{array}{c}<0.01- \\
6.0\end{array}$ & 84.5038 & 0.0118 & 0.0129 & 0.0073 & 0.0038 & 0.152 & 0.152 \\
\hline $\begin{array}{l}\text { Blanke and Weiß } \\
\text { (1986), M3 }\end{array}$ & 24 & $273-304$ & $\begin{array}{c}<0.01- \\
6.0\end{array}$ & 86.416 & 0.0981 & 0.059 & 0.0296 & 0.0228 & 0.504 & 0.504 \\
\hline $\begin{array}{l}\text { Blanke and Weiß } \\
\text { (1986), M4 }\end{array}$ & 24 & $273-304$ & $\begin{array}{c}<0.01- \\
6.0\end{array}$ & 81.2158 & 0.0075 & 0.0087 & 0.0055 & 0.0024 & 0.025 & 0.025 \\
\hline $\begin{array}{l}\text { Blanke and Weiß } \\
\text { (1986), M5 }\end{array}$ & 24 & $273-304$ & $\begin{array}{c}<0.01- \\
6.0\end{array}$ & 82.6909 & 0.2522 & - & 0.0516 & - & 0.097 & 0.096 \\
\hline $\begin{array}{l}\text { Blanke and Weiß } \\
\text { (1986), M6 }\end{array}$ & 24 & $273-304$ & $\begin{array}{c}<0.01- \\
6.0\end{array}$ & 85.4207 & 0.4812 & - & 0.0909 & - & 0.262 & 0.260 \\
\hline $\begin{array}{l}\text { Blanke and Weiß } \\
\text { (1986), M7 }\end{array}$ & 24 & $273-304$ & $\begin{array}{c}<0.01- \\
6.0\end{array}$ & 81.8371 & 0.1898 & 0.1156 & 0.0353 & 0.0304 & 0.043 & 0.044 \\
\hline $\begin{array}{l}\text { Blanke and Weiß } \\
\text { (1986), M8 }\end{array}$ & 24 & $273-304$ & $\begin{array}{c}<0.01- \\
6.0\end{array}$ & 83.8939 & 0.5624 & - & 0.1023 & - & 0.197 & 0.195 \\
\hline $\begin{array}{l}\text { Blanke and Weiß } \\
\text { (1986), M9 }\end{array}$ & 24 & $273-304$ & $\begin{array}{c}<0.01- \\
6.0\end{array}$ & 83.3283 & 0.599 & 0.2795 & 0.2596 & - & 0.325 & 0.324 \\
\hline $\begin{array}{l}\text { Blanke and Weiß } \\
\text { (1986), M10 }\end{array}$ & 24 & $273-304$ & $\begin{array}{c}<0.01- \\
6.0\end{array}$ & 80.088 & 0.9019 & 0.4349 & 0.127 & 0.125 & 0.679 & 0.677 \\
\hline $\begin{array}{l}\text { Ewing and Goodwin } \\
\text { (1993) }\end{array}$ & 11 & 255.00 & $0.06-6.1$ & 93.961 & 0.024 & 0.017 & 0.001 & 0.006 & 0.047 & 0.047 \\
\hline Fawcett (1995) & 42 & $293-304$ & $0.3-11$ & 87.645 & 0.484 & 0.297 & 0.003 & 0.011 & 0.031 & 0.031 \\
\hline $\begin{array}{l}\text { Ingrain et al. (1993), } \\
\text { M1 }\end{array}$ & 58 & $212-347$ & $0.1-18$ & 88.405 & 0.226 & 0.149 & 0.049 & 0.056 & 0.317 & 0.306 \\
\hline $\begin{array}{l}\text { Ingrain et al. (1993), } \\
\text { M2 }\end{array}$ & 75 & $213-346$ & $0.2-18$ & 89.569 & 0.226 & 0.149 & - & 0.015 & 0.209 & 0.191 \\
\hline $\begin{array}{l}\text { Labes et al. (1994), } \\
\text { M1 }\end{array}$ & 240 & $262-355$ & $12-70$ & 88.405 & 0.226 & 0.149 & 0.049 & 0.056 & 0.374 & 0.358 \\
\hline $\begin{array}{l}\text { Labes et al. (1994), } \\
\text { M2 }\end{array}$ & 286 & $272-414$ & $20-70$ & 89.569 & 0.226 & 0.149 & - & 0.015 & 0.535 & 0.532 \\
\hline $\begin{array}{l}\text { Younglove et al. } \\
\text { (1993), M1 }\end{array}$ & 83 & $250-350$ & $0.4-11$ & 96.561 & 0.098 & 0.098 & 0.032 & 0.046 & 0.027 & 0.027 \\
\hline $\begin{array}{l}\text { Younglove et } \quad \text { al. } \\
\text { (1993), M2 }\end{array}$ & 82 & $250-350$ & $0.5-24$ & 90.708 & 0.141 & 0.106 & 0.065 & 0.027 & 0.021 & 0.021 \\
\hline $\begin{array}{l}\text { Younglove et al. } \\
\text { (1993), M3 }\end{array}$ & 91 & $250-350$ & $0.4-11$ & 83.98 & 0.067 & 0.04 & 0.008 & 0.013 & 0.037 & 0.036 \\
\hline $\begin{array}{l}\text { Younglove et al. } \\
(1993), \text { M4 }\end{array}$ & 44 & $299-350$ & $0.4-11$ & 74.348 & 3.026 & - & 0.575 & - & 0.084 & 0.065 \\
\hline \multicolumn{11}{|c|}{ Isobaric heat capacity $c_{p}$} \\
\hline $\begin{array}{l}\text { van Kasteren and } \\
\text { Zeldenrust } \\
\text { M1 }\end{array}$ & 11 & $115-265$ & 5.07 & 89.94 & 0.63 & 0.74 & 0.03 & 0.01 & 0.850 & 0.803 \\
\hline
\end{tabular}


Table A2. Average absolute relative deviations (AARD) of the experimental bubble-point pressure data, which were available for the development of the GERG-2008 ${ }^{11}$ and which contain butanes or pentanes. The AARD was calculated with EOS-LNG and GERG-2008 ${ }^{11}$ for comparison. The listed mole fractions indicate only the fractions of the components studied in this work (methane: $x_{\mathrm{C} 1}, n$-butane: $x_{\mathrm{C} 4}$, isobutane: $x_{\mathrm{C} 4 \mathrm{i}}, n$-pentane: $x_{\mathrm{C} 5}$, isopentane: $x_{\mathrm{C} 5 \mathrm{i}}$ ). For information on the complete composition and the designation of the mixtures, see the GERG Technical Monograph No. $15 .^{23}$

\begin{tabular}{|c|c|c|c|c|c|c|c|c|c|c|}
\hline \multirow[t]{2}{*}{ Author/Designation } & $N$ & $T_{\min }-T_{\max }$ & $\begin{array}{c}p_{\min }- \\
p_{\max }\end{array}$ & $x_{\mathrm{C} 1}$ & $x_{\mathrm{C} 4}$ & $x_{\mathrm{C} 4 \mathrm{i}}$ & $x_{\mathrm{C} 5}$ & $x_{\mathrm{C} 5 \mathrm{i}}$ & $\begin{array}{l}\mathrm{AARD}_{p l i q} \\
(\mathrm{EOS}-\mathrm{LNG})\end{array}$ & $\begin{array}{c}\mathrm{AARD}_{p l i q} \\
\text { (GERG- } \\
\text { 2008) }\end{array}$ \\
\hline & & $\mathrm{K}$ & $\mathrm{MPa}$ & mol- $\%$ & mol- $\%$ & mol- \% & mol- $\%$ & mol- $\%$ & $\%$ & $\%$ \\
\hline Haynes (1982), M1 & 4 & $110-126$ & $\begin{array}{c}0.24- \\
0.52\end{array}$ & 89.071 & 4.998 & - & - & - & 2.4 & 0.50 \\
\hline Haynes (1982), M2 & 5 & $115-136$ & $\begin{array}{c}0.12- \\
0.43\end{array}$ & 85.133 & 4.3 & - & - & - & 0.37 & 0.15 \\
\hline Haynes (1982), M3 & 4 & $115-131$ & $\begin{array}{c}0.12- \\
0.32\end{array}$ & 84.566 & 2.45 & - & - & - & 0.11 & 0.38 \\
\hline Haynes (1982), M4 & 5 & $115-136$ & $\begin{array}{c}0.12- \\
0.43\end{array}$ & 86.04 & - & 4.57 & - & - & 0.37 & 0.29 \\
\hline Haynes (1982), M5 & 4 & $115-131$ & $\begin{array}{c}0.12- \\
0.32\end{array}$ & 85.378 & - & 4.741 & - & - & 0.33 & 0.78 \\
\hline Haynes (1982), M6 & 4 & $115-131$ & $\begin{array}{c}0.12- \\
0.32\end{array}$ & 85.892 & 0.705 & 0.53 & - & - & 1.5 & 1.7 \\
\hline Haynes (1982), M7 & 4 & $115-131$ & $\begin{array}{c}0.12- \\
0.32\end{array}$ & 84.558 & 1.252 & 1.259 & - & - & 0.16 & 0.37 \\
\hline Haynes (1982), M8 & 4 & $115-131$ & $\begin{array}{l}0.22- \\
0.48\end{array}$ & 81.249 & 2.708 & - & - & - & 2.3 & 0.86 \\
\hline Haynes (1982), M9 & 4 & $115-131$ & $\begin{array}{c}0.30- \\
0.61\end{array}$ & 80.94 & - & 4.667 & - & - & 3.4 & 2.1 \\
\hline Haynes (1982), M10 & 4 & $115-131$ & $\begin{array}{c}0.15- \\
0.37\end{array}$ & 90.613 & 0.306 & 0.3 & - & - & 1.8 & 1.9 \\
\hline Haynes (1982), M11 & 3 & $115-126$ & $\begin{array}{c}0.16- \\
0.30\end{array}$ & 88.225 & 0.492 & 0.49 & - & - & 4.7 & 5.0 \\
\hline Haynes (1982), M12 & 4 & $115-131$ & $\begin{array}{c}0.18- \\
0.42\end{array}$ & 85.934 & 0.707 & 0.519 & - & - & 4.9 & 5.3 \\
\hline Haynes (1982), M13 & 5 & $110-131$ & $\begin{array}{c}0.08- \\
0.32\end{array}$ & 85.341 & 0.992 & 0.854 & 0.089 & 0.097 & 0.33 & 0.48 \\
\hline Haynes (1982), M14 & 4 & $110-126$ & $\begin{array}{c}0.07- \\
0.22\end{array}$ & 75.442 & 1.057 & 0.978 & 0.083 & 0.089 & 0.31 & 0.54 \\
\hline Haynes (1982), M15 & 5 & $110-131$ & $\begin{array}{c}0.12- \\
0.37\end{array}$ & 75.713 & 1.326 & 1.336 & 0.216 & 0.223 & 3.7 & 5.4 \\
\hline Haynes (1982), M16 & 4 & $110-126$ & $\begin{array}{c}0.12- \\
0.29\end{array}$ & 74.275 & 0.893 & 0.843 & 0.067 & 0.069 & 7.1 & 8.0 \\
\hline Haynes (1982), M17 & 4 & $115-131$ & $\begin{array}{c}0.15- \\
0.37\end{array}$ & 90.068 & 0.284 & 0.291 & 0.011 & 0.01 & 1.3 & 1.4 \\
\hline $\begin{array}{lll}\text { Hiza } & \& & \text { Haynes } \\
(1980), & \text { M7 } & \end{array}$ & 4 & $105-121$ & $\begin{array}{c}0.05- \\
0.17\end{array}$ & 85.442 & 2.901 & 2.577 & - & - & 1.2 & 1.7 \\
\hline $\begin{array}{l}\text { Hiza \& Haynes } \\
(1980), \text { M8 }\end{array}$ & 2 & $105-111$ & $\begin{array}{c}0.19- \\
0.25\end{array}$ & 79.09 & 4.77 & - & - & - & 7.1 & 1.6 \\
\hline $\begin{array}{l}\text { Hiza \& } \quad \text { Haynes } \\
(1980), \text { M9 }\end{array}$ & 4 & $105-121$ & $\begin{array}{c}0.20- \\
0.38\end{array}$ & 80.6 & - & 5.0 & - & - & 5.9 & 6.5 \\
\hline $\begin{array}{l}\text { Hiza \& Haynes } \\
(1980), \text { M10 }\end{array}$ & 4 & $105-121$ & $\begin{array}{c}0.18- \\
0.44\end{array}$ & 81.3 & 2.42 & 2.41 & - & - & 14 & 17 \\
\hline
\end{tabular}




\section{APPENDIX - B}

In Tables B1 and B2, test values for computer implementation of the pure fluids and mixture models are provided.

Table B1. Test values for computer implementation of the pure-fluid equations. For the calculation of these numbers, the pure-fluid equations of GERG-2008 ${ }^{11}$ have to be used.

\begin{tabular}{|c|c|c|c|c|c|c|c|}
\hline$T / \mathrm{K}$ & $\rho /\left(\mathrm{mol} \mathrm{m}^{-3}\right)$ & $p / \mathrm{MPa}$ & $c_{p} /\left(\mathrm{J} \mathrm{mol}^{-1} \mathrm{~K}^{-1}\right)$ & $w /\left(\mathrm{m} \mathrm{s}^{-1}\right)$ & $h /\left(\mathrm{J} \mathrm{mol}^{-1}\right)$ & $s /\left(\mathrm{J} \mathrm{mol}^{-1} \mathrm{~K}^{-1}\right)$ & $a /\left(\mathrm{J} \mathrm{mol}^{-1}\right)$ \\
\hline \multicolumn{8}{|c|}{ methane } \\
\hline 100 & 27406.610 & 1 & 54.868319 & 1464.5158 & -15236.349 & -113.32123 & -3940.7137 \\
\hline 120 & 0 & 0 & 33.282635 & 287.93074 & -6041.2613 & - & - \\
\hline 140 & 28000 & 86.944725 & 49.940566 & 1717.1465 & -10929.814 & -103.18433 & 410.82371 \\
\hline \multicolumn{8}{|c|}{$n$-butane } \\
\hline 300 & 9843.1324 & 1 & 142.63587 & 900.91307 & -21373.441 & -78.648099 & 2119.3951 \\
\hline 350 & 0 & 0 & 111.86921 & 232.56836 & 5451.6508 & - & - \\
\hline \multicolumn{8}{|c|}{ isobutane } \\
\hline 310 & 9240.7816 & 1 & 145.53721 & 757.31587 & -18230.312 & -71.028634 & 3680.3490 \\
\hline 370 & 0 & 0 & 116.36648 & 238.75073 & 7651.7986 & - & - \\
\hline 420 & 8000 & 21.886007 & 167.02059 & 625.65914 & -687.40298 & -29.460374 & 8950.2030 \\
\hline \multicolumn{8}{|c|}{$n$-pentane } \\
\hline 320 & 8315.8811 & 1 & 174.34854 & 917.11174 & -22939.139 & -74.192342 & 682.15867 \\
\hline 380 & 0 & 0 & 146.14923 & 215.48326 & 10885.768 & - & - \\
\hline 490 & 8000 & 81.238484 & 209.67109 & 1070.5936 & 14531.654 & -5.6882702 & 7164.0963 \\
\hline 350 & 7750.9465 & 1 & 185.36233 & 723.97364 & -16198.681 & -55.939712 & 3251.2021 \\
\hline 410 & 0 & 0 & 156.07505 & 223.39951 & 15395.183 & - & - \\
\hline 495 & 7000 & 35.733998 & 215.14793 & 719.56797 & 13984.485 & 4.5579997 & 6623.4179 \\
\hline
\end{tabular}




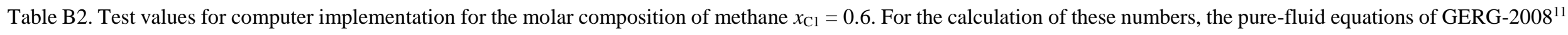
have to be used.

\begin{tabular}{|c|c|c|c|c|c|c|c|}
\hline$T / \mathrm{K}$ & $\rho /\left(\mathrm{mol} \mathrm{m}^{-3}\right)$ & $p / \mathrm{MPa}$ & $c_{p} /\left(\mathrm{J} \mathrm{mol}^{-1} \mathrm{~K}^{-1}\right)$ & $w /\left(\mathrm{m} \mathrm{s}^{-1}\right)$ & $h /\left(\mathrm{J} \mathrm{mol}^{-1}\right)$ & $s /\left(\mathrm{J} \mathrm{mol}^{-1} \cdot \mathrm{K}^{-1}\right)$ & $a /\left(\mathrm{J} \mathrm{mol}^{-1}\right)$ \\
\hline \multicolumn{8}{|c|}{ methane $+n$-butane } \\
\hline 150 & 18.002169 & 10 & 77.267071 & 1403.3993 & -22943.229 & -116.52476 & -6020.0044 \\
\hline 200 & 0 & 0 & 50.685467 & 245.98640 & -5437.2169 & - & - \\
\hline 300 & 30 & 0.074343218 & 61.334843 & 294.99437 & 61.371614 & 8.4300240 & -4945.7429 \\
\hline \multicolumn{8}{|c|}{ methane + isobutane } \\
\hline 160 & 17241.868 & 5 & 74.785284 & 1331.9880 & -21294.389 & -107.68110 & -4355.4044 \\
\hline 210 & 0 & 0 & 49.836159 & 252.48358 & -4824.3458 & - & - \\
\hline 350 & 100 & 0.28707693 & 67.807492 & 314.72845 & 3166.9980 & 6.8573366 & -2103.8391 \\
\hline \multicolumn{8}{|c|}{ methane $+n$-pentane } \\
\hline 130 & 17089.860 & 8 & 79.265640 & 1625.1808 & -28032.170 & -137.18563 & -10666.152 \\
\hline 280 & 0 & 0 & 66.877640 & 262.83238 & -1236.8530 & - & - \\
\hline 400 & 500 & 1.5482355 & 90.379908 & 293.73614 & 7003.4459 & 3.9203586 & 2338.8314 \\
\hline \multicolumn{8}{|c|}{ methane + isopentane } \\
\hline 170 & 16073.699 & 5 & 73.858626 & 1124.0030 & -23615.595 & -109.92284 & -5239.7800 \\
\hline 220 & 0 & 0 & 57.100707 & 235.86043 & -4921.2983 & - & - \\
\hline 380 & 450 & 1.3276094 & 84.553729 & 285.77896 & 5619.9888 & 1.5214116 & 2091.6092 \\
\hline
\end{tabular}

Supporting information available:

Four text files containing the parameters of the equations are available. For the use in TREND ${ }^{117}$, they have to be renamed into methanebutane.mix, methane-isobutan.mix, methane-pentane.mix, and methane-ipentane.mix. 